\title{
MERCURY BOILER DEVELOPMENT ON THE
}

SNAP 2/MRPC PROGRAM

\section{AEC RESEARCH AND DEVELOPMENT REPORT}

Prepared under Subcontract AT(04-3)-690

for

Atomics Energy Commission

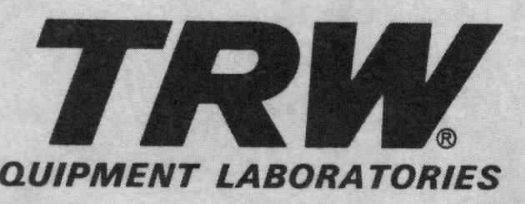




\section{DISCLAIMER}

This report was prepared as an account of work sponsored by an agency of the United States Government. Neither the United States Government nor any agency Thereof, nor any of their employees, makes any warranty, express or implied, or assumes any legal liability or responsibility for the accuracy, completeness, or usefulness of any information, apparatus, product, or process disclosed, or represents that its use would not infringe privately owned rights. Reference herein to any specific commercial product, process, or service by trade name, trademark, manufacturer, or otherwise does not necessarily constitute or imply its endorsement, recommendation, or favoring by the United States Government or any agency thereof. The views and opinions of authors expressed herein do not necessarily state or reflect those of the United States Government or any agency thereof. 


\section{DISCLAIMER}

Portions of this document may be illegible in electronic image products. Images are produced from the best available original document. 


\section{LEGAL NOTICE}

This report was prepared as an account of Government sponsored work. Neither the United States, nor the Commission, nor any person acting on behalf of the Commission:

A. Makes any warranty or representation, expressed or implied, with respect to the accuracy, completeness, or usefulness of the information contained in this report, or that the use of any information, apparatus, method, or process disclosed in this report may not infringe privately owned rights; or

B. Assumes any liabilities with respect to the use of, or for damages resulting from the use of any information, apparatus, method, or process disclosed in this report.

As used in the above, "person acting on behalf of the Commission" includes any employee or contractor of the Commission, or employee of such contractor, to the extent that such employee or contractor of the Commission, or employee of such contractor prepares, disseminates, or provides access to, any information pursuant to his employment or contract with the Commission, or his employment with such contractor.

Printed in the United States of America

Available from

Clearinghouse for Federal Scientific and Technical Information

National Bureau of Standards, U. S. Departmant of Commerce

Springfield, Virginia 22151

Price: Printed Copy $\$ 3.00$; Microfiche $\$ 0.65$ 
TRW-690-32

TRW REPORT No. ER-7252

AEC CATEGORY UC-33, TID-4500 (51st EDITION) MERCURY RANKINE POWER CONVERSION PROGRAM (SNAP 2) TOPICAL REPORT No. 34

\section{MERCURY BOILER DEVELOPMENT ON THE \\ SNAP 2/MRPC PROGRAM}

LEGAL NOTICE

By

R. J. ZIOBRO

A. E. KOESTEL

\section{AEC RESEARCH AND DEVELOPMENT REPORT JUNE 3, 1968}

Prepared under Subcontract AT(04-3)-690

for

Atomics Energy Commission

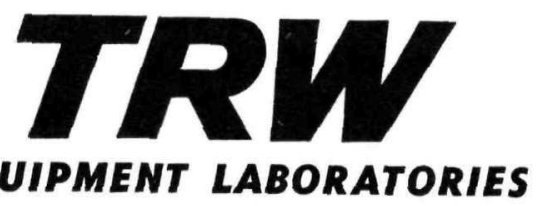




\section{DISTRIBUTION}

This report has heen distributed according to the cateqory "Propulsion \& Energy Conversion Systems (U-33)" as qiven in "Standard Distribution Lists for Unclassified Scientific and Technical Reports," TID-4500 (5lst Ed.), September 1, 1967. 
This report summarizes the entire SNAP 2/MRP boiler research and development proqram from 1958 through 1967. The heat transfer, hydrodynamics, mechanical design, test results, and metallurgical results will be presented in a chronological sequence with the text material abstracted from previously published reports. An assessment of the current status of the developed boiler hardware and the boiler design technology is made.

TRW-690-32 
Paqe No.

II. MERCURY FORCED CONVECTION BOILING HEAT

TRANSFFR • • • • • • • • • • • • • • 20

A. BOILING MATHEMATICAL MODFis • • • • • 22

1. Vapor Only Model • • • • • • • . 22

2. Homogeneous Model • • • • • • • . 23

3. Drop Model • • • • . • • • • • 25

a. Theory • • • • • • • • • • 25

b. Analysis . . . . . . . . . 29

4. Wetting Model • . . . . . . . . 40

B. HOT PLATE TESTS • • • • • • • • . 40

C. FORCED CONIECTION BOILINC RESFAPCH TFSTS • • $\triangle 5$

D. CONDITIONING PHENOMENON • • • • • • • 6 .

1. Single Tube Boiler Tests . . . . . 62

2. Pool Boiling Tests • • • • • • • • 75

3. Conditioning Conclusions . • • • • • 32

E. GRAVTTY CONSIDFRATIONS • • • • • • • • 92

III. MFCHANICAL DFSign FEATURES • • • • • • • • 85

A. REQUTREMENTS • • • • • • • • • • • 35

B. CONFICURATION • • • • • • • • • • 35

C. SELEction of materials • • • • • • • • 96

D. THERMAL STRFSS • • • • • • • • • • 97

E. INTERNAL BUTT WELD • • • • • • • • • 89

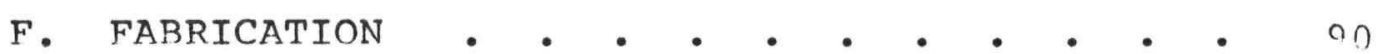

. FLIGHT OUALIFICATION TESTS • • • • • • 92

IV. TEST CELL EXPERIENCE • • • • • • • • • • 05

A. INSTRUMFNTATION • • • • • • • • • • 95

TRW $-690-32$ 
B. NaK TEMPERATURE PROFILES • • • • • • 96

C. TEST PROBLEMS • • • • • • • • • • 96

V. METALLURGICAL ASPECTS • • • • • • • • • 108

A. CORROSION AND DEPOSITION . . . . . . 108

B. EROSION • • • • • • • • • • • • 109

C. EMBRITTLEMENT • • • • • • • • • • 113

VI. CONCLUSIONS • • • • • • • • • • • • • • • • 117 
Page No.

1. SNAP 2/MRP System Schematic - • - . - . -

2. Single Tube Boiler (Preliminary Test Section No. 1

3. Thirteen Tube Boiler (Model 1

4. Seven Tube Boiler (Model 3)

5. Photograph and Schematic Diagram of the Model 5C (Four Tube Boiler)

6. "Vapor Only" Boiling Model . . . . . . . .

7. Overall Boiling Heat Transfer Correlation for

8. Boil-Off Times for Mercury Drops on Various

Surfaces • • • • • • • • • • • • • •

9. Hot Plate Boiling Regimes . . . • . . . . 28

10. Effect of Contact Angle on Contact Area - . . 29

11. Drop Models in Spheroidal Film Boiling . . . . 31

12. Some Spheroidal Boiling Modes Encountered in Forced Convection Vortex Boiling of Pure Mercury • . . . . . • • . • . . .

13. Spheroid Flow Dynamics • • • • • • • . 36

14. Spray-Annular Boiling . . • . . . • . . 41

15. Comparison of Theoretical NaK Temperature Profile for Mercury Wetting With Test Data (5C-2

Boiler)

16. Experimental Set-up to Determine Heat Transfer to Mercury Drops . . . . . . . . . . .

17. $h_{\delta}$ versus $\Delta_{T}$ for Mercury Drops on a Hot 
18. $q$ versus $\Delta T$ for Mercury Drops on a Hot Plate

19. Open Stainless Steel Hot Plate Mercury Drop

Evaporation Data (Ref. 5) Showing Various Boiling Regimes and Values for $\beta$ and $\psi$ (Data Corrected for Radiation, Convection, and Diffusion Effect)

20. Controlled Atmosphere Hot Plate Test Chamber • .

21. Rig Schematic for Simultaneous operation of Four Test Chambers

22. Instrumented Test Chamber Without Insulation - .

23. Schematic Diagram of SNAP 2 Boiling Research Rig

24. Typical Boiling Research Test Section

25. Heat Flux and Temperature Difference Distribution Along Test Section SN 3

26. Typical Mercury Forced Convection Vortex Boiling Heat Flux Versus $\Delta T$ Curve (For a Given Mass Velocity, Pressure, and quality)

27. Vortex Forced Convection Boiling Pressure Dron Correlation for Test Section SN 3

28. Single-Phase Friction Factor . . . . . .

29. NaK Temperature Profiles for Three Different Heat Transfer Models

30. Schematic Diagram of the Boiler Deconditioning Test Rig

31. Typical Measured NaK Temperature-Profile From

Phase I Deconditioning Tests . . . . . .

32. Flow Regimes for Non-Wetting Mercury Flowing

With Nitrogen in Glass Tubes

$$
\text { TRW-690-32 }
$$


Page No.

33. Comparison of $\mathrm{NaK}$ Temperatures With Computed

Curve for sluq Flow Adjusted for Heat Loss

34. Macrographs of Sections of Multi-Channel

Plug

35. Flow Passage of Multi-Channel Plug . . .

36. Schematic Diagram of Boiler Test Rig for

Phase II Conditioning Tests . . . .

37. NaK Shell Temperature Profile During Wetting.

38. NaK Shell Temperature Profile During Non-

wetting Vapor Film Spheroidal Boiling .

39. NaK Shell Temperature Profile Durina Non-

wetting Contact Spheroidal Boiling

40. Typical Non-Wetting Vapor Film Spheroidal

Boiling Temperature Profile . . . .

41. Conditioned Temperature Profile Resulting

From Pressure Increase After Profile

Measurement in Figure 40

42. Boiler Deconditioned After Plug is Bypassed

Following Measurements in Fiqure 41 . . . .

43. Pluq Activated, Boiler Remained Deconditioned After Measurement in Figure 42

44. Mapping Result of Deconditioning Phenomenon (Instantaneous Conditioning and Deconditioning)

45. Effect of Contamination on Pool Boiling

Heat Transfer With Mercury at $950^{\circ} \mathrm{F}$. . . .

46. Developed ' $g$ ' Forces in the Boiling

Mercury .

47. Trepan Groove Tube Sheet Configuration . .

48. Internal Butt Weld Tube Sheet Configuration .

$$
\text { TRW }-690-32
$$


LIST OF FIGURES

(Cont.)

Page No.

49. Variation of $\mathrm{T}_{\mathrm{Na}}$ with Distance for Preliminary

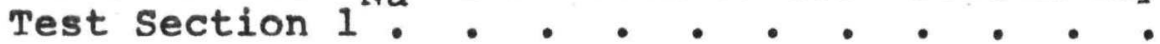

50. Variation of $\mathrm{T}_{\mathrm{Na}}$ with Distance for Preliminary

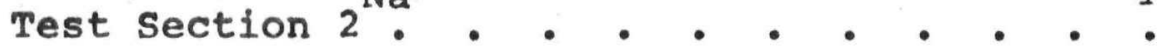

51. Sodium and Estimated Mercury Equilibrium Temperature Distribution in the Model 1 Boiler

52. Sodium and Estimated Mercury Equilibrium Temperature Distribution in the Model 1

Boiler

53. NaK Temperature versus Length for the

54. NaK Temperature versus Length for the Model 3 Boiler • • • • • • • • • • • 102

55. Comparison Between Calculated and Measured Boiler Performance - Model 5C . . . . . .

56. Measured Boiler Performance with Probable Wetting - Model 5C . . . . . . . . . 103

57. Measured Boller Performance With Probable Slug Flow - Model 5C . . . . . . .

58. NaK Temperature versus Length for the Model 7 Boiler . . . . . . . . . . . 104

59. Temperature Oscillation in the Model 5C-8 Boiler

60. Penetration, Deposition (Tube 2), and NaK Shell Temperature versus Tube Length 5C-9 Boiler . . . . . . . . .

61. Boiler Corrosion and Deposition Composition

62. Comparison of Corrosion Rate Constant at Maximum Penetration with Laboratory Data on Haynes 25 Corrosion - • • • • • •

63. Bent Model 5C-5 Swirl Wire and Erosion Failure TRW-690-32 


\section{$\frac{\text { LIST OF FIGURES }}{\text { (Cont.) }}$}

Page No.

64. Photomicroqraphs of Model 5C-1 Tube Sections .

115

65. Boiler Tubing Annealed Coiling Study . .

116

TRW-690-32 


\section{LIST OF TABLES}

Paqe No.

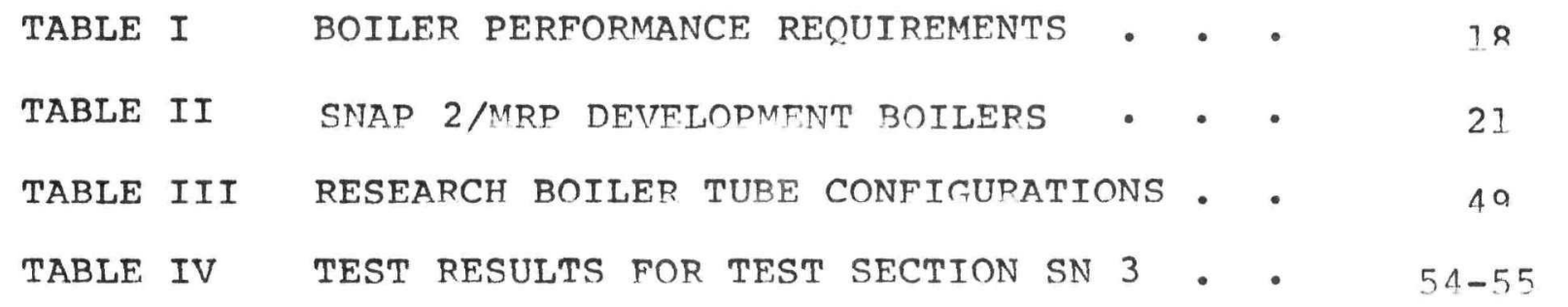

TRW-690-32 
This report reviews the boiler component research and development efforts that were performed for the Atomic Energy commission. Work began in 1958 under the SNAP 2 Program and was terminated in 1967. SNAP 2 was originally directed toward a flight test of a mercury Rankine power conversion system coupled to a nuclear reactor. The flight test objectives were abandoned because of a lack of specific mission application and the program was renamed the Mercury Rankine Power conversion Program (MRPCP) and redirected toward component development.

Figure 1 shows a schematic of the MRP system. The system definition evolved throughout the program and the effect upon boiler performance requirements is shown in Table 1 . Figures 2 through 5 are photographs of development boilers which were all, once-through, forced-circulation heat exchangers. Heat is transferred from the reactor to the mercury in a pumped NaK-78 loop. The mercury is pumped through the boiler tubing and is preheated, boiled, and superheated in a single pass through the boiler.

The first test data was obtained from Preliminary Test section No. 1 in 1959 (Figure 2). This was a single mercury tube configuration and its performance was grossly inadequate. The Model 1 boiler, Figure 3, had 13 tubes, was tested in 1960 and was found to be overdesigned. The Models 2, 3, and 4 boilers all had seven tubes and were similar in configuration. The Model 3 is shown in Figure 4. Tests on the 7 tube designs in 1960 and 1961 demonstrated that most of the overdesign was eliminated but improvement in gross weight and NaK pressure drop were desired. The Model 5C boiler (Figure 5), first tested in 1962. accomplished the weight and performance objectives and became the reference boiler for the balance of the program. Twelve of the Model 5C boilers were built and their accumulative operation exceeded 20,000 hours. A shortened version of the Model $5 \mathrm{C}$, the Model 7, was tested in 1964. It performed as predicted and had less margin to accommodate the deconditioned mode of operation, as would be expected. Dimensional information and performance summaries for all of the developmental boilers are presented in Table 2 in section II. 


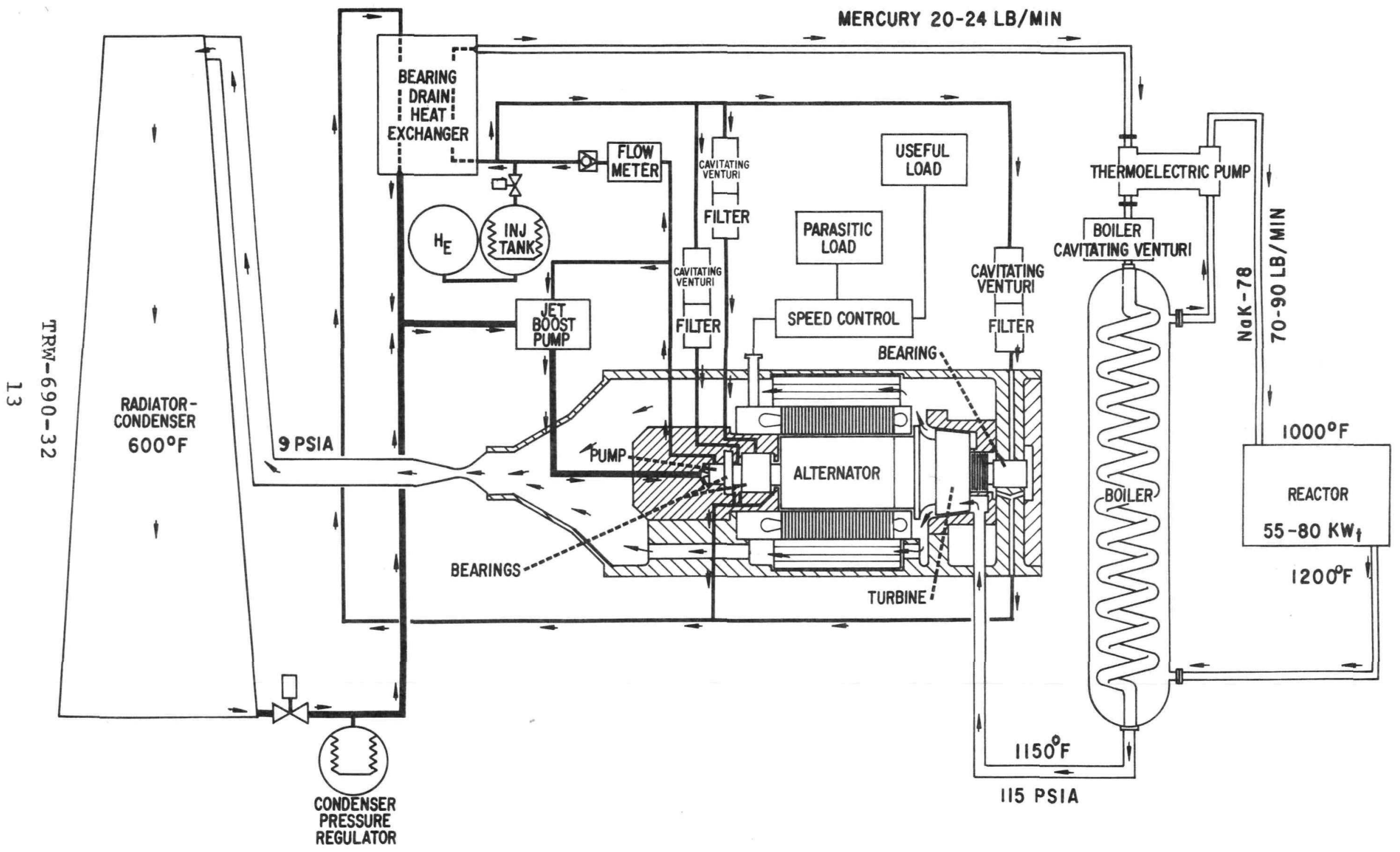

FIGURE 1 SNAP 2/MRPCP SYSTEM SCHEMATIC 


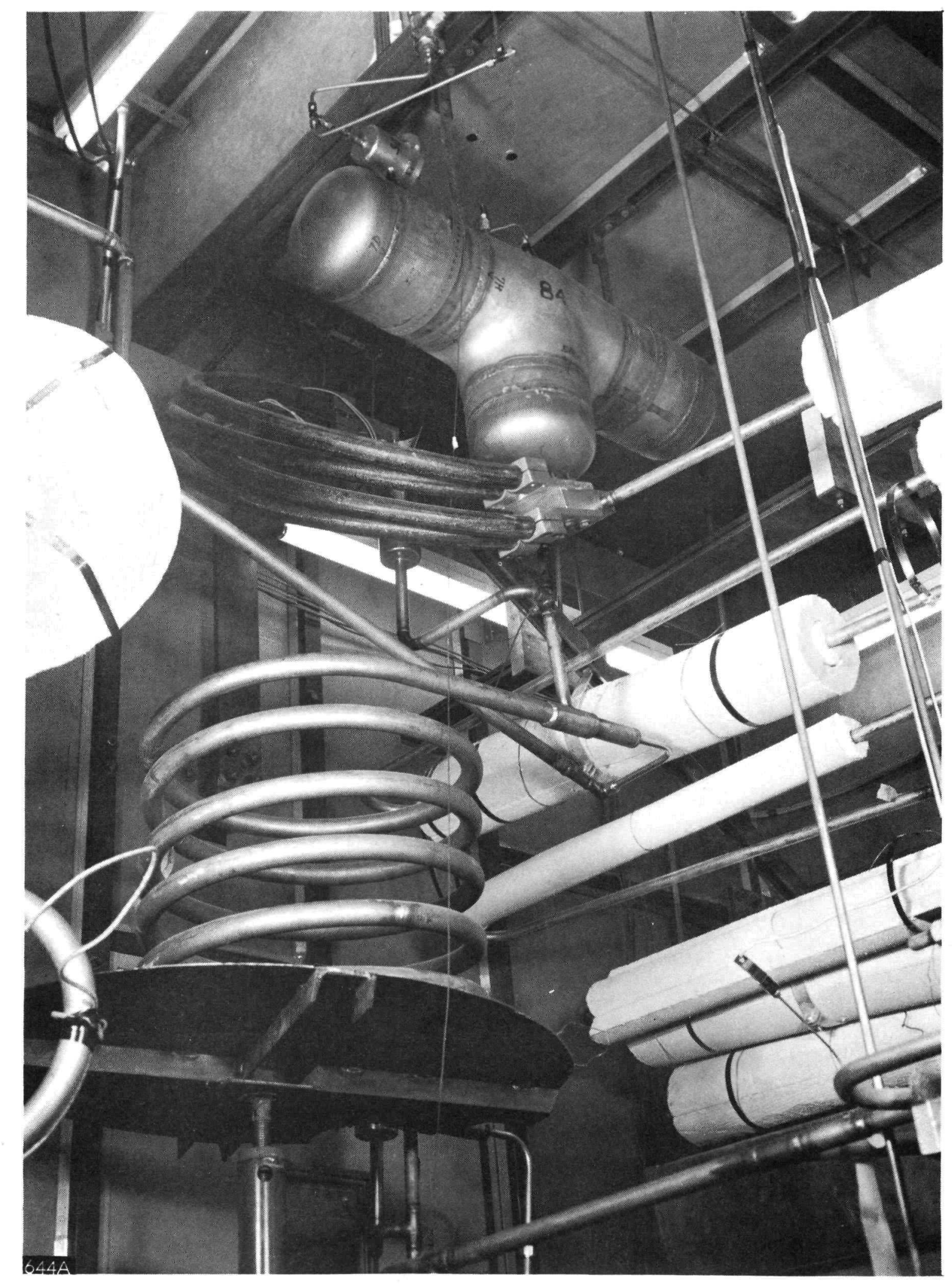

FIGURE 2 SINGLE TUBE BOILER ( PRELIMINARY TEST SECTION NO. 1 ) TRW-690-32 


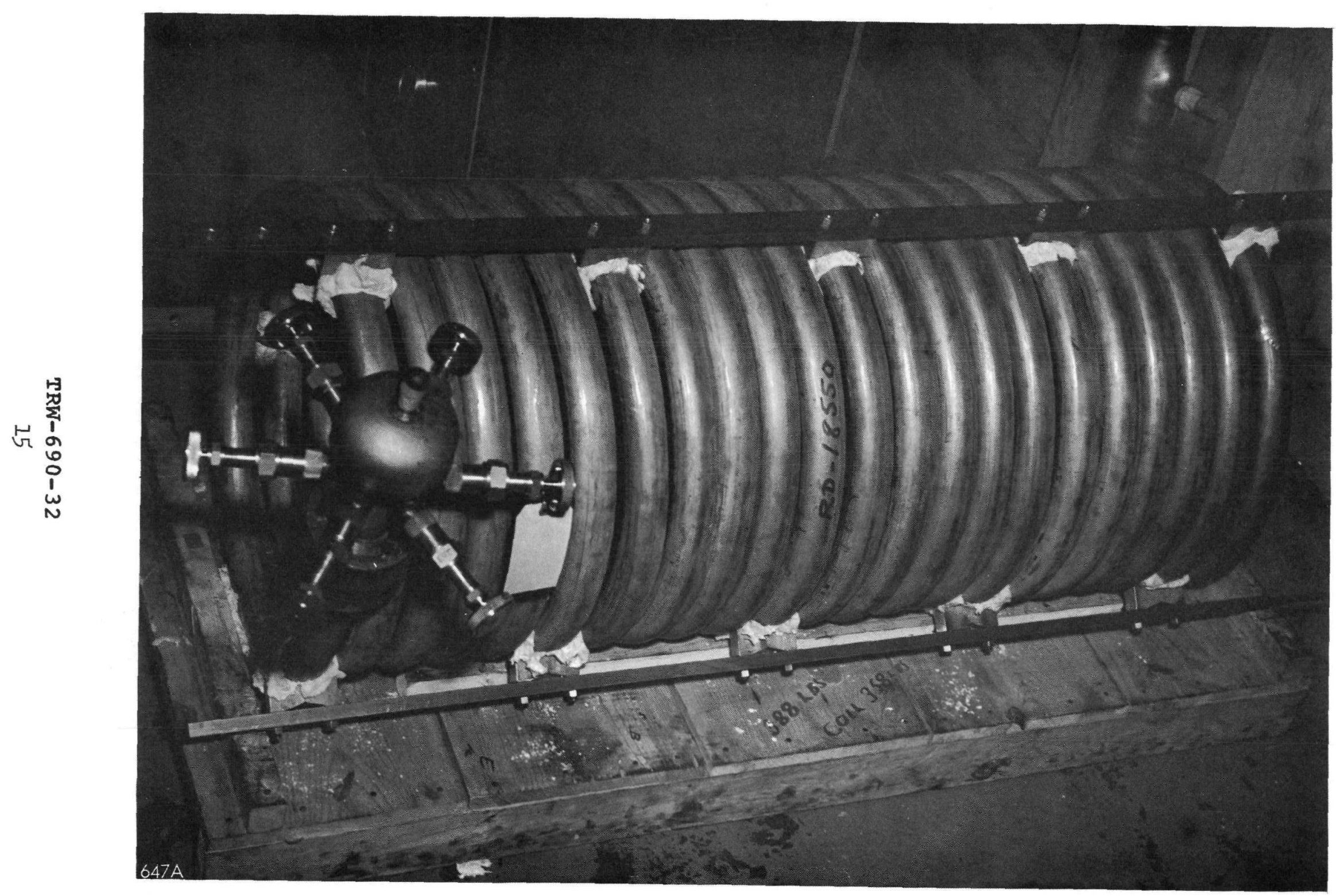

FIGURE 3 THIRTEEN TUBE BOILER (MODEL 1 ) 


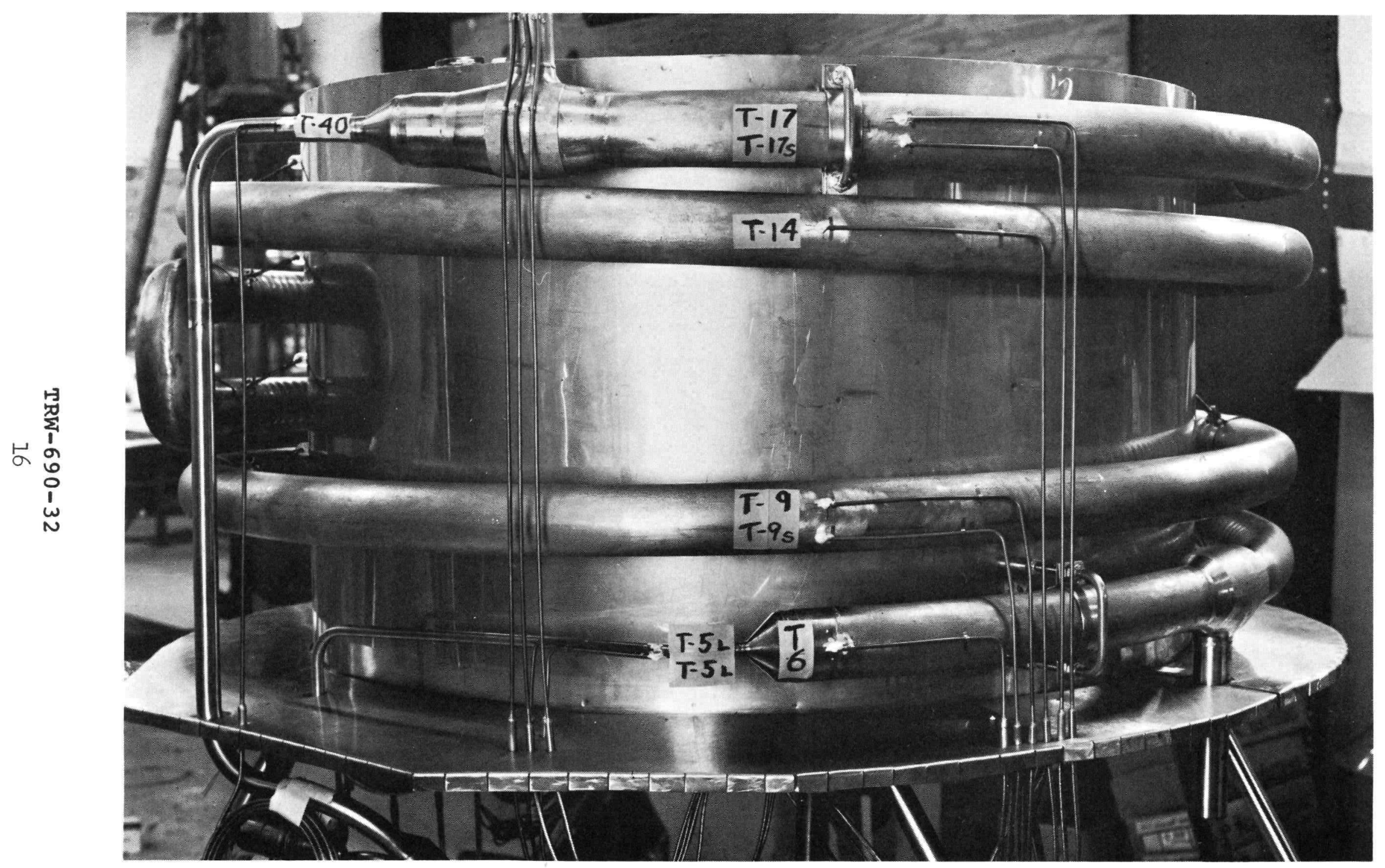

FIGURE 4 SEVEN TUBE BOILER (MODEL 3 ) 

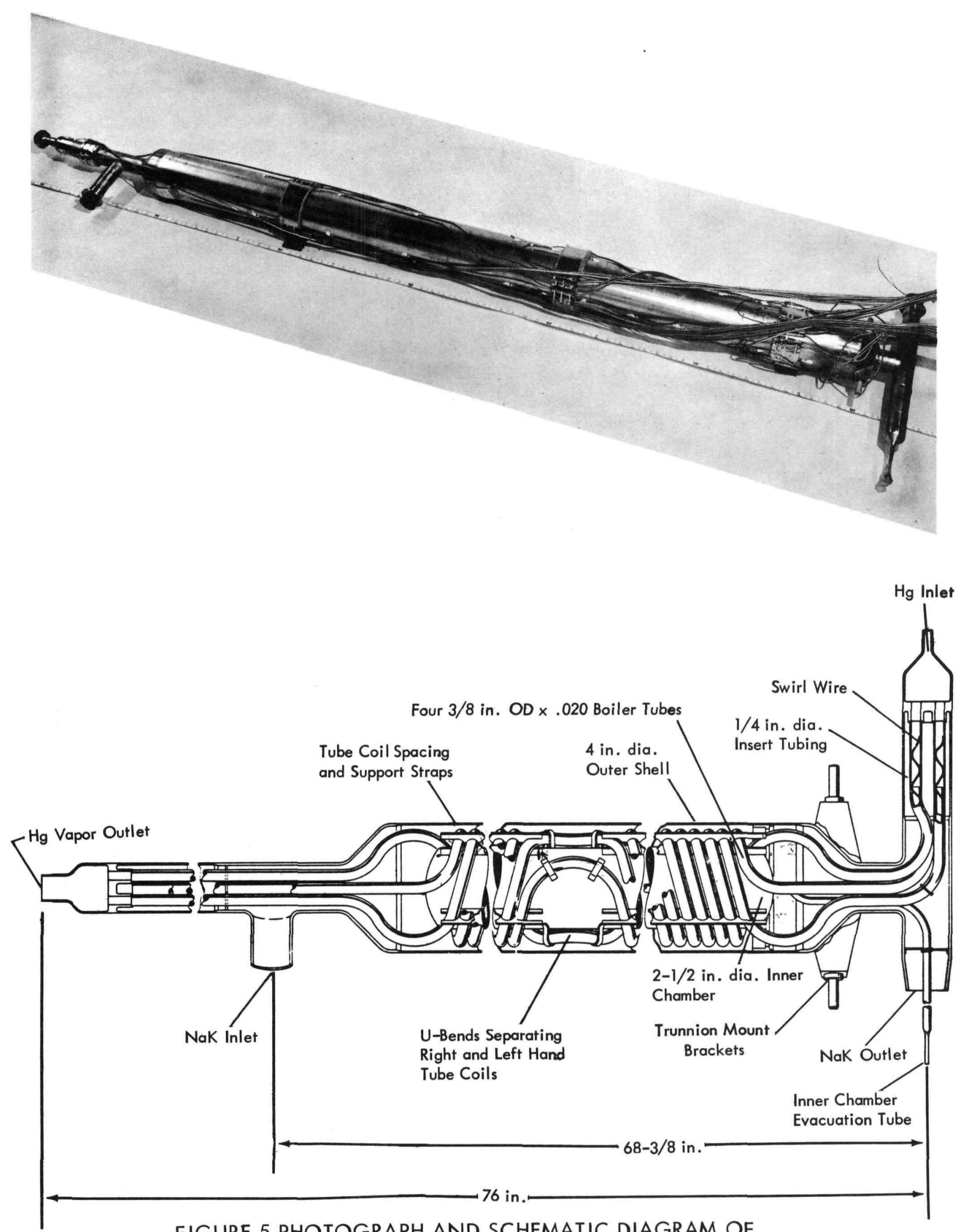

FIGURE 5 PHOTOGRAPH AND SCHEMATIC DIAGRAM OF THE MODEL 5C (FOUR TUBE BOILER )

TRW-690-32 
Peak boiler activities occurred during the 1959 through 1962 time period. The prototype boiler configuration was established and a mercury boiling research program was conducted during this time. Probably the most significant contribution of the boiler program was the development of the heat transfer and hydrodynamic design techniques related to forced convection vortex spheroidal boiling. This work is presented in considerable detail in Section II of this report.

TABLE 1

BOILER PERFORMANCE REQUIREMENTS

\begin{tabular}{|c|c|c|c|c|c|c|c|}
\hline & $\begin{array}{l}\text { Plim. Test } \\
\text { Sect. } 162 \\
\text { E Model } 1 \\
1959 \\
\end{array}$ & $\begin{array}{c}\text { Model } \\
2 \\
1960 \\
\end{array}$ & $\begin{array}{l}\text { Model } \\
3 \& 4 \\
1961 \\
\end{array}$ & $\begin{array}{l}\text { Model } \\
5 \mathrm{C} \\
1962 \\
\end{array}$ & $\begin{array}{c}\text { Model } \\
7 \\
1964 \\
\end{array}$ & $\begin{array}{c}\begin{array}{c}\text { Model } \\
8\end{array} \\
1965 \\
\end{array}$ & $\begin{array}{l}\text { Final } \\
\text { per } \\
\mathrm{NE} 2 \mathrm{FSl}- \\
50-001 \\
\end{array}$ \\
\hline NaK Inlet Temp, ${ }^{\circ} \mathrm{F}$ & $1200 *$ & 1200 & 1215 & 1215 & 1215 & 1195 & $1195 \pm 25$ \\
\hline NaK outlet Temp, ${ }^{\circ} \mathrm{F}$ & $1000 *$ & 1000 & 1015 & 1015 & 1015 & 1024 & $\begin{array}{r}1004+69 \\
-38\end{array}$ \\
\hline $\begin{array}{l}\text { NaK Inlet Toler- } \\
\text { ance, of }\end{array}$ & -- & -- & \pm 23 & \pm 15 & \pm 15 & \pm 25 & -- \\
\hline $\mathrm{NaK}$ Flow, $1 \mathrm{~b} / \mathrm{min}$ & $44 *$ & 71.5 & 72.4 & 71.1 & 71.1 & 85 & $\begin{aligned} 70.0 & +20 \\
& -23.5\end{aligned}$ \\
\hline $\mathrm{NaK} \Delta \mathrm{P}$, psia & $2.0 *$ & 2.0 & 1.4 & 1.4 & $\begin{array}{l}0.6 \\
\max \end{array}$ & .25 & $\begin{array}{c}.25+03 \\
-0\end{array}$ \\
\hline $\begin{array}{l}\text { Hg Inlet Press, } \\
\text { psia }\end{array}$ & 140 & 230 & -- & 195 & -- & 170 & -- \\
\hline Hg Inlet Temp, oF & 425 & 430 & 483 & 535 & -- & $710+90$ & $\begin{array}{c}690+117 \\
-50\end{array}$ \\
\hline $\begin{array}{l}\text { Hg Outlet Press. } \\
\text { psia. }\end{array}$ & 100 & 115 & 115 & 119 & 119 & 120 & $115 \pm 5$ \\
\hline Hg Outlet Temp. ${ }^{\circ} \mathrm{F}$ & 1150 & 1150 & 1158 & 1154 & 1160 & 1160 & $1150 \pm 25$ \\
\hline Hg Flow, $1 \mathrm{~b} / \mathrm{min}$ & 16 & 18.6 & 20.1 & 20.0 & 20.0 & 22.4 & $\begin{array}{r}19.8+.2 \\
-.4\end{array}$ \\
\hline
\end{tabular}

*Original reactor coolant was Na not NaK

Boiler development activities were minimized in the 1962 through 1967 time period. Compact boilers were used as vapor generators in system test rigs at TRW and AI. Prequalification testing of the compact boiler was accomplished, and several fabrication improvements were incorporated into the design. Most 
of the metallurgical dissection work was performed in this period giving corrosion and deposition data in addition to assurance of mechanical integrity of the boiler for the 10,000 hour design life. Operational experiences with boiler deconditioning led to boiler conditioning investigations. A single tube test rig was constructed and equipped with conventional instrumentation plus acoustic instruments and an $x$-ray-television monitoring system enabling visual study of the boiling process as it occurs inside the metal tubing. The program was terminated before the conditioning investigation was completed. Progress had been made toward the design of boiler inlet inserts which make a boiler less sensitive to deconditioning tendencies. A complete understanding of the causes of deconditioning remains unattained.

The program has developed a technology which has been demonstrated for the design of high performance, lightweight, compact, once through mercury boilers. Further experimental work is required in the area of conditioning to insure long term performance reliability under all operating conditions. 


\section{MERCURY FORCED CONVECTION BOILING HEAT TRANSFER AND HYDRODYNAMICS}

The SNAP 2 boiler is a counterflow shell and tube heat exchanger required to transfer a nominal $50 \mathrm{KW}$ of thermal energy. NaK-78 is the hot-shell side fluid. Mercury enters the boiler as a subcooled liquid and exits as a superheated vapor.

There are three distinct heat transfer processes occurring as the mercury flows through the boiler:

1. liquid to liquid forced convection preheating

2. liquid to two-phase flow boiling

3. liquid to gas forced convection heating

Single phase heat transfer processes such as preheating and superheating are predictable by classical techniques applicable to mercury which behaves as a conventional fluid.

Mercury boiling heat transfer differs from that of conventional fluids and other liquid metals due to erratic wetting characteristics, high surface tension, and the large ratio of liquid-to-vapor density. Essentially, no mercury boiling design data was available in 1958 when the SNAP 2 boiler program was initiated. Even today, the literature does not contain satisfactory liquid metal boiling heat transfer correlations (1).

Under the SNAP 2/MRPCP boiler program, design and correlating expressions for five boiling transfer modes, slug flow, fog flow (with wetting liquid film) spheroidal contact, spheroidal intermittent contact, and spheroidal film, have been analytically developed and experimentally supported. Table 2 summarizes the application of the evolving design technology to successive boiler designs achieving the boiler component program objectives with the compact Model 5C and 7 designs. A state-ofthe-art advancement in mercury boiling technology is apparent from the successful application of the technology to the mercury boilers in the sunflower (2), SCAP (3), and SNAP 8 (4) boilers. It is considered that the spheroidal boiling equations are sufficiently general to be applicable to any fluid, regardless of whether the spheroidal state exists due to nonwetting or to high temperature differences.

Detail development of mercury boiling heat transfer and hydrodynamic technology has been published in several contract reports (5), (6), (7), (8) and (9). Application to the compact boiler designs is reported in (10). (11) and (12). 
TABLE 2 SNAP 2/MRP DEVELOPMENTAL BOILERS

\begin{tabular}{|c|c|c|c|c|c|c|c|c|}
\hline \multirow[b]{2}{*}{$\begin{array}{l}\text { Design and } \\
\text { Test Conditions }\end{array}$} & \multicolumn{8}{|c|}{ Model No. } \\
\hline & $\begin{array}{l}\text { Test Section } \\
\text { No. } 1\end{array}$ & $\begin{array}{l}\text { Test Section } \\
\text { No. } 2\end{array}$ & (13 $\begin{array}{l}1 \\
\text { Tube) }\end{array}$ & $\left(\begin{array}{c}2 \\
(P C S-I)\end{array}\right.$ & $(P C S-I I)$ & 4 & $5 C$ & 7* \\
\hline $\begin{array}{l}\text { Number of Tubes } \\
\text { Tube Dimensions }\end{array}$ & 1 & 1 & $13 * *$ & 7 & 7 & 7 & 4 & 4 \\
\hline $\begin{array}{l}\text { OD and wall (in.) } \\
\text { Length (ft) }\end{array}$ & $\begin{array}{l}0.50 \times 0.49 \\
34\end{array}$ & $\begin{array}{l}0.50 \times 0.49 \\
34\end{array}$ & $\begin{array}{l}5 / 16 \times 0.035 \\
110\end{array}$ & $\begin{array}{l}5 / 16 \times 0.028 \\
62\end{array}$ & $\begin{array}{l}0.329 \times 0.028 \\
38\end{array}$ & $\begin{array}{l}0.329 \times 0.028 \\
39\end{array}$ & $\begin{array}{l}3 / 8 \times 0.020 \\
29\end{array}$ & $\begin{array}{l}3 / 8 \times 0.020 \\
19\end{array}$ \\
\hline Shell Dimensions & None & $\begin{array}{l}0.04 \times 0.4 \\
\text { in. pitch- } \\
\text { twisted } \\
\text { ribbon }\end{array}$ & $\begin{array}{l}0.051-i n \\
\text { wire } 1-i n \\
\text { pitch }\end{array}$ & $\begin{array}{l}0.054 \text { in. } \\
\text { wire } 1-i n . \\
\text { pitch }\end{array}$ & $\begin{array}{l}0.040 \text { in. } \\
\text { wire } 1-i n . \\
\text { pitch }\end{array}$ & $\begin{array}{l}0.040 \text { in. } \\
\text { wire } 1-i n . \\
\text { pitch }\end{array}$ & $\begin{array}{l}0.040 \text { in. wire } \\
1-i n \text {. pitch } \\
\text { plus insert } \\
50 \text { in. lian. } x\end{array}$ & $\begin{array}{l}0.040 \text {-in. wire } \\
\text { l-in. pitch } \\
\text { plus insert } .25 \\
\text { in. dia. by } 24 \text { in. } \\
\text { long }\end{array}$ \\
\hline $\begin{array}{l}\text { Overall } \\
\text { length (ft) }\end{array}$ & 34 & 34 & 110 & 62 & 38 & 39 & 6.5 & 4.5 \\
\hline Diameter (in.) & $1-5 / 16$ & $1-5 / 16$ & 1.90 & 1.90 & 2.125 & 2.125 & 4 & 4 \\
\hline Configuration & $\begin{array}{l}17.75 \text { in. } \\
\text { heiix }\end{array}$ & $\begin{array}{l}17.75 \text { in. } \\
\text { heilix }\end{array}$ & $\begin{array}{l}19.5-i n . \\
\text { heiix }\end{array}$ & $\begin{array}{l}19.5-i n . \\
\text { heilix }\end{array}$ & 39-in. helix & 52 in. helix & $\begin{array}{l}\text { Straight } \\
\text { cylinder }\end{array}$ & $\begin{array}{l}\text { Straight } \\
\text { cylinder }\end{array}$ \\
\hline Thermal Design Basis & $\begin{array}{l}\text { Pure gas heat } \\
\text { transfer }\end{array}$ & $\begin{array}{l}\text { Pure gas heat } \\
\text { transfer }\end{array}$ & $\begin{array}{l}\text { Test sections } \\
1 \text { and } 2\end{array}$ & Model I data & Model 2 data & Model 2 data & $\begin{array}{l}\text { Research } \\
\text { boiler data }\end{array}$ & Model $5 \mathrm{C}$ data \\
\hline \multicolumn{9}{|l|}{ Weight (lb) } \\
\hline Dry & 38 & 42 & 388 & 160 & 79 & 82 & 30 & 21 \\
\hline wet & 51 & 55 & 518 & 260 & 117 & 120 & 40 & 30 \\
\hline $\begin{array}{l}\text { Integrated Test } \\
\text { Time (hr) }\end{array}$ & 50 & 50 & 100 & 2550 & 8200 & $0+$ & 25,500 & 650 \\
\hline $\begin{array}{l}\text { Average Boiling Heat } \\
\left.\text { Flux (Btu/hr-ft }{ }^{2}\right)\end{array}$ & 4000 & 13,000 & 6000 & 21.000 & 24,000 & - & 80,000 & 80,000 \\
\hline Year Tested & 1959 & 1959 & 1960 & 1960 & $1961-1964$ & 1962 & $1962-1967$ & $1964-1966$ \\
\hline
\end{tabular}

Model 6 designed but not fabricated

Todel 4 fabricated but not tested

*6 valved, allowing variation from 7 to 13 
A. BOILING MATHEMATICAL MODELS

Development boilers were designed, bullt and tested for each of the following thermodynamic models: vapor only, homogeneous, and drop model.

1. Vapor only Model

The first design model was developed on a presumably conservative basis to consider heat transfer from the tube to the gas only (mercury vapor). Heat transfer to the mercury liquid fraction was ignored. The evaporation of the mercury liquid was accounted for only in the gas mass velocity term which increased as the vapor quality increased. The vapor addition was modeled to appear to be added through a porous tube wall. See Figure 6 .

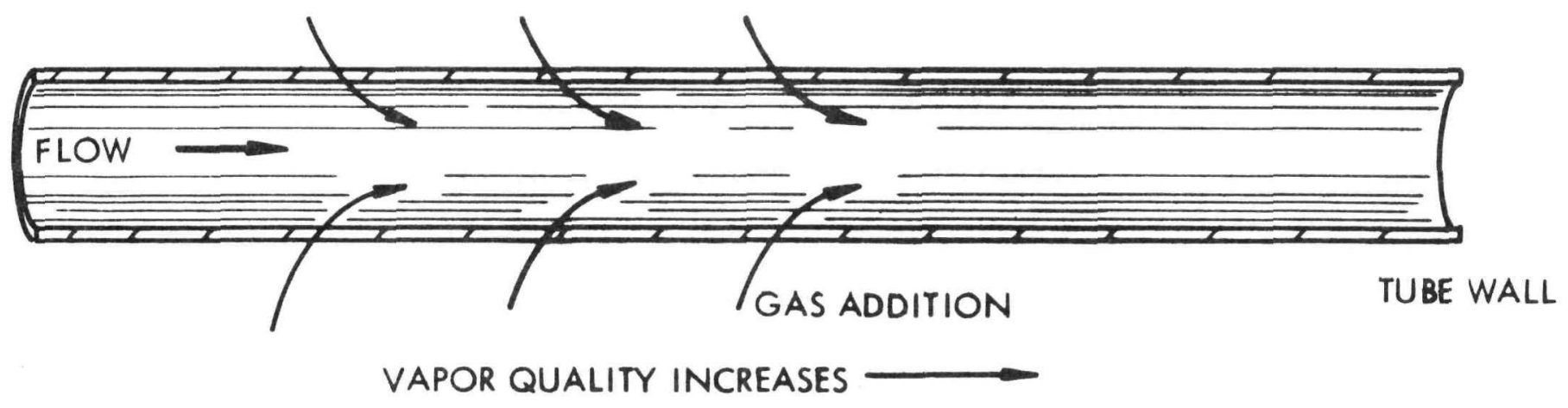

Figure 6 - "Vapor Only" Boiling Model

A Dittus-Boelter form of design equation was used with the quality change integrated from 0 to $100 \%$ resulting in Equation 1.

$$
N_{u}=\frac{h D}{K_{v}}=\frac{0.023}{1.8}\left(\frac{D G_{E}}{\mu_{v}}\right)^{.8}\left(\frac{\mu_{v} C p_{v}}{K_{v}}\right)^{.4} \text { Equation (1) }
$$

Experimentally, the boiler produced an exit vapor quality of $10 \%$ instead of the 100\% design value. Performance was improved to $22 \%$ exit quality demonstrated in the tests of an identical boiler equipped with a twisted tape turbulator. The significant conclusion reached in these tests was that the mechanics of the liquid dispersion was important and could not be ignored. Details of the development and evaluation of the vapor only model are reported in $(6)$. 
The Dittus-Boelter equation form was retained with modifications to permit the fluid transport properties to be evaluated as a mixture. The assumed flow pattern was a homogeneous fog or mist flow mixture. Detailed evaluation of properties showed that the vapor values for thermal conductivity and viscosity were approximately equal to the mixture values. The specific heat term in the Prandtl number was replaced with an expression used to define the assumed vaporization process. Equation 2, for the homogeneous model, was derived for use in correlating existing test data to determine values for the constant and $\mathrm{m}$.

$$
N u=\frac{h D}{K_{v}}=\text { Const. }\left(\frac{D G}{\mu_{v}}\right)^{.8}\left(\frac{\lambda \mu_{v}}{\left(T_{w}-T_{\text {sat }}\right) K_{v}}\right)^{m} \text { Equation (2) }
$$

These data are shown in Figure 7 along with the design curve and test results of the Model 1 boiler.

It was concluded that the correlating parameters brought some order to the data but a better physical boiling model was required. Additional details are given in (6).

3. Drop Model

The physical model which proved most useful was the subject of intensive formulation, analysis, experimentation and refinement from 1959 to 1963. As new experiences developed on the program and the work of other investigators, e.g., (13), (14) and (15) became available, modifications and extensions to the mercury boiling theory were made through 1967 when the boiler program was terminated.

Boiling heat transfer is a complex technology. The formulation of forced convection spheroidal boiling design expressions for mercury based on the drop model was a complex effort on this program constructed from the results of several subtasks reported in many documents. For example, two phase flow patterns were visually studied in adiabatic $\mathrm{Hg}-\mathrm{N}_{2}$ tests (6) (16) in 1959-1960 with data preserved on high speed movie films. Forced convection mercury boiling flow patterns were visually studied in 1964-1965 in Nak heated metal tubes using an $x-r a y$ television technique (8) and (17) with data preserved on movie films. Zero gravity aspects were investigated in zero-g aircraft maneuvers (5) and simulated in the ground laboratory (11). Open atmosphere mercury drop hot plate tests were conducted in 1959 (6) and supplemented in controlled atmosphere mercury drop-hot plate tests in 1964 (18).

The reader is referred to (6) and (7) for the detailed development of the film, contact, and intermittent contact boiling theories and techniques: to (8) and (9) for slua flow and fog flow boiling information; and to (10), (11), and (12) for application to design. Boiler test data, in excess of 30,000 
$\square$ PRELIMINARY TEST SECTION NO. 1

- 13 TUBE

- PRELIMINARY TEST SECTION NO. 2 (ADJUSTED bY $2 / 3$ TO ACCOUNT FOR EFFECT OF TWISTED RIBBON SWIRL DEVICE WITH I FOOT PITCH)

$\triangle$ "SNAP 1" BOILER DATA (ADJUSTED BY $1 / 3$ TO ACCOUNT FOR EFFECT OF WIRE SWIRL DE VICE WITH I INCH PITCH)

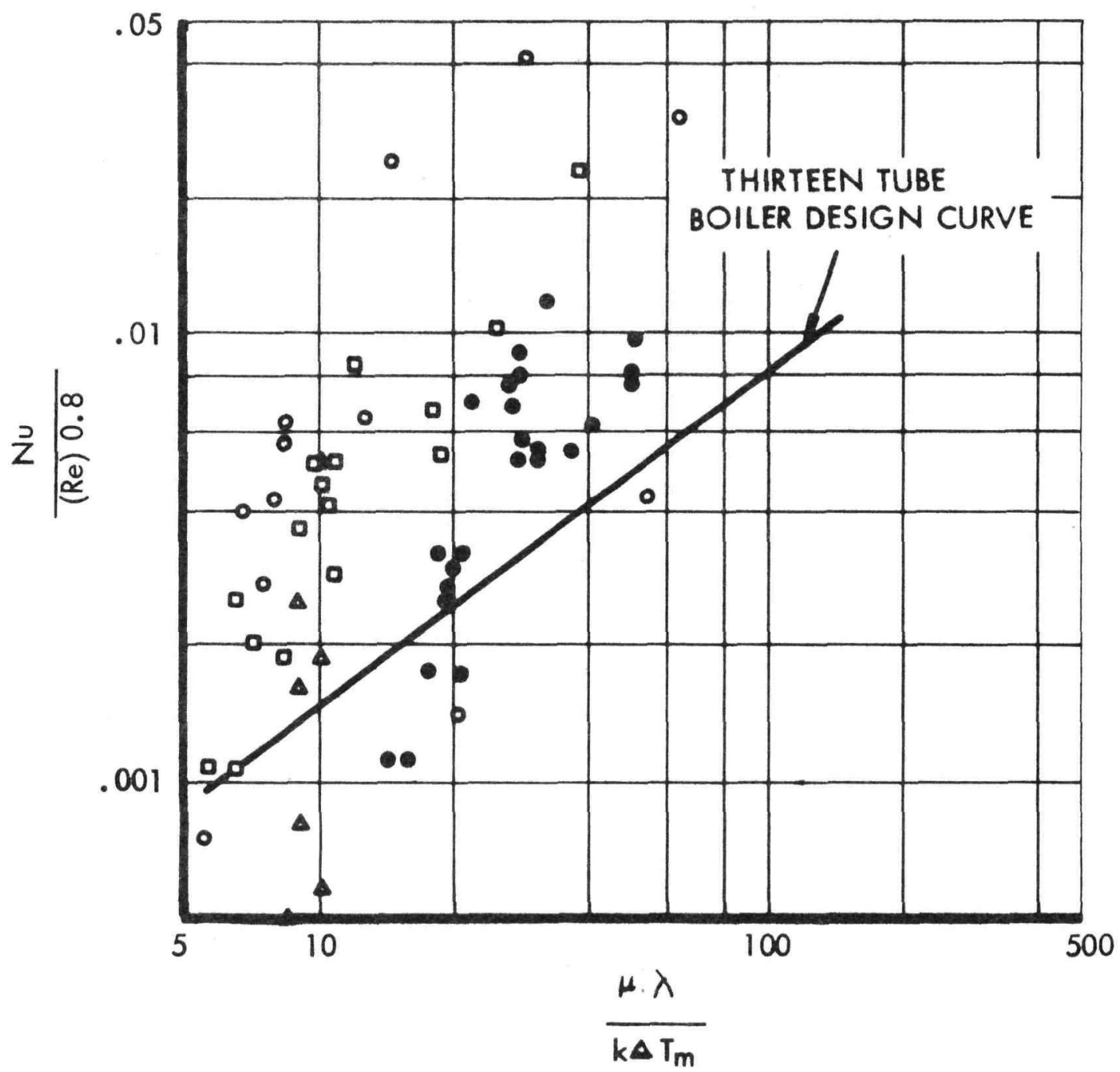

FIGURE 7 OVERALL BOILING HEAT TRANSFER CORRELATION FOR MERCURY 
hours, is partially reported in these documents, the balance available from separate program data reports.

The drop heat transfer evolutionary development is chronologically summarized as follows:

a) availability of preliminary test section and SNAP I test data

b) drop-hot plate tests

c) adiabatic $\mathrm{Hg}-\mathrm{N}_{2}$ visual flow pattern studies

d) analytical formulation of nonwetting spheroidal drop film boiling model for application on overall basis

e) analytical formulation of nonwetting spheroidal contact and film boiling models for application on a local basis

f) local experimentation in boiling research rig and empirical formulation of nonwetting intermittent contact model

g) analytical formulation of wetting model and fog flow model

h) analytical formulation of nonwetting slug flow model.

The following paragraphs will summarize the formulation of the equation for spheroidal forced convection boiling departing from the chronological sequence as required for clarity.

\section{a. Theory}

When a liquid to be boiled is forced by a pump into a heated tube held at a high temperature, the first instance of vapor generation can "ball up" the liquid into globules. The vapor which is generated propels the liquid globules through the tube at an ever increasing rate as more and more vapor is formed by boiling.

Sufficient residence time must be provided by the tube length to completely vaporize the individual liquid agglomerates. During spheroidal boiling, vapor is generated between the liquid spheroids and the heated wall resulting in a vapor repulsion force which tends to lift the liquid from the surface. This reduces the vapor generating rate. In order to counteract this effect a swirl wire is inserted into the tube. The body force created by the swirling flow pushes the liquid to the wall until 
a balance is formed between the vapor repulsion force and the centrifugal force.

Tests have shown that the liquid and vapor phases are not in equilibrium during spheroidal boiling. The vapor is superheated at a temperature near that of the wall whereas the liquid is in the saturated state. The net effect of this phenomena is that a significant portion of the total heat transfer is made to flow through a small area between the liquid globule and the wall. The high density of liquid mercury especially restricts the available area for heat transfer.

The understanding of the mechanics of forced convection vortex boiling of pure mercury spheroids started with hot plate tests in which distilled mercury drops were evaporated on different surfaces both clean and contaminated. The time to completely vaporize a drop of mercury was measured. On the basis of these tests a theory can be developed for spheroidal boiling under static conditions in a gravity environment. The analysis can then be generalized to include a variable acceleration field as in swirl flow. The "boil-off" time can be related to the available evaporation resident time in the boiler tube by considering the hydrodynamic interaction between the vapor and liquid spheroids resulting in slip and droplet propulsion. The formulation of the equations of forced convection spheroidal boiling is based on this format.

Spheroidal boiling heat transfer can be conveniently divided into four zones namely

1) spheroids supported by a vapor film generated between the liquid and heated wall;

2) spheroids in contact with the heated surface, the amount of contact being dependent on the contact angle,

3) spheroids in intermittent contact (transition zone between 1) and 2); and

4) spheroids approaching the tube diameter in size (slug flow boiling in low quality region).

The last has been observed in steel tubes by means of an $\mathrm{X}$-ray image amplifier (8), (9) and (17).

Figure 8 shows measured boil-off times as a function of wall temperature for mercury drops on different surfaces. Figure 9 interprets the data of Figure 8, defines the various boiling regimes, and indicates the effect of contact angle on boil-off time. Film boiling of drops should not depend on the surface condition. The contact evaporization rate does depend on contact 

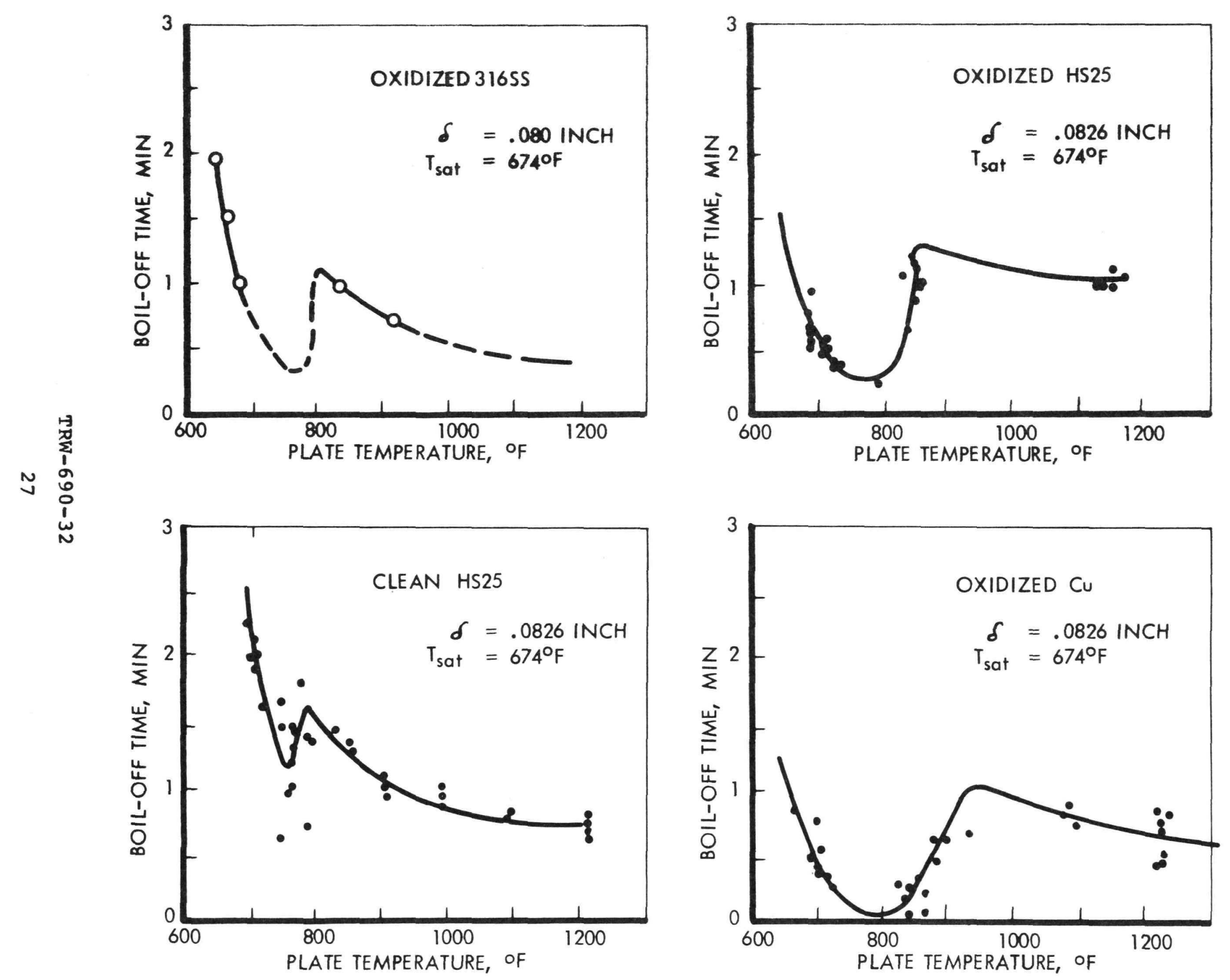

FIGURE 8. BOIL-OFF TIMES FOR MERCURY DROPS ON VARIOUS SURFACES 


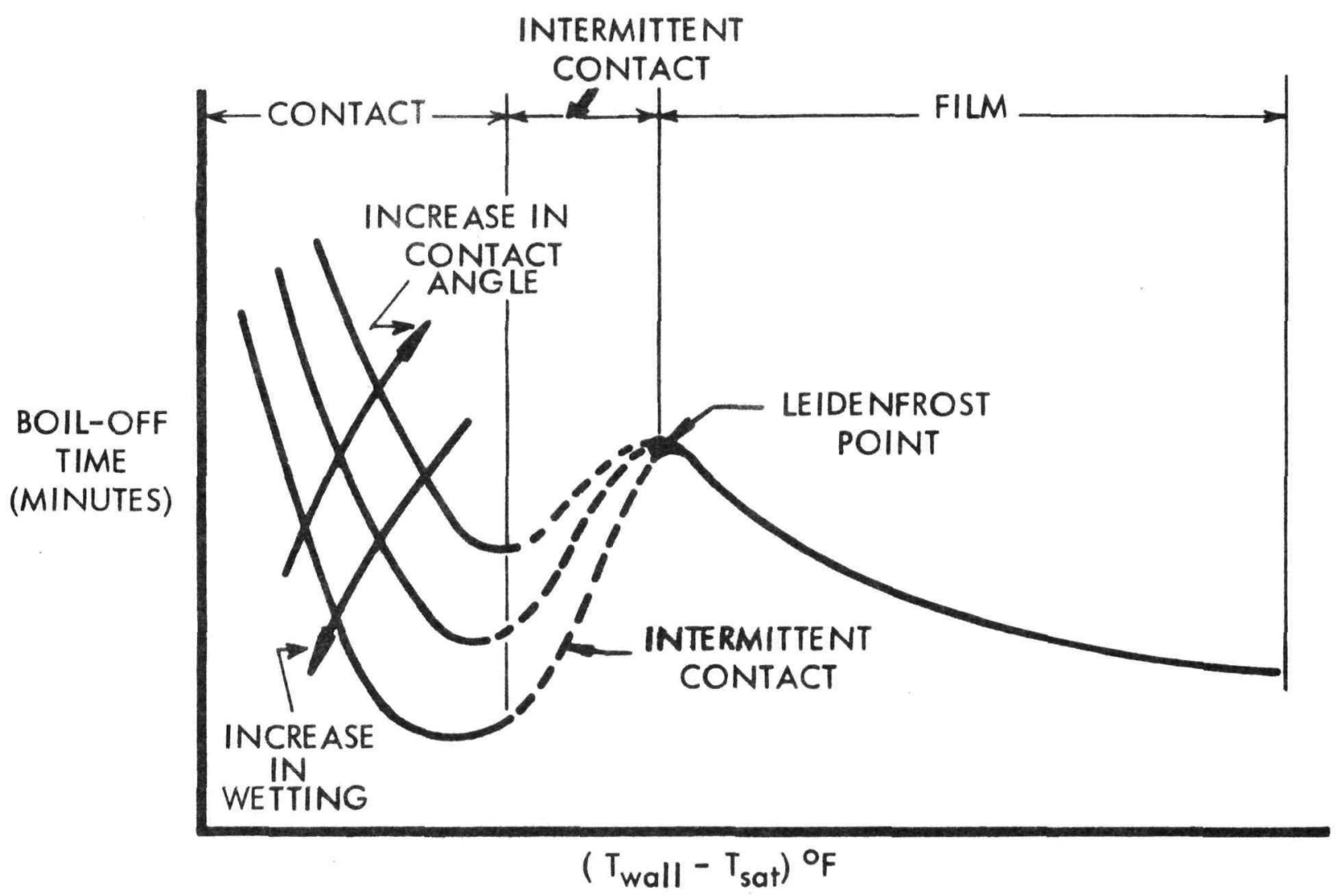

FIGURE 9 HOT PLATE BOILING REGIMES

TRW $-690-32$ 
angle since the liquid contact area increases with a decrease in contact angle as is plotted in Figure 10. The mercury contact angle is "normally" $135^{\circ}$ to $140^{\circ}$ and for a decrease of $20^{\circ}$, the contact area is doubled and presumably the time to boil off a given volume drop is halved. It should be noted that the measured boil-off time (Figure 8) for the Leidenfrost point is approximately one minute. One should appreciate the long boiler tubes required to provide the drop residence for complete evaporization even when there is a relatively large slip between the vapor and liquid phase velocities. Accelerations due to swirl flow compress the vapor film and decrease the boil-off time thereby making swirl type inserts mandatory for high performance mercury boiling. When wetting or non-wetting contact spheroidal boiling occurs complete evaporization will occur in a much shorter tube length.

\section{b. Analysis}

Hot plate boiling of liquid spheroids can be generalized for application to forced convection boiler design by first deriving droplet heat transfer equations from basic physical laws. In forced convection boiling with swirl flow, the liquid globules are held against the heated surface by the radial acceleration. Under these conditions the liquid experiences an environment which is different from that on a hot plate, that is 1) the radial acceleration is a variable along the tube and not equal to one-g as on a hot plate, 2) the drops are in transit thereby presenting a moving heat sink to the heated surface, 3) the boiloff time is now related to tube length, and 4) the flow parameters such as vapor velocity and slip determine the liquid resident time in the tube (available boil-off time).

The derivation of the droplet heat transfer equation in the film boiling regime involves the following:

1) The vapor pressure between the liquid and heat wall is determined by the pressure necessary to evacuate the vapor generated by the heat conduction across the vapor film. This involves a momentum balance parallel to the wall. Figure 11 gives the momentum equations for three physical models.

2) The force due to the vapor pressure on the liquid globule balances the body force (gravity or radial acceleration). See Figure 11. This is a force balance normal to the heated surface. 


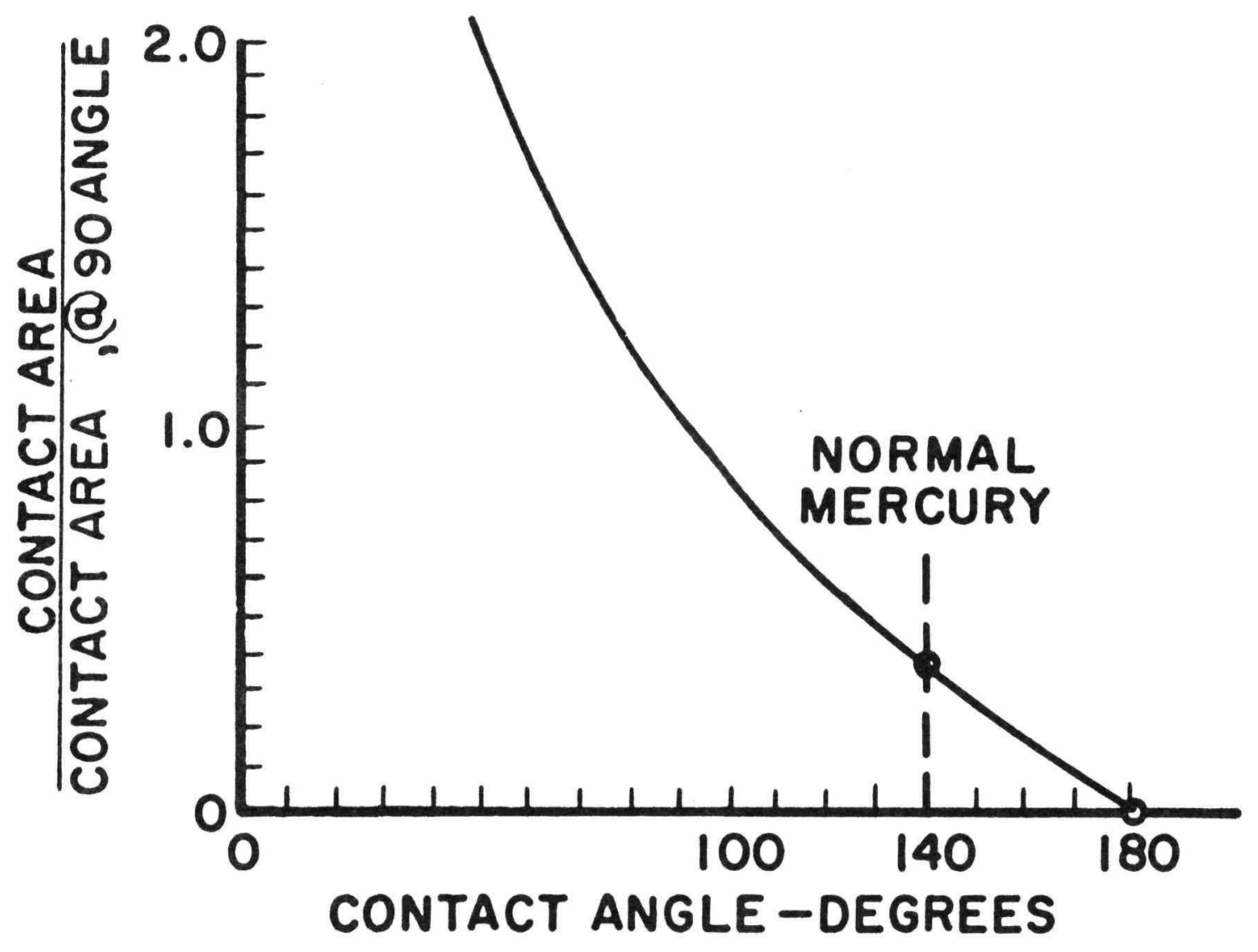

FIGURE 10 EFFECT OF CONTACT ANGLE ON CONTACT AREA 


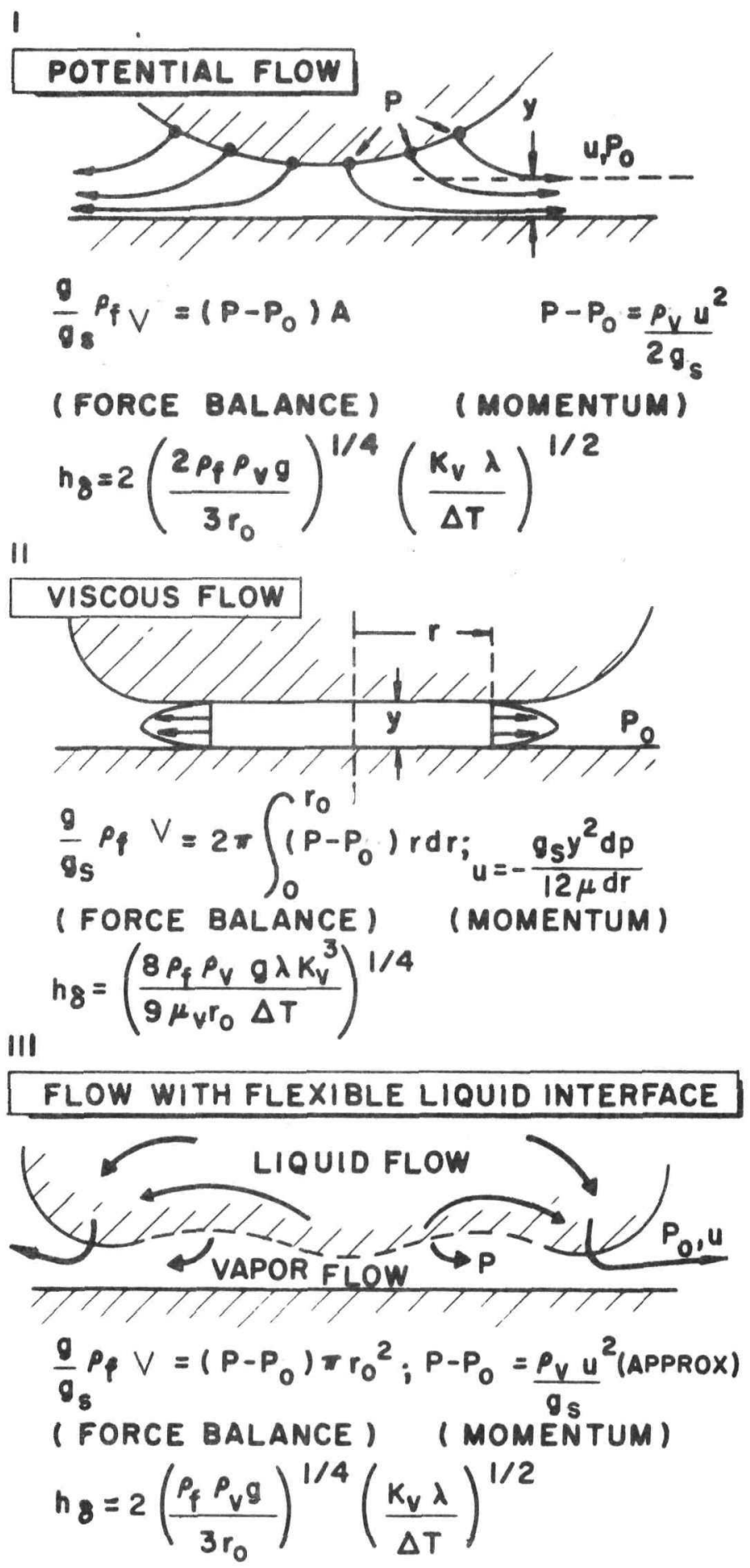

FIGURE 11 DROP MODELS IN SPHEROIDAL FILM BOILING 
3) The latent heat generated equals the conducted heat namely,

$$
\mathrm{m}_{\mathrm{v}} \lambda=\frac{\mathrm{Kv}}{\mathrm{y}} \pi \mathrm{r}_{0}^{2}(\Delta \mathrm{T})
$$

Equation (3)

and the droplet heat transfer coefficient is defined as,

$$
\mathrm{h}_{\delta} \equiv \mathrm{Kv} / \mathrm{y}
$$

4) The vapor generated is equal to the vapor outflow from beneath the liquid namely.

$$
m_{v}=2 \pi r_{0} \quad y \quad \rho_{v} u
$$

These four conditions result in the equations for the spheroidal heat transfer coefficients presented in Figure 11 below its corresponding physical model. Details of this development can be found in (6) and (7).

The spheroidal heat transfer coefficient for the contact boiling regime is estimated to be,

$$
\frac{h_{\delta} r_{0}}{K_{f}}=1
$$

Equation (5)

where

$$
h_{\delta} \equiv \frac{m_{V} \lambda}{\pi r_{0}^{2} \Delta T}
$$

The equation applies to a liquid drop in which heat is conducted from a wall of infinite conductivity through a liquid-wall interface having a contact angle of approximately $180^{\circ}$, and then conducted throughout the liquid mass to the liquid-vapor interface where the conducted heat becomes the latent heat in the vapor generated. For a wall having a thermal conductivity approaching that of the liquid, as in mercury on stainless steel, the spheroidal heat transfer coefficient can be estimated by, 


$$
\frac{h_{\delta} r_{o}}{K_{f}}=1 / 2
$$

Equation $(6$

Details of this development can be found in (6).

Since no theory is available for the case of intermittent contact spheroidal boiling, predictions in the heat transfer coefficient can be made empirically by means of a multiplying factor applied to the spheroidal film heat transfer-equation, see (6).

A designer cannot readily apply the spheroidal heat transfer coefficients to the design of a forced convection vortex boiler. of greater utility is the local boiling heat transfer coefficient based on the tube wall surface, defined as,

$$
h=\frac{G D}{4} \frac{\lambda}{\Delta T} \frac{d x}{d L}
$$

Equation

which value is established by the heat transfer paths from the tube wall to the liquid phase as determined by the basic spheroidal boiling regimes depicted in Figure 12. Experimental evidence has indicated that the heat transfer from the heated surface to the dry vapor between the liquid agglomerates, and then to the individual liquid globules is ngeligible when contrasted to the heat flow directly to the liquid through a small tube area adjoining the dispersed liquid phase. It has been found that the vapor phase is superheated to a temperature approaching that of the tube wall which implies non-thermodynamic equilibrium between the vapor and liquid phases.

In making the transformation from hot plate heat transfer to forced convection spheroidal boiling tubes the following equations and assumptions are required:

1) Droplet heat balance

$h_{\delta}=-4 \lambda \frac{\rho f}{\Delta T} \quad \frac{d r_{0}}{d \theta} \quad$ where $h_{\delta}=\frac{K_{v}}{y}$ Equation

Basis: The heat transfer from the wall to a spherical drop results in latent heat formation and a time rate of size reduction.

TRW-690-32 
$\longrightarrow \quad \begin{aligned} & \text { INCRE ASE IN WETTING } \\ & \text { (DECREASE IN CONTACT ANGLE) }\end{aligned}$
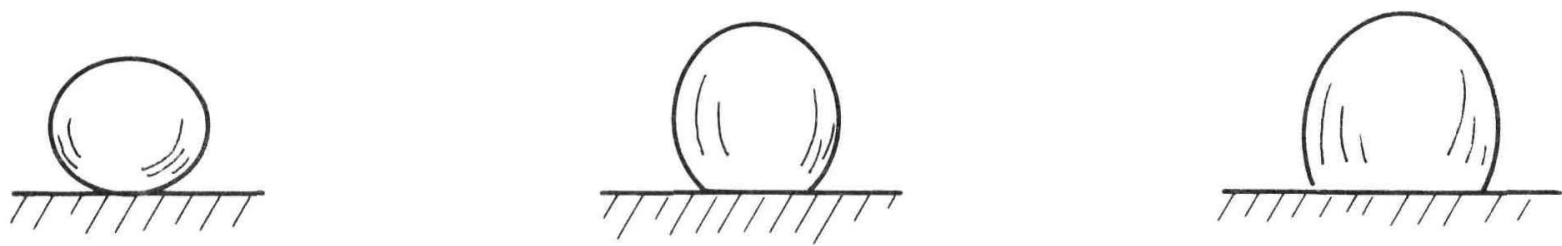

LIQUID CONTACT

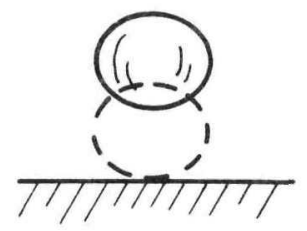

$\frac{\text { TRANSITION }}{\text { (INTERMITTENT) }}$

CONTACT)
INCREASE IN DROP SIZE

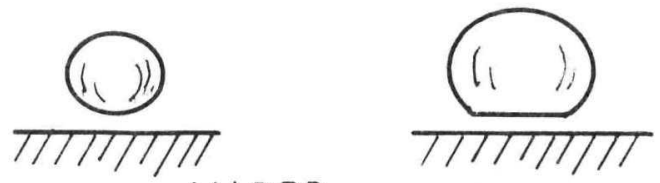

VAPOR
FILM

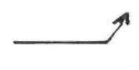

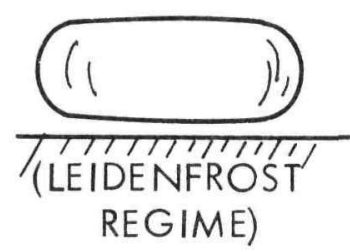

REGIME)

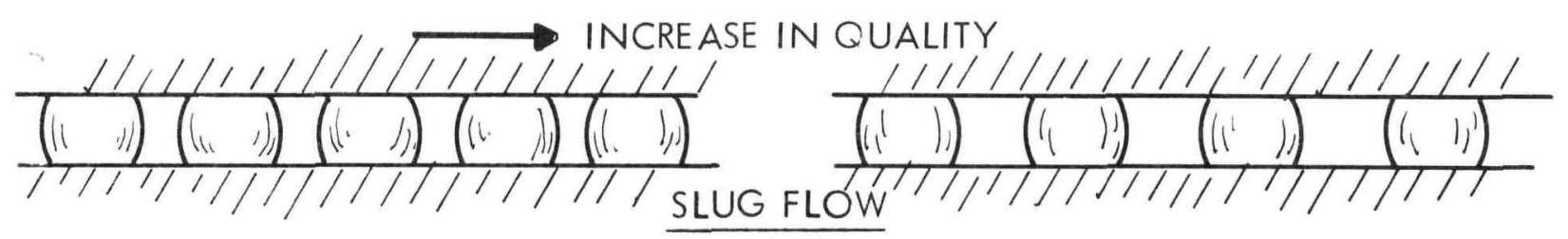

REGIME IN WHICH LIQUID SPHEROIDS ARE RADIALLY LIMITED BY TUBE DIAMETER

FIGURE 12. SOME SPHEROIDAL BOILING MODES ENCOUNTERED IN FORCED CONVECTION VORTEX BOILING OF PURE MERCURY

$$
\text { TRW }-690-32
$$


2) Residence time and tube length

$$
d \theta=\frac{d L}{u \epsilon}
$$

Basis: The residence time of the liquid phase is greater than that of the vapor due to the slip.

3) Slip ratio

$$
\epsilon=\frac{6 K_{v}}{h_{\delta} r_{0}}
$$

Equation (10)

Basis: The slip is determined by the forces acting on the droplet. The drag due to flowing vapor is equated to the viscous vapor shear force exerted by the wall on the liquid as shown in Figure 13. The result is a relation between the spheroidal vapor film heat transfer coefficient and the slip. The slip ratio for contact boiling can be estimated if it is assumed that

$$
\epsilon(\text { contact })=\epsilon(\text { film })
$$

when $h \quad$ (contact) $=h \quad($ film $)$

4) Swirl acceleration

$$
g=\left(\frac{\epsilon G_{\tan \alpha}}{\rho_{v}}\right)^{2} \quad \frac{2}{D} \quad \text { Equation (11) }
$$

Basis: The radial acceleration is determined from

$$
g=\frac{u_{t}^{2} 2}{D} \quad \text { see Figure } 13
$$



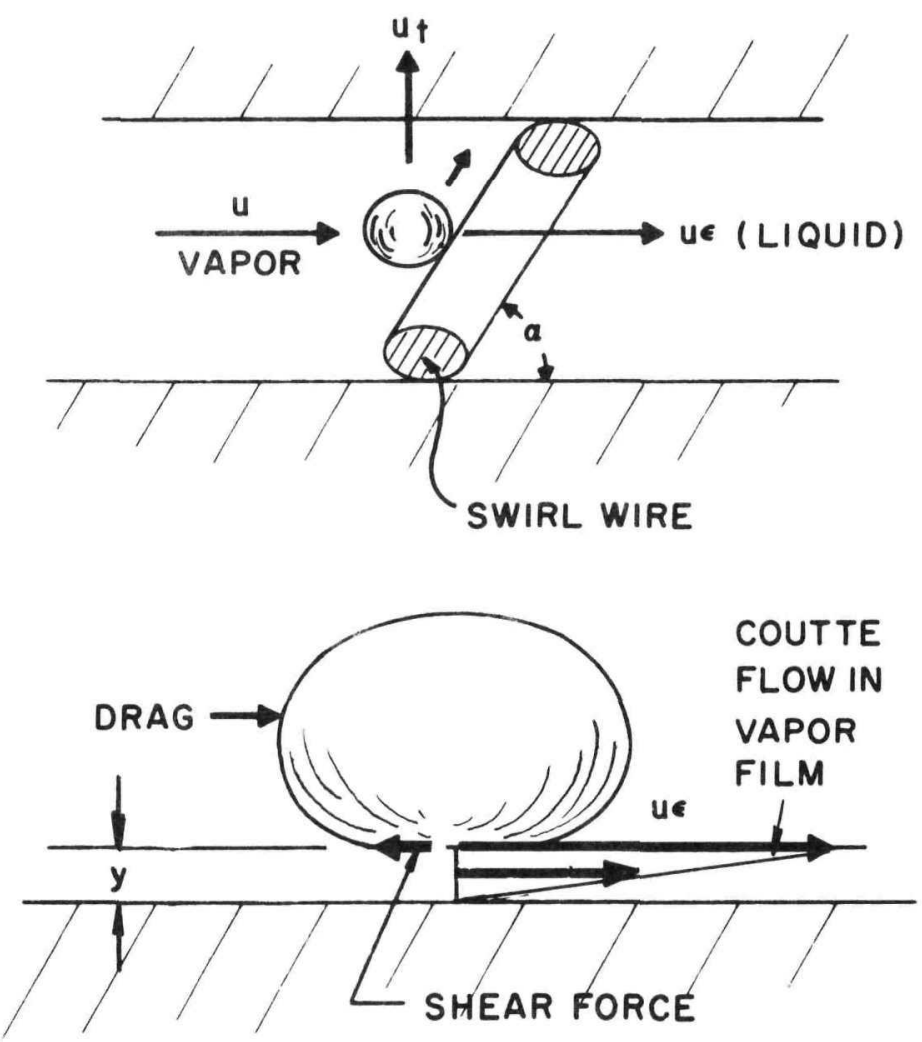

$\pi r_{0}^{2} C_{d} P_{v} \frac{\left(u-u_{e}\right)^{2}}{2 g_{s}}=\frac{\mu_{v} u \in \pi r_{0}^{2}}{g_{s} y}$

WHERE

$$
C_{d}=\frac{24}{R_{e}}=\frac{24 \mu_{v}}{2 r_{0} \rho_{v}(u-u \epsilon)} \text { and } y=k_{v} / h_{8}
$$

FIGURE 13 SPHEROID FLOW DYNAMICS

$$
\text { TRW-690-32 }
$$


5) Relation between drop size and flow quality

$$
\begin{aligned}
& r_{0}=r_{\infty}(1-x)^{1 / 3} \\
& \frac{d x}{d r_{0}}=-\frac{3}{r_{\infty}} \quad(1-x)^{2 / 3}
\end{aligned}
$$

Equation (12)

Equation (13)

Basis: This relationship is obtained from continuity. The number of droplets flowing at each cross-section remains constant (no agglomeration), and the size of each drop is diminished by evaporation. It is assumed that the quality is zero at the point where the initial drop size $(r \infty)$ is established.

This size is assumed equal to the wire diameter since for a drop greater than the wire diameter the flowing vapor could shear it down to wire size. These five relationships when combined with the equations for the spheroidal heat transfer coefficient and the equations defining the tube surface heat transfer coefficient result in:

$$
\frac{h D}{K_{v}}=\frac{1}{32} N_{\delta}^{2}\left(\frac{K_{f}}{K_{v}}\right)^{2}\left(\frac{D}{\delta_{0}}\right)^{2} \frac{1-x}{x} \quad \frac{\rho_{v}}{\rho_{f}} \quad \text { Equation (14) }
$$

where $\quad$ Nu $\delta \equiv \frac{h_{\delta} 2 r_{0}}{K_{f}}$

Equation 14 gives the local heat transfer coefficient for spheroidal contact boiling.

$$
\frac{h D}{K_{v}}=6^{1 / 3} \frac{(1-x)^{1 / 3}}{x^{1 / 3}} \frac{D}{\delta_{0}}(\tan \alpha)^{2 / 3}\left(\frac{\rho_{v}}{\rho_{f}}\right)^{2 / 3}\left(\frac{D G}{\mu_{v}}\right)^{2 / 3}\left(\frac{\lambda \mu_{v}}{\Delta T} K_{v}\right)_{\text {Equation (15) }}^{2 / 3}
$$

Equation 15 gives the local heat transfer coefficient for spheroidal film boiling.*

*Equation 15 is based on Model III of Figure 11. It can be shown that the ratio of the heat transfer coefficients as computed from each of the mathematical models results in:

$$
\frac{h_{I}}{h_{\text {III }}}=2^{1 / 2} \text { and } \frac{h_{\| I}}{h_{I I}}=\left(\frac{6 \lambda \mu}{\Delta T K_{V}}\right)^{1 / 3}
$$


For the case of spheroidal intermittent contact boiling, the equation for the heat transfer coefficient is empirically determined by means of experimental multiplying factors applied to Equation 15, resulting in

$\frac{h D}{K_{v}}=C^{4} 234\left(\frac{K_{v}}{K_{f}}\right)^{4}(1-x)^{4 / 3} \times\left(\frac{\delta o}{D}\right)\left(\tan \frac{D G}{\mu_{v}} \frac{\lambda \mu_{v}}{K_{v} \Delta T_{m}}\right)^{2}$ Equation (16)

Transitions from contact to vapor film boiling appear to occur in forced convection boiling at wall superheats of somewhere between $10^{\circ} \mathrm{F}$ and $100 \circ \mathrm{F}$ depending on mass velocity and pressure level (8). This can be contrasted to a value of approximately $100^{\circ} \mathrm{F}$ as determined from hot plate, drop boil-off tests. See Figure 8.

Equations 14 and 15 show that as the initial drop size increases (increase in liquid phase agglomeration) the heat transfer coefficient decreases. This decrease is limited to a low value at which the liquid globule bridges the tube. This limit is termed slug flow and represents a flow pattern giving the lowest possible heat flux in spheroidal boiling systems. The causes for the formation of slug flow are still speculative and are discussed in (8), (9) and (19). The boiling tube length required for slug flow boiling, slug flow termination, and the establishment of the initial drop size, $\delta_{0}$, at which dropwise vortex boiling begins is of importance to the boiler designer. For pure nonwetting mercury the slug flow boiling heat transfer coefficient can be readily derived as follows:

The heat transfer coefficient for an individual liquid slug (see Figure 12) can be estimated by means of the classical viscous flow equation for uniform wall heat addition, namely.

$$
\frac{h_{\ell} D}{K_{f}}=\frac{48}{11}
$$


Assume that the vapor slugs contain superheated vapor and act as "heat dams". If there is no slip between the vapor and liquid phases, the static quality equals the flowing quality. As a result it can be shown that.

$$
h=\frac{h_{l}(1-x)}{1-x\left(1-\frac{\rho_{f}}{\rho_{l}}\right)}
$$

Equation (18)

for slug flow vaporization. Combining one obtains

$$
h=\frac{\frac{48}{11} \frac{K l}{D}(1-x)}{1-x\left(1-\rho_{f} / \rho_{v}\right)}
$$

which equation gives the local boiling heat transfer coefficient for non-wetting mercury slug flow. Detailed development and application to design of the slug flow equation is given in (8). Experience has shown that in the design of a high performance boiler, slug flow boiling should be suppressed. This is accomplished by means of plug type inserts placed in the inlet region of the boiler. High velocity swirl devices and multichannel plugs have been investigated and are described (8) and (19).

Also it can be shown that the contact boiling regime gives much shortex tube lengths than does the vapor film boiling regime. As a result it is desirable to produce a strong swirl flow with high radial accelerations in order to increase the extent of contact boiling.

Several representative boiler performance NaK temperature profiles are shown in section IV-B. Figure 55 is an example of a performance profile predicted by equations 14,15 and 16 with measured test data also plotted showing the excellent agreement between "nonwetting" design and performance predictability. The various boiling zones are designated as predicted by the local design equations.

Figure 56 is an example of better performance which was the most frequently encountered mode of operation. In this mode, wetting has occurred resulting in mercury film heat transfer coefficients so high as to make the mercury resistance negligible. Wetting also occurs in various degrees, Figure 56 representing a maximum experienced at SNAP 2 conditions. Wetting heat transfer is discussed in the following section.

Figure 57 is an example of poorer performance which was occasionally experienced and termed "deconditioned" operation. 
The deconditioning phenomenon occurs in various degrees sometimes so severe that liquid is spilled from the boiler discharge. The topic is discussed in section II-D.

\section{Wetting Model}

Exceptionally short boiling lengths were obtained in several tests determined to be the result of wetting. Figure 14 depicts the flow pattern and NaK temperature profile when complete wetting results and the two-phase flow pattern is of the sprayannular film type. Where the liquid film is continuous the heat transfer coefficients in the mercury are very large and can be ignored. The overall resistance can be approximated by summing the $\mathrm{NaK}$ and tube metal resistance. The liquid film is replenished by eddy diffusion of droplets from the vapor stream. When the film evaporation rate exceeds the diffusion rate the film can be destroyed and heat transfer rates reduced. For the condition that all of the liquid that diffuses to the wall is evaporated, the heat transfer is given by:

$$
h=\frac{K_{G} S(1-x) G_{0} \lambda}{\left(T_{w}-T_{H g}\right)}
$$

Equation (20)

Values for the dimensionless mass transfer coefficient KG are approximated from the analogy between mass and momentum transfer:

$$
K_{G}=\frac{0.023}{R_{e} 0.2} \quad \text { for } \epsilon=1
$$

Equation (21)

Figure 15 shows the comparison with test data. Detailed development and application to design is given in (8).

B. HOT PLATE TESTS

Heat transfer to mercury drops was experimentally investigated by evaporating individual mercury drops of known size on a hot metallic plate. The results of these experiments were utilized in the theoretical spheroidal boiling development of Section II-A-3. The raw data, shown in Figure 8, consisted of boil-off times measured as a function of plate temperature. Drop size and type of plate surface were the significant variables.

The initial test rig used a stainless steel plate partially immersed in a lead bath to provide a uniform heating surface temperature. Figure 16 is a sketch of the experimental setup. 


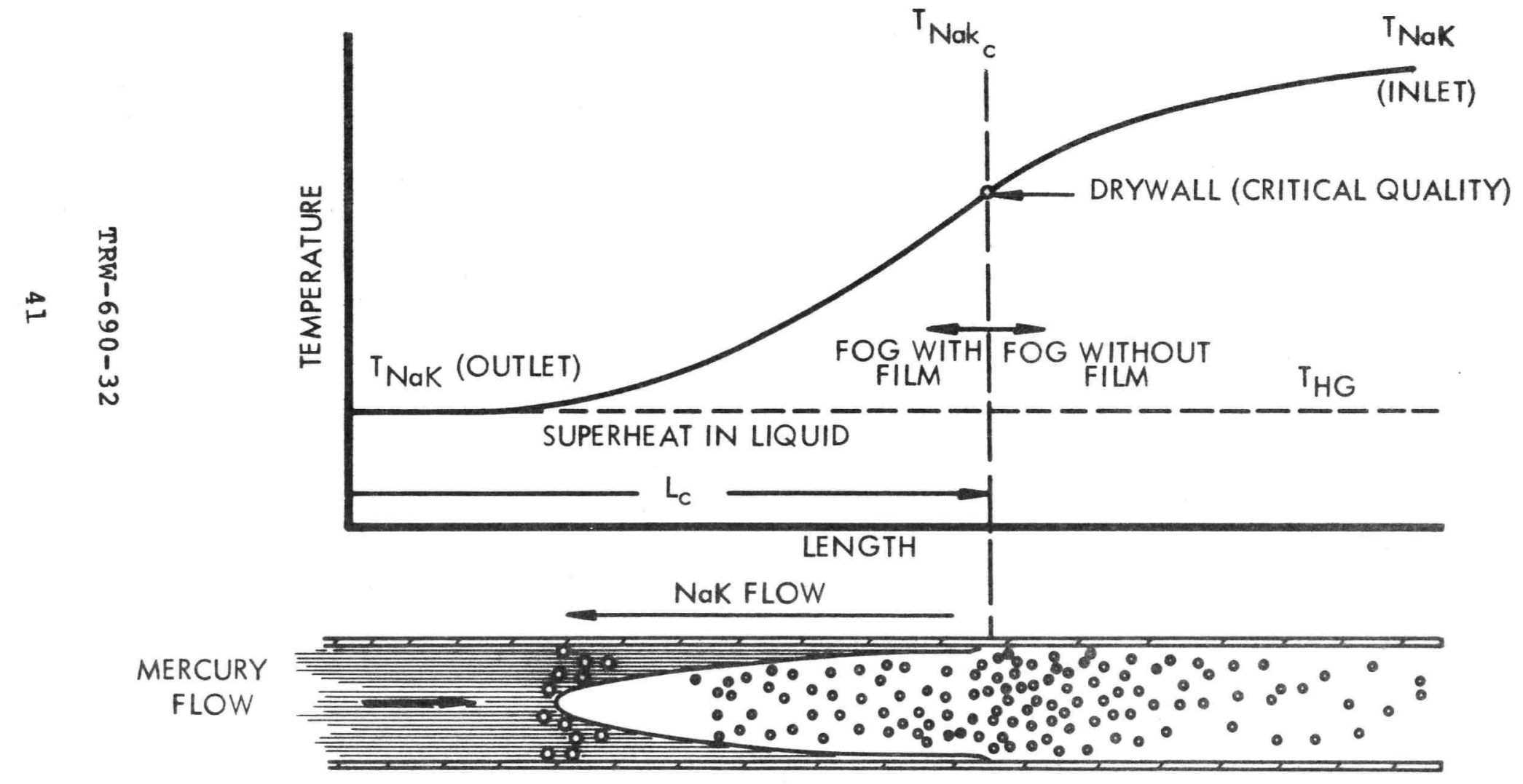

FIGURE 14 SPRAY-ANNULAR BOILING 


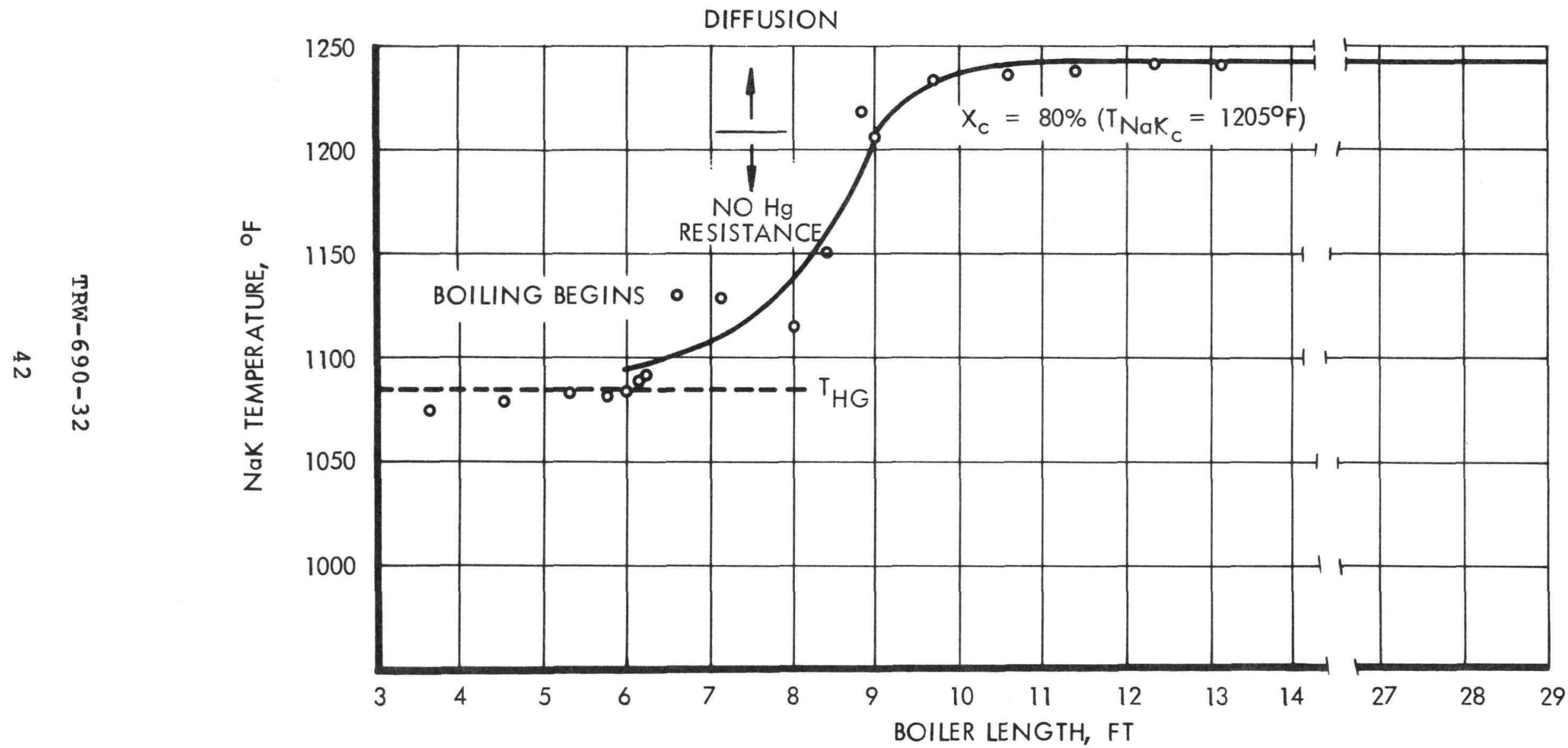

FIGURE 15 COMPARISON OF THEORETICAL NaK TEMPERATURE PROFILE FOR Hg WETTING WITH TEST DATA (5C-2 BOILER) 


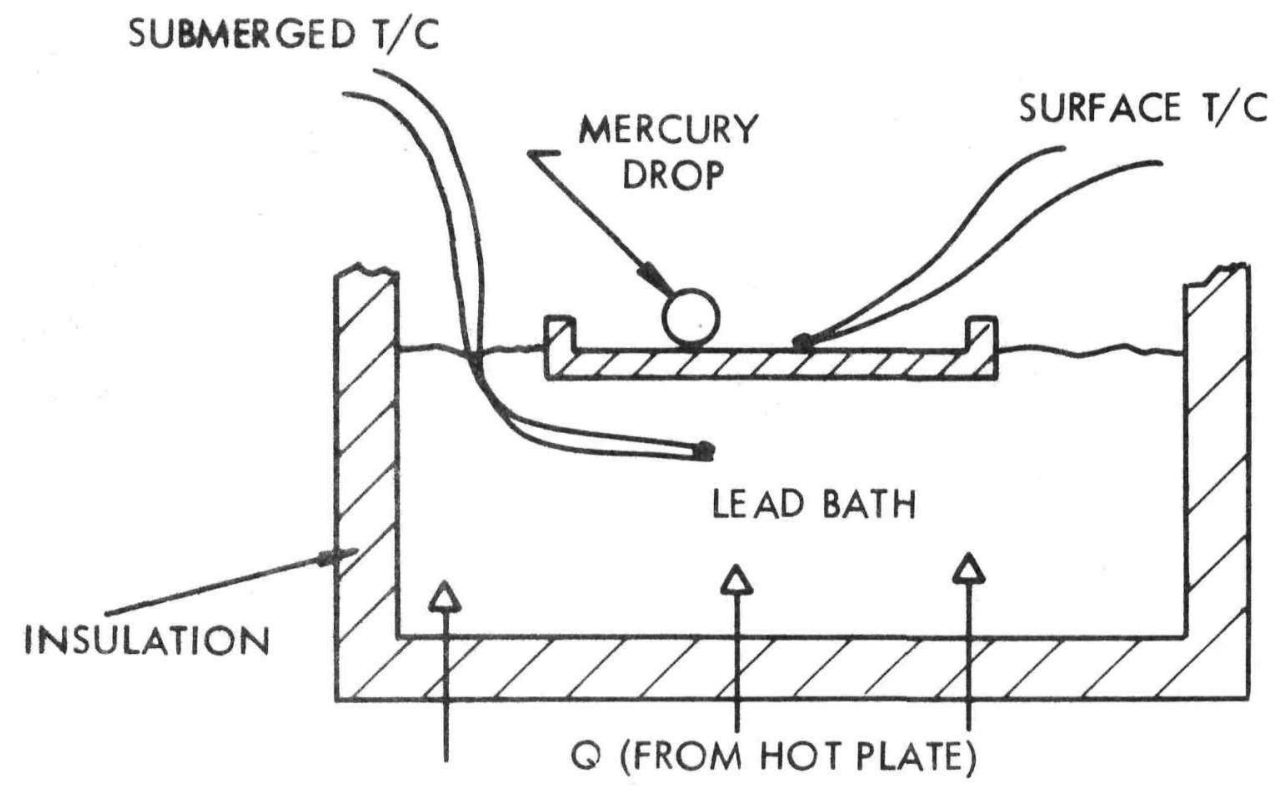

Figure 16. Experimental Setup to Determine Heat Transfer to Mercury Drops

A correlation was obtained between drop weight and drop diameter. Drops were prepared on a weight basis and rolled onto the hot plate which had been stabilized at a predetermined temperature. The tests were performed on an open hot plate exposed to air requiring corrections to be applied in reducing the data to conditions approximating the environment existing in a boiler tube.

A diffusion correction to account for the mass transfer of mercury vapor to the surrounding air was the principal correction. Additional corrections to account for radiation and convection effects due to the low temperature surroundings were applied. Figures 17 and 18 show some basic parametric plots of the reduced corrected data. Figure 19 illustrates an example in which the data was used in conjunction with the drop model equations in Figure 11 to gain insight into the transition or intermittent contact boiling regime.

References (6) and (7) give additional details of these experiments and data manipulation.

Subsequent hot plate tests were conducted in a controlled atmosphere. A sketch of a test chamber is shown in Figure 20. The test setup permitted four chambers to be run simultaneously (see the schematic in Figure 21). A photograph of an instrumented test chamber prior to the installation of the insulation is shown in Figure 22.

The boiling surfaces were Haynes 25 ground to an 8 rms finish and annealed and cleaned to simulate a prototype boiler tube. Cleaned and oxidized surfaces were tested to simulate 


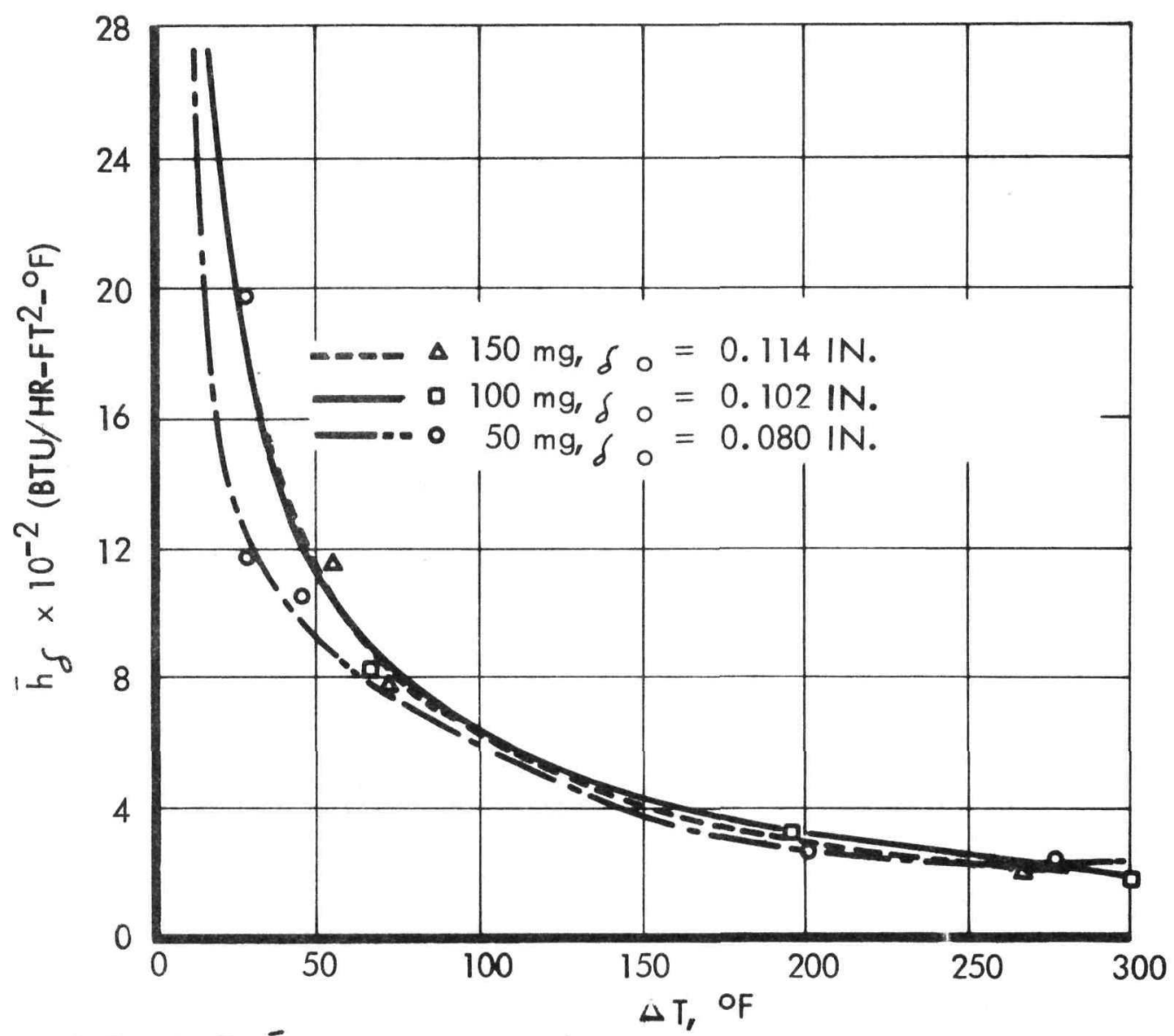

FIGURE $17 \bar{h}_{\delta}$ VS. $\triangle T$ T FOR MERCURY DROPS ON A HOT PLATE IN AIR

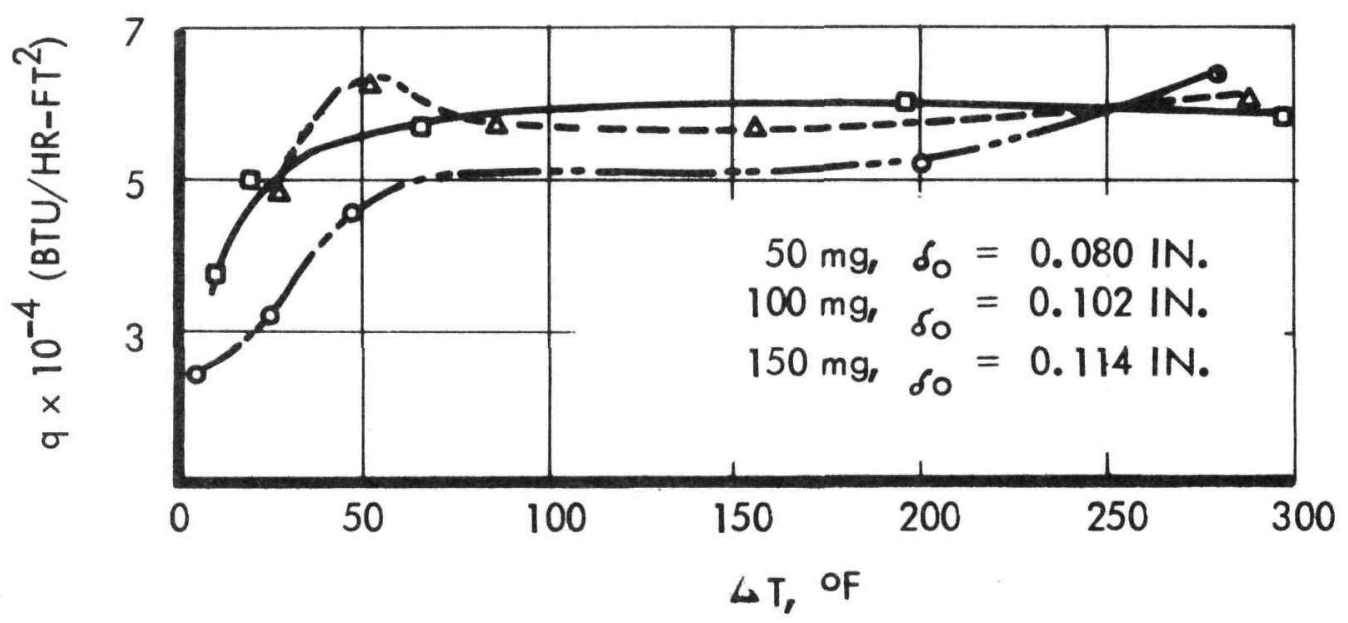

FIGURE 18 q VS. $\triangle T$ T FOR MERCURY DROPS ON A HOT PLATE IN AIR

TRW-690-32 


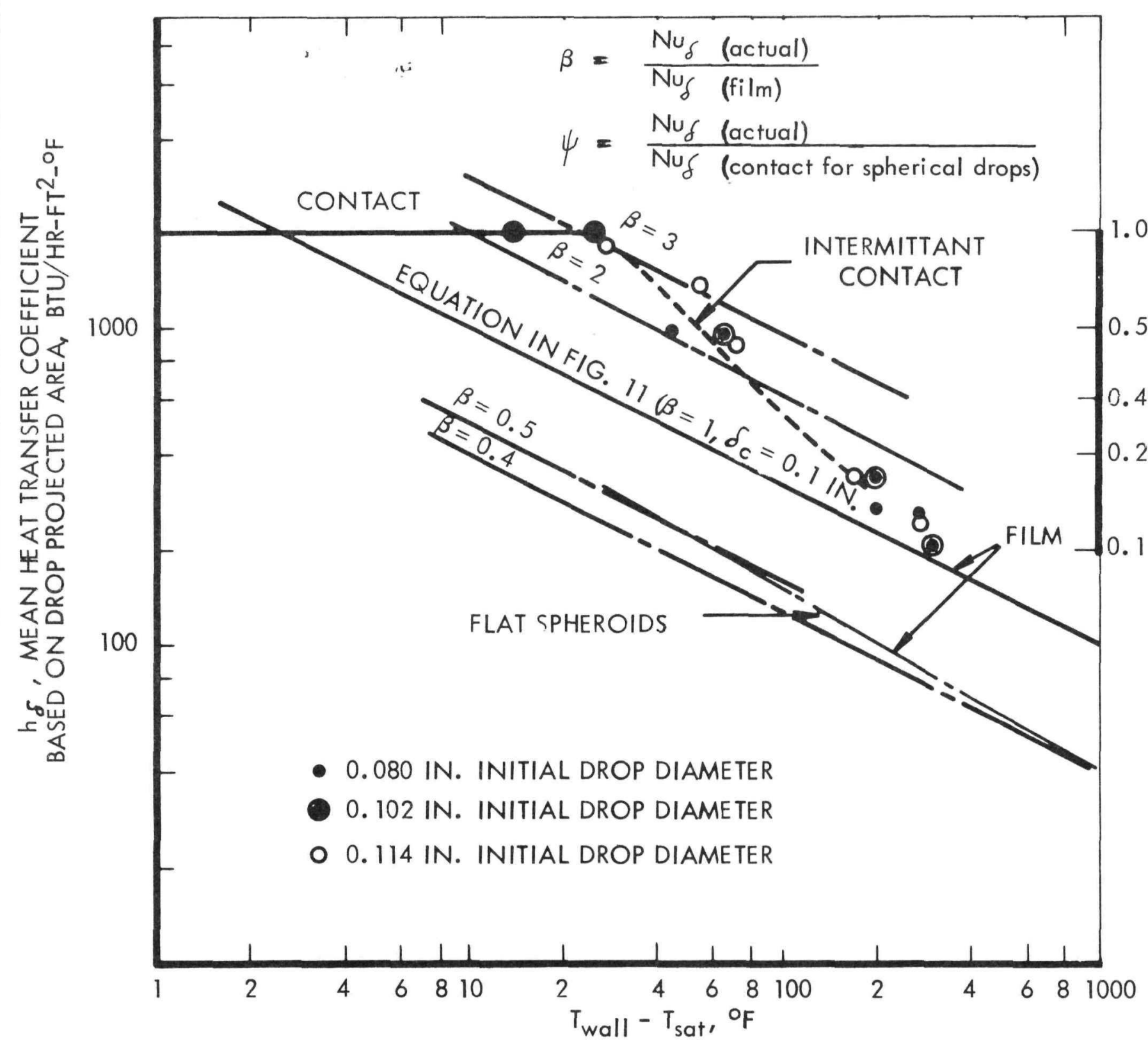

FIGURE 19 OPEN STAINLESS STEEL HOT PLATE MERCURY DROP EVAPORATION DATA (REF. 6$)$ SHOWING VARIOUS BOILING REGIMES AND VALUES FOR $\beta$ AND $\psi$ (DATA CORRE CTED FOR RADIATION, CONVECTION, \& DIFFUSION EFFECTS)

TRW-690-32 


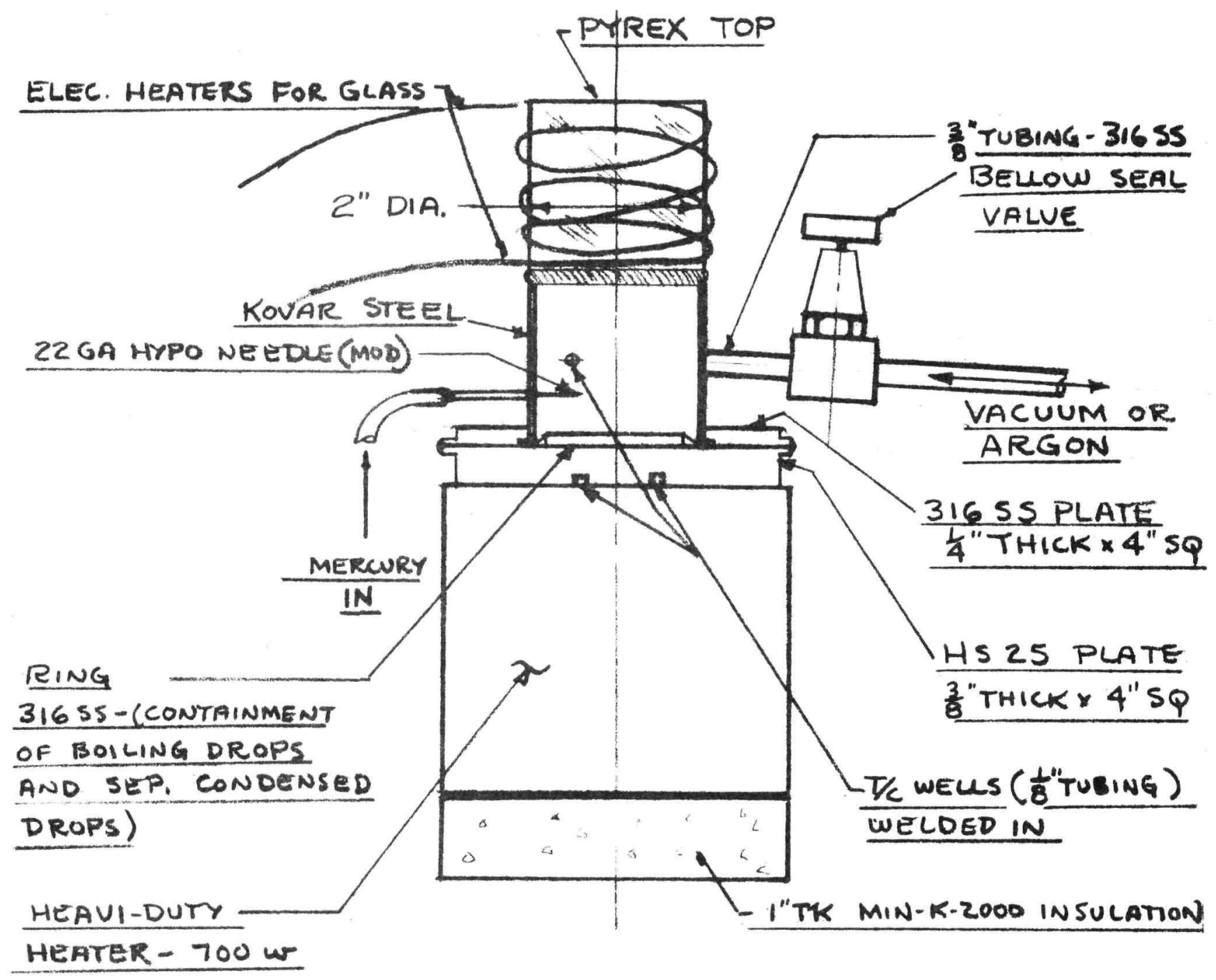

NOTE: 1. WHOLE UNIT INSULATEO WITH KAOWOOL

2. GLASS ELECTRICALLY HEATED

3. AODITIONAL T/C'S NOT SHOWN

$A$ - 3 ON GLASS

B. 3 ON KOVAR STL

C- 3 ON TOP PLATE $(31655)$

D 4 ON BOTTOM PLATE (HS 25)

FIGURE 20 CONTROLLED ATMOSPHERE HOT PLATE TEST CHAMBER

TRW-690-32 


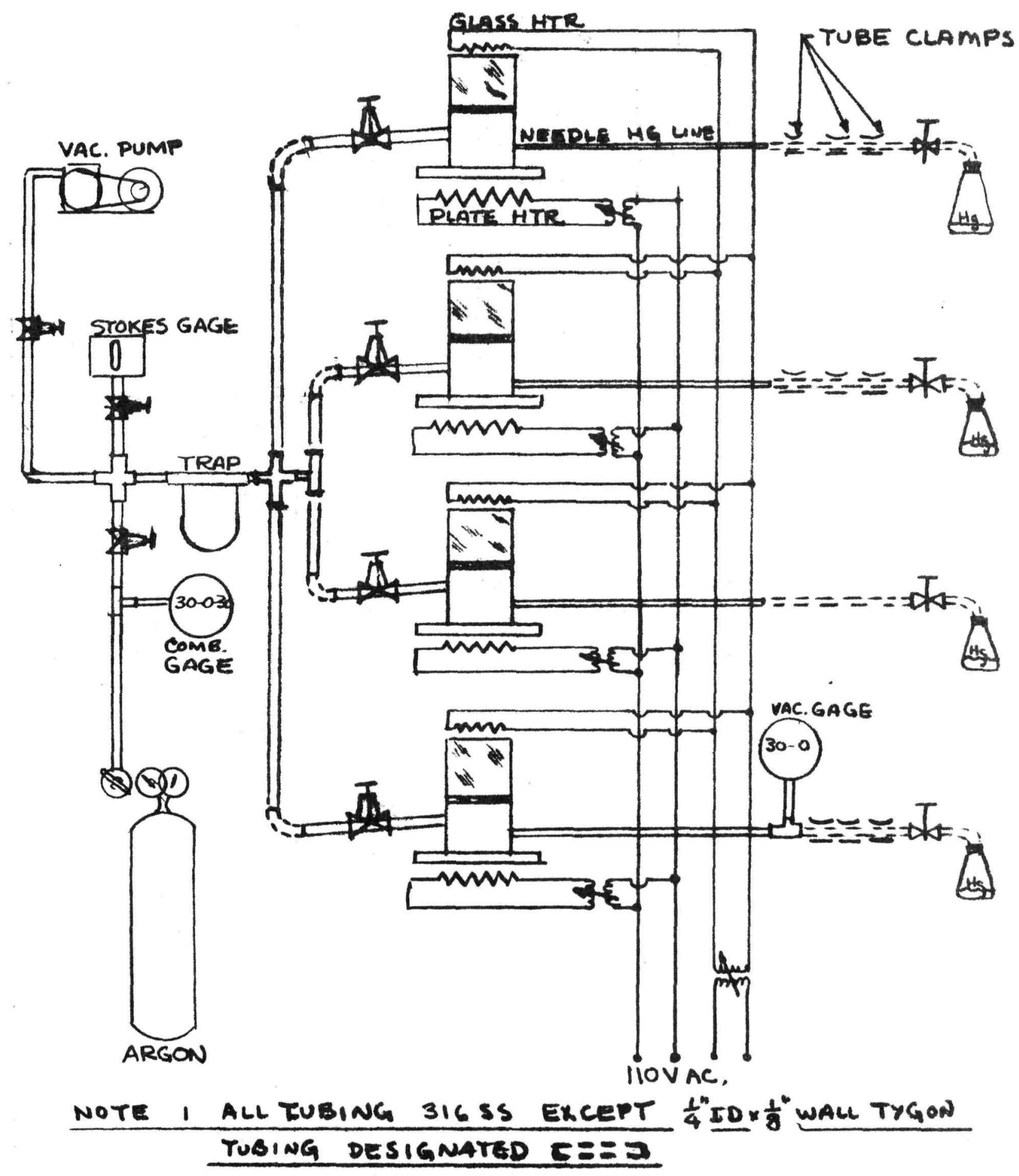

FIGURE 21 RIG SCHEMATIC FOR SIMULTANEOUS OPERATION OF FOUR TEST CHAMBERS

TRW-690-32 


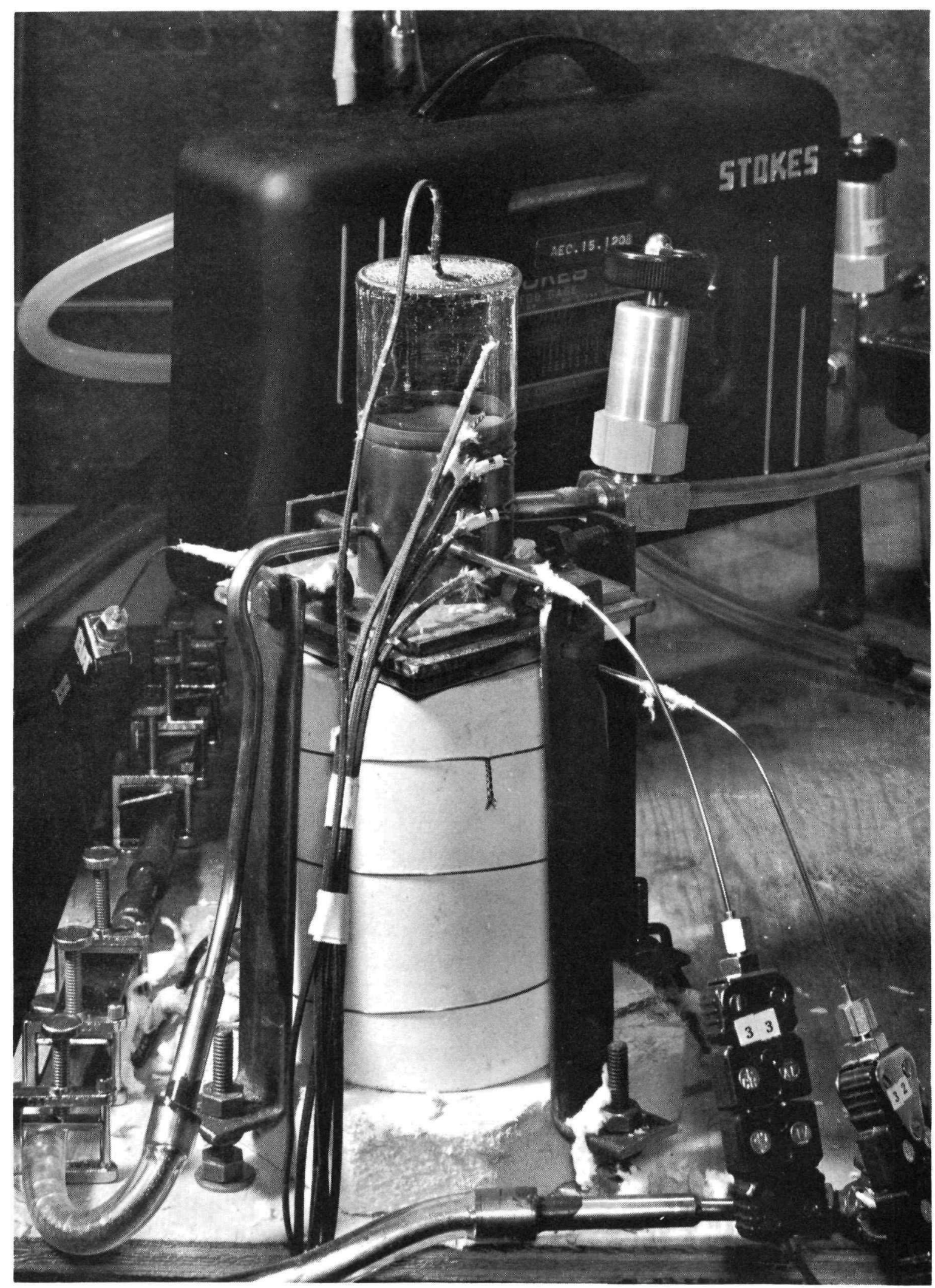

FIGURE 22 INSTRUMENTED TEST CHAMBER WITHOUT INSULATION TRW-690-32 
prototype boiler operating conditions. The atmosphere in the chamber had provisions for control of argon, vacuum, or mercury vapor environments. Data was also collected in an open air atmosphere as the result of breakage of the chamber's pyrex glass dome. A chamber was machined on the outer circumference of the test surface to collect condensate from the test chamber side walls and minimize reagglomeration with the test drops.

The drops were injected with a calibrated 22 gage hypodermic needle which was attached to a sealed $1 / 8$ inch oD tubular injection port. Differences in the wetting due to surface treatment was observed through the glass domes.

Tests with the oxidized copper surface were performed in an open air atmosphere utilizing the lower test chamber assembly but no glass dome.

Figures 8, 9, and 10 display and interpret the test data. Additional details are presented in (9) and (18).

C. FORCED CONVECTION BOILING RESEARCH TESTS

Local tests were run on the configurations described in Table 3 to verify the theoretical heat transfer equations presented in section II-A-3 and to provide empirical data on the heat transfer and pressure drop.

TABLE 3

RESEARCH BOILER TUBE CONFIGURATIONS

\begin{tabular}{|c|c|c|c|c|c|c|c|c|c|c|c|}
\hline $\begin{array}{l}\text { Desig- } \\
\text { nation }\end{array}$ & $\begin{array}{l}\text { OD } \\
\text { In. }\end{array}$ & $\begin{array}{l}\text { Wall. } \\
\text { In. }\end{array}$ & $\begin{array}{l}\text { ID } \\
\text { In. }\end{array}$ & $\begin{array}{c}\text { Swirl } \\
\text { Wire } \\
\text { Dia, in. } \\
\text { o }\end{array}$ & $\begin{array}{l}\text { Swirl } \\
\text { Wire } \\
\text { Pitch } \\
\text { In, P } \\
\end{array}$ & $\underline{\mathrm{P} / \mathrm{Di}}$ & Di/so & Length & Material & $\begin{array}{l}\text { Heat } \\
\text { Transfer } \\
\text { Means } \\
\end{array}$ & $\begin{array}{r}\text { No. } \\
\text { Data } \\
\text { Points } \\
\end{array}$ \\
\hline SN 1 & $5 / 8$ & 0.065 & 0.495 & 0.054 & 1.8 & 3.64 & 9.2 & 30 in. & 316 SS & Radiation & 39 \\
\hline B & $5 / 16$ & 0.028 & 0.256 & & Bare & Tube & & 30 in. & HS- 25 & Radiation & 19 \\
\hline SN 2 & $5 / 16$ & 0.028 & 0.256 & 0.054 & 1.0 & 3.9 & 4.7 & 30 in. & $316 \mathrm{sS}$ & Radiation & 15 \\
\hline SN 3 & $5 / 16$ & 0.028 & 0.256 & 0.028 & 1.0 & 3.9 & 9.2 & 30 in. & HS -25 & $\begin{array}{l}\text { Radiation } \\
\text { or } \\
\text { Conduction } \\
\text { Through } \\
\text { "Thermon" } \\
\text { Cement }\end{array}$ & 72 \\
\hline $\begin{array}{l}\text { Rig } \\
\text { Boiler }\end{array}$ & $3 / 8$ & 0.035 & 0.305 & 0.062 & 0.88 & 2.9 & 4.9 & $115 \mathrm{ft}$. & $316 \mathrm{SS}$ & $\begin{array}{l}\text { Conduction } \\
\text { Through } \\
\text { "Thermon" }\end{array}$ & 42 \\
\hline
\end{tabular}

TRW-690-32 
A schematic of the boiling research test rig is presented in Figure 23. Typical test section construction is shown in Figure 24 .

The test section assemblies were single tubes 48 inches long having a 30 inch zone radiantly heated by $25 / 8$ inch $0 . D$. concentric electrical heaters. The heat heaters were surrounded by a 5 inch O.D. guard heaters which were controlled to eliminate radial heat loss from the test heaters. The annular space between the test heaters and the guard heaters contained thermal insulation. The overall assembly was insulated and enclosed in a sheet metal housing.

Tube wall surface temperatures were measured at 4 inch axial intervals. Immersion thermocouples and Bourdon pressure gages were installed at the inlet and outlet of the test section. Flow was provided by a pressurized bellows system. Flow rate was monitored by an orifice-manometer type meter, however, the flow rate used in data analysis was determined by accumulating mercury on a weigh scale over a measured time increment. The quality level was controlled by means of the forced convection boiler upstream of the test section. Pressure level was controlled by varying the condenser cooling air flow rate and manipulating the condenser exit valving. Power input was computed from the product of the current and voltage.

Ideally, the independent effects of a great number of variables were desired. These variables included flow rate; temperature difference; pressure; quality; tube material; tube diameter and wall thickness; inserts; swirl wire insert diameter and pitch; and operation in the film, intermittent contact, and contact boiling regimes. Compromises were made in the selection of configuration and parameter variation to reduce the prohibitive number of data points to a manageable quantity. Four test sections were tested, three having swirl wire inserts and one having a bare bore. The rig boiler was fully instrumented to provide supplemental data. Table 3 lists the significant geometric variables and the number of data points obtained with each configuration. The SN 3 test section experimentation was conducted to obtain the independent effects of flow, pressure, quality and temperature difference on heat flux. Experiments with SN 1, SN 2, and B test sections were conducted in a random manner leaving the burden of correlation to the theory and trends established by the SN 3 data. In Table 3 it is noted that some 


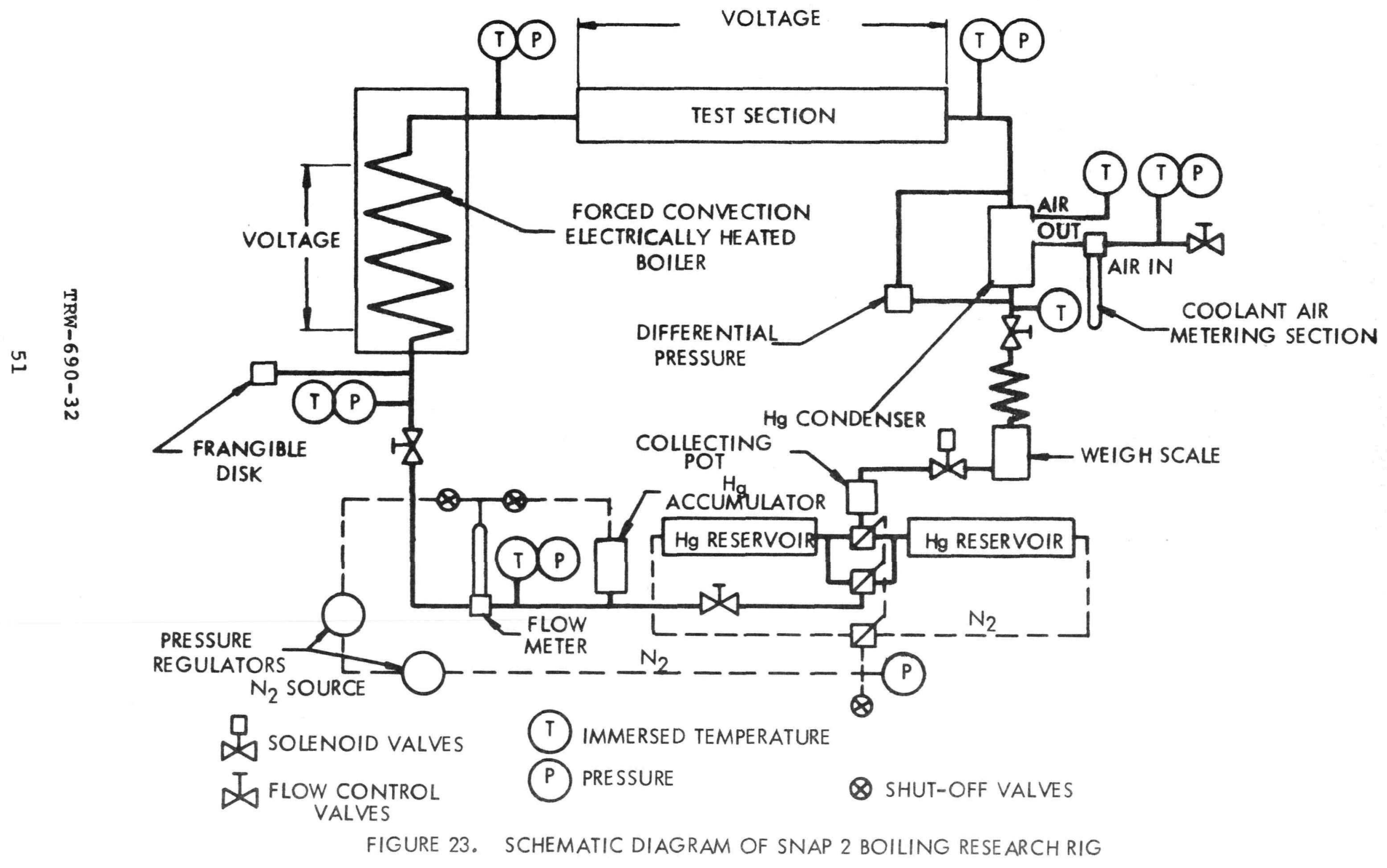




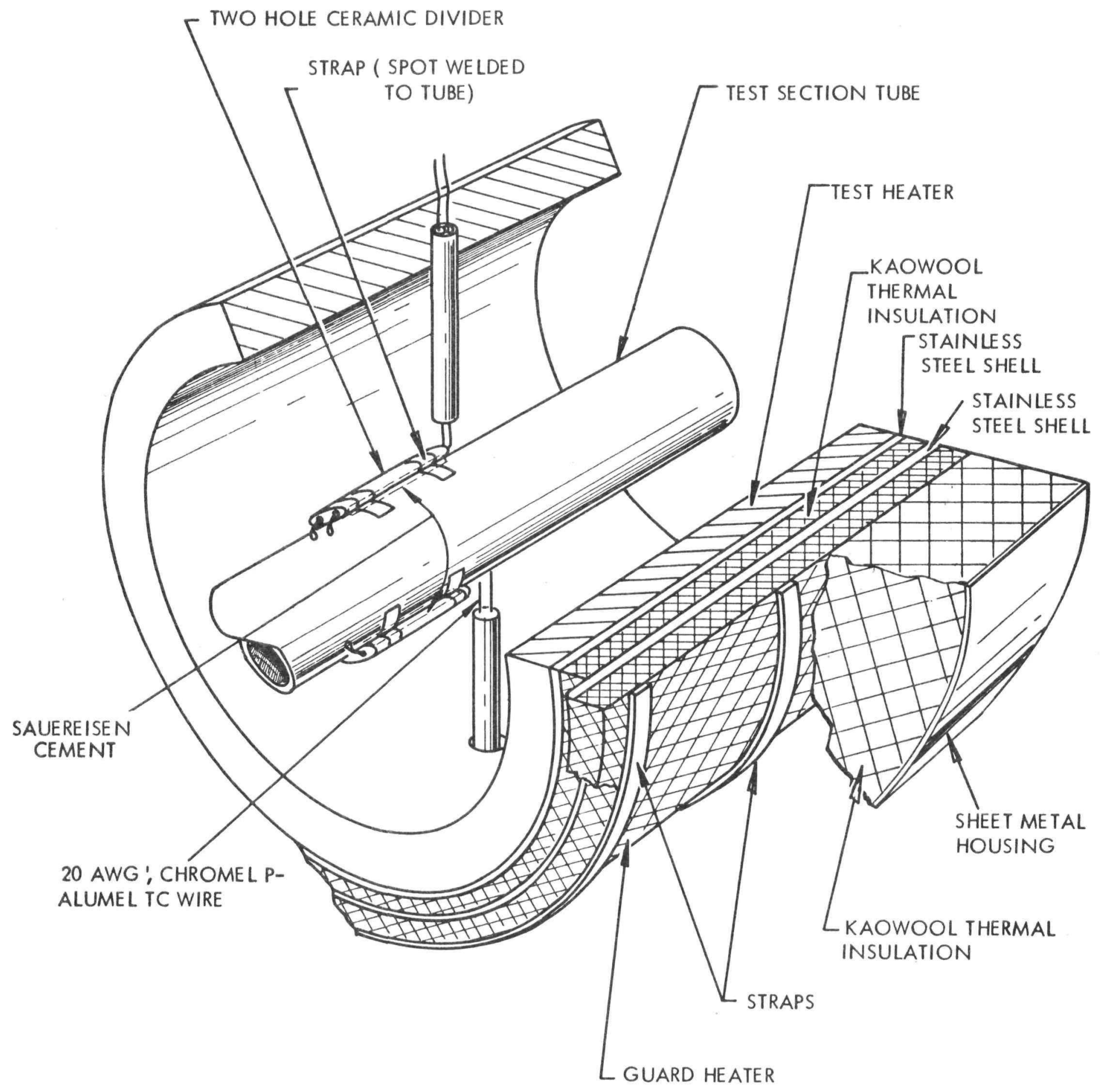

FIGURE 24 TYPICAL BOILING RESEARCH TEST SECTION CONSTRUCTION

TRW-690-32 
of the $\mathrm{SN} 3$ data was obtained with the heat input through "Thermon" cement by conduction. This was done for the high heat flux runs to avoid the excessive heater temperatures that would prevail if the heat was transferred by radiation. The "Thermon" heat transfer cement completely filled the annular space between the heater and the tube in these tests.

A computer was used to aid in data reduction and compilation of correlating parameters. Table 4 is a typical display of data and heat transfer and pressure drop correlating parameters. Figure 25 is representative of the graphical displays made of local heat flux and temperature difference distributions along the test sections. Reference (7) contains the data and correlations generated in the boiling research program. The data substantiated the heat transfer theory.

Several curves of heat flux versus temperature differences were prepared for use in design applications. Figure 26 shows schematically one typical boiling curve for the forced convection boiling of mercury in dropwise flow. The appropriate analytical equation developed for each regime is identified by equation number. The intersections of the equations define the termination of a regime or the beginning of a new boiling regime. The effects of mass velocity, pressure and quality are presented in detail in reference (7). The arrows on Figure 26 indicate the trends due to increases in mass velocity, pressure, and quality.

Pressure drop correlations were obtained for three test sections, test section $\mathrm{SN} 1$ data being omitted because of low values. The two phase boiling pressure drop is computed from:

$$
\Delta P_{T P}=\varnothing f_{v} \frac{L}{D} \frac{G^{2}}{2 \rho_{v} g_{s}}
$$

The multiplier $\varnothing$ is defined as the ratio of the two phase pressure drop to the gas only pressure drop. Figure 27 shows $\varnothing$ correlated against the Martinelli parameter. The friction factor $\left(f_{v}\right)$ is the all gas value obtained from tests using nitrogen in 10 foot long test sections. The effect of swirl wire inserts and tube coiling are included in values of $f_{v}$ used for design. Figure 28 shows the single phase friction factor plotted against Reynolds number. 
TABLE 4

TEST RESULTS FOR TEST SECTION SN 3

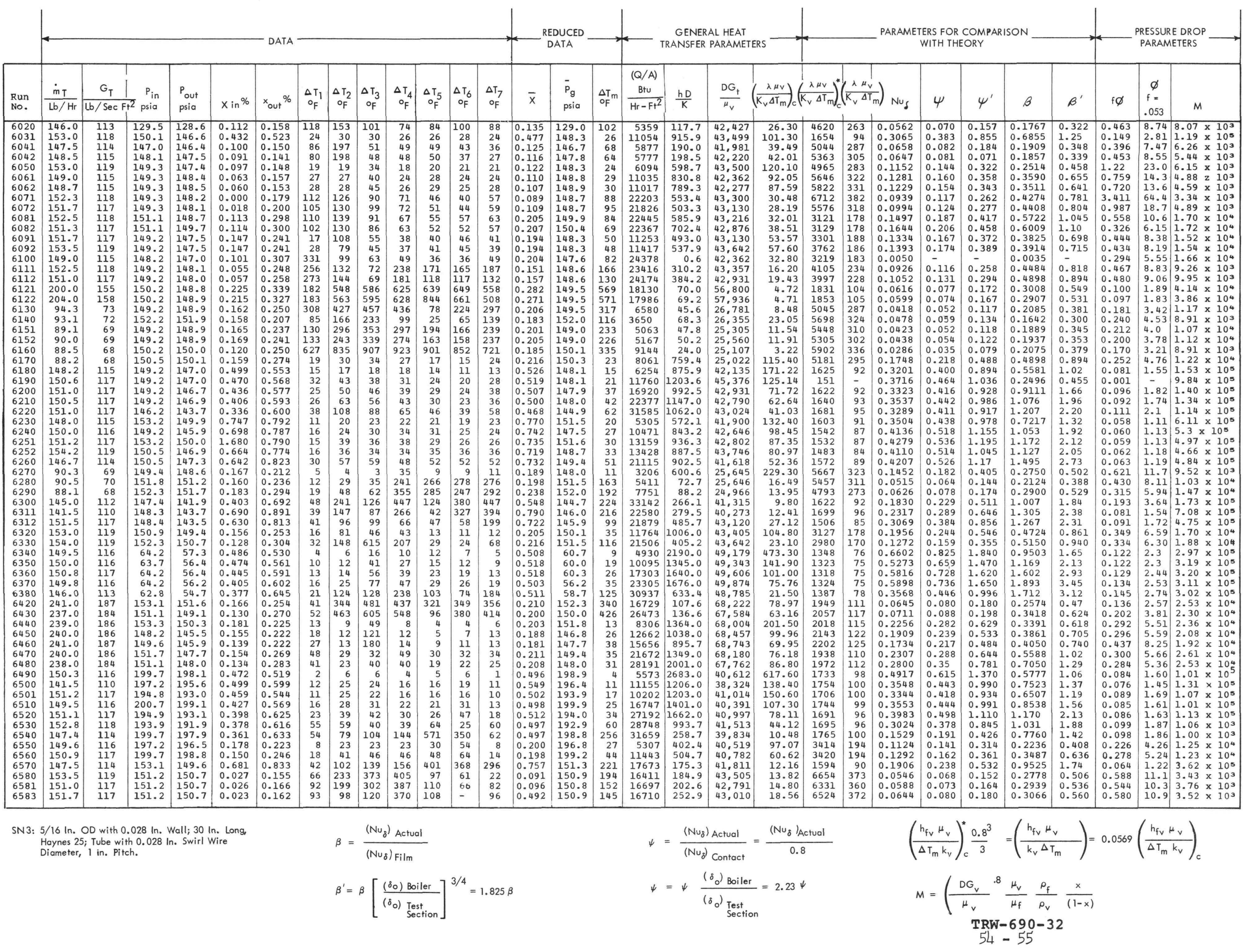


Blank Page 

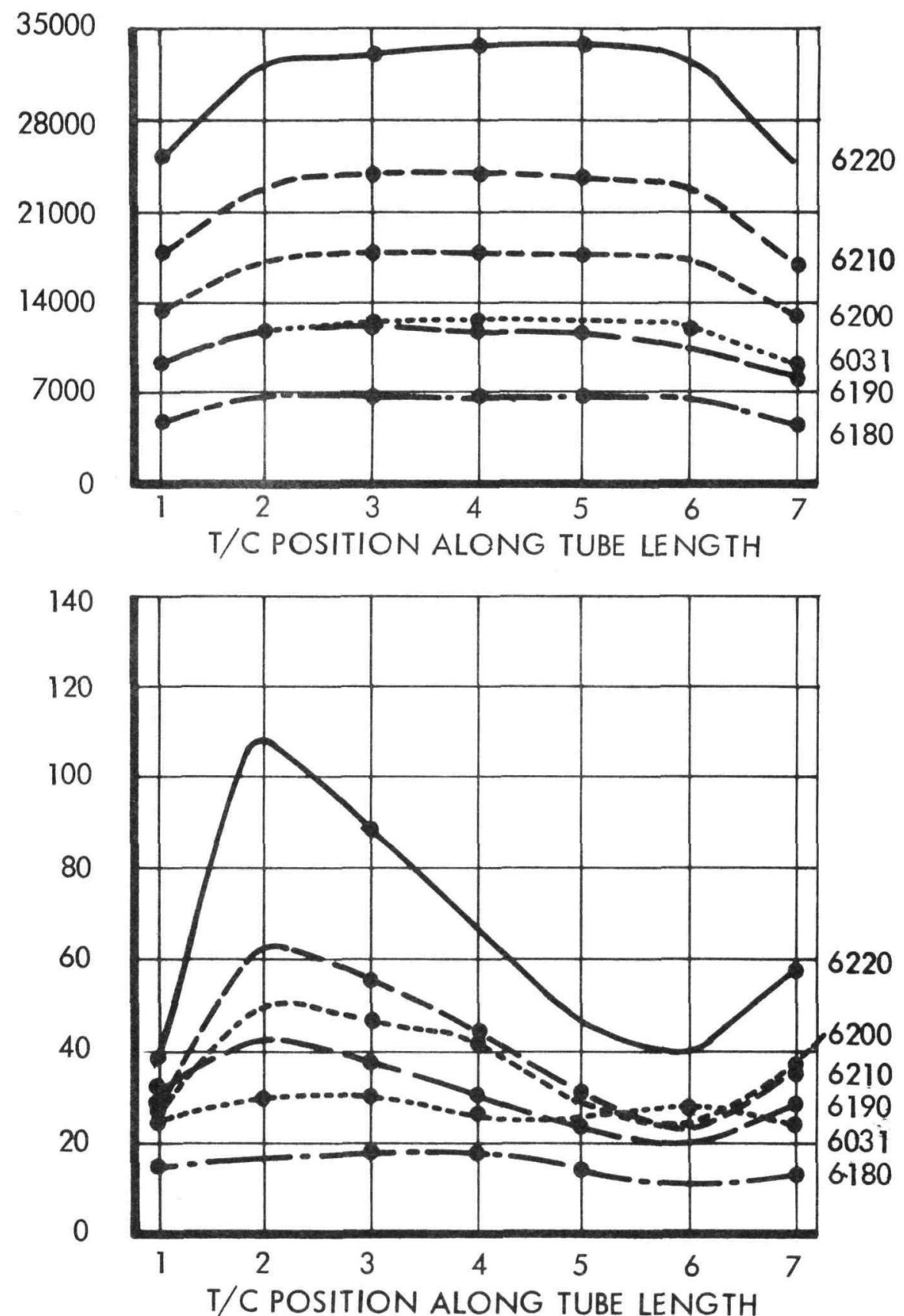

\begin{tabular}{|c|c|c|c|c|c|}
\hline Run No. & $\underline{\mathrm{m}}, \mathrm{lb} / \mathrm{hr}$ & P, psia & $\bar{x}$ & $Q / A_{l}$ Btu $/ h r-f^{2}$ & $\angle T$ \\
\hline 6031 & 153 & 148.35 & .4779 & 11,000 & 26.6 \\
\hline 6180 & 148.5 & 148.1 & .5268 & 6,250 & 15.7 \\
\hline 6190 & 150.6 & 148.1 & .5193 & 11,800 & 21.5 \\
\hline 6200 & 151 & 147.95 & .5072 & 16,900 & 31.5 \\
\hline 6210 & 150.5 & 148.05 & .5001 & 22,400 & 43 \\
\hline 6220 & 151 & 144.95 & .4687 & 31,600 & 66 \\
\hline
\end{tabular}

FIGURE 25. HEAT FLUX AND TEMPERATURE DIFFERENCE DISTRIBUTION ALONG TEST SECTION SN 3

TRW-690-32 


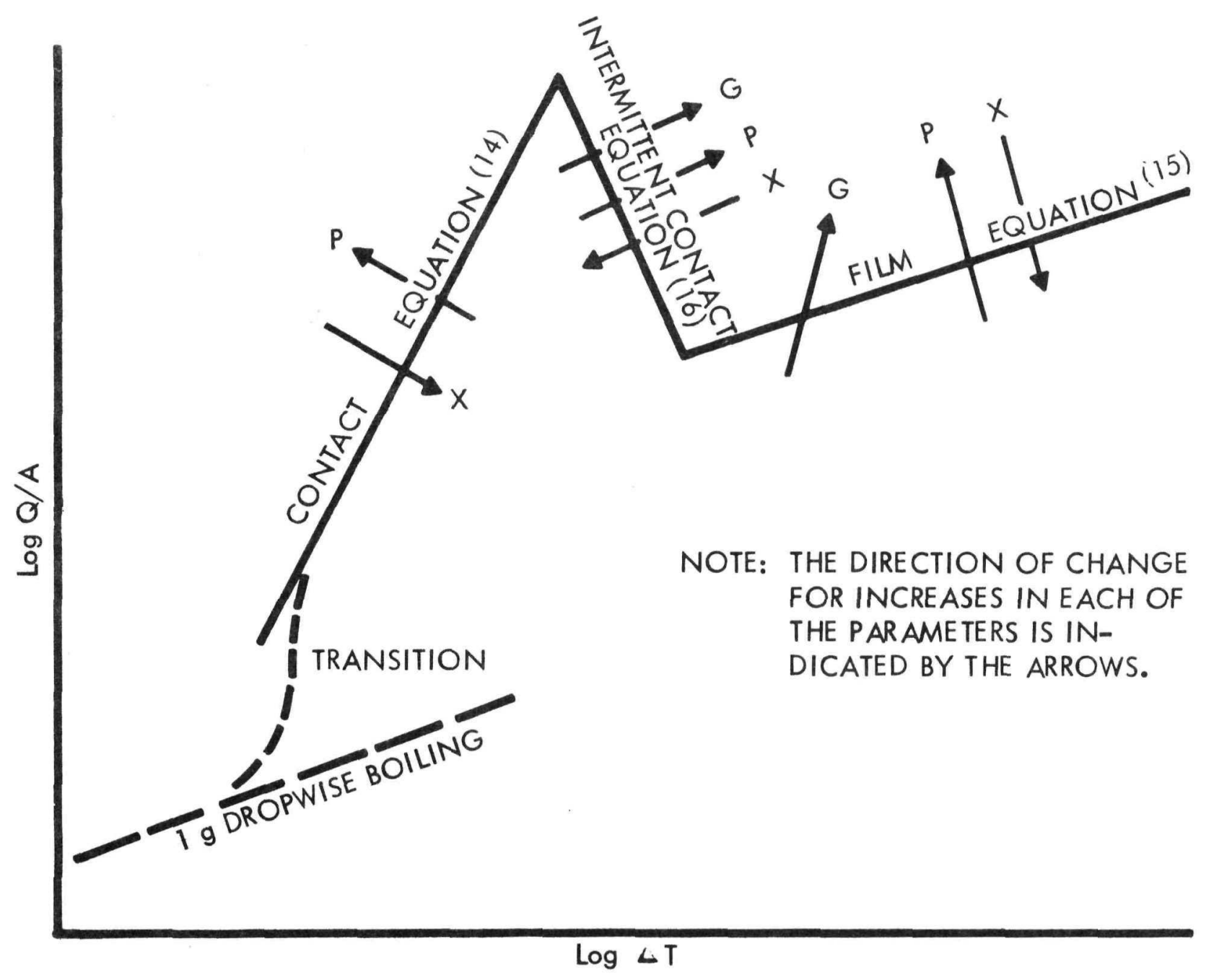

FIGURE 26. TYPICAL MERCURY FORCED CONVECTION VORTEX BOILING HEAT FLUX VS. $\triangle T$ CURVE (FOR A GIVEN MASS VELOCITY, PRESSURE, \& QUALITY)

TRW-690-32 


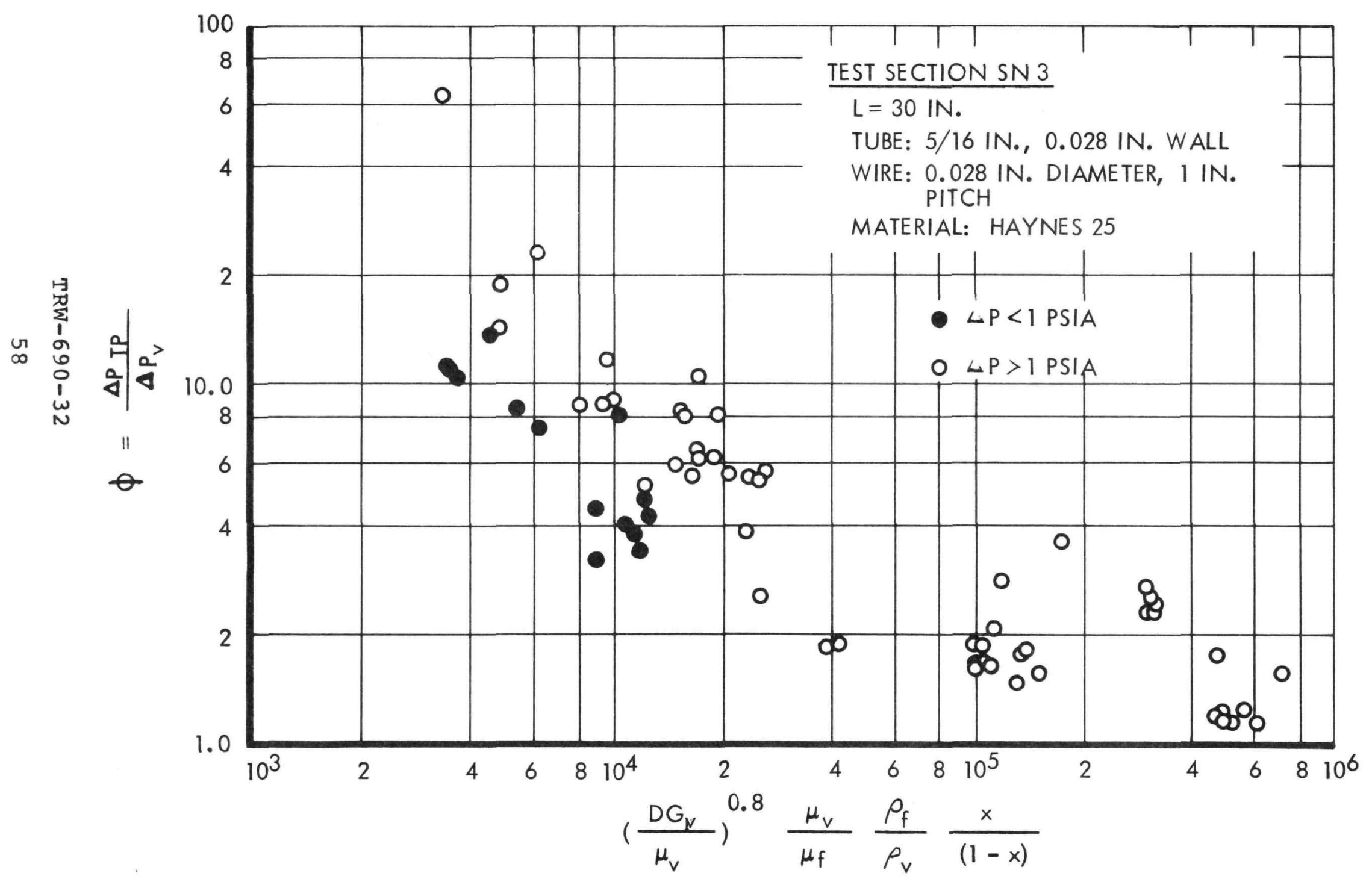

FIGURE 27 VORTEX FORCED CONVECTION BOILING PRESSURE DROP CORRELATION FOR TEST SECTION SN 3 


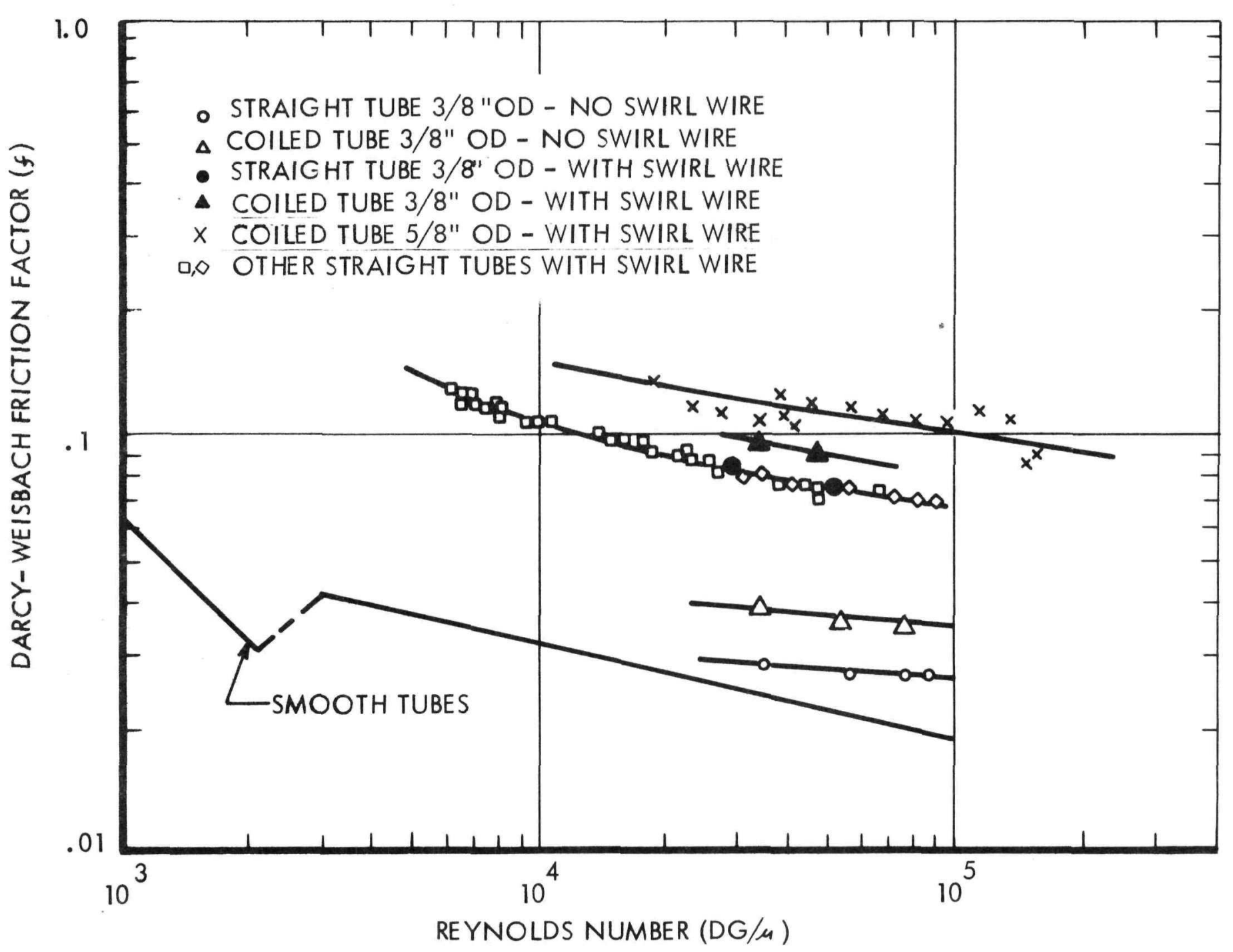

FIGURE 28 SINGLE PHASE FRICTION FACTOR

TRW-690-32 
Operating experience with MRPCP boilers has indicated that boiler performance is occasionally erratic in that exceptionally low heat transfer rates are encountered at times. This condition has been referred to as a "deconditioned state" and has been observed over a short period of time and at times has occurred continuously. The heat transfer behavior of a Nak heated mercury boiler can be characterized by the shape of the Nak temperature profile. In general, three shapes have been observed. Actual profiles are shown in Figures 55, 56, 57 in section IV-B. These are shown schematically in Figure 29. Curve A in Figure 29 represents the NaK temperature profile as predicted by the mathematical model developed for nonwetting spheroidal boiling discussed earlier. Normally, a boiler initially behaves in the manner denoted by curve $A$ and eventually appears to improve in performance until it gives a profile appearance indicated by curve B in Figure 29. Curve B represents the limit of a high heat transfer rate, and curves between curves $A$ and $B$ would represent different degrees of boiler conditioning. Under certain circumstances, a given boiler has been observed to shift its performance to curve $C$ which represents an exceptionally poor heat transfer rate, usually with large amounts of moisture appearing at the boiler outlet. Curve $\mathrm{C}$ is normally referred to as a deconditioned boiler.

To circumvent the conditioning problems experienced with the boilers up to and including the Model 3, tube inserts were designed and first used in the Models $5 \mathrm{C}$ and 7 boilers. The insert tubes completely filled the central core of the boiler tube; i.e., the insert diameter equalled the mercury tube inside diameter minus twice the swirl wire diameter. The insert reduced the flow area of the boiler tube by approximately one-half, thereby doubling the velocity. Plugging the core of the tube forced the mercury to flow in a spiral or voxtex flow pattern. The insert length was selected on the basis of a critical Weber number that insured vortex flow to be self-sustaining downstream of the insert.

The design of the insert tubes was based on the following postulated causes of deconditioning:

1) Deconditioning is caused by an unfavorable flow regime initiated by liquid superheat instabilities that result from lack of nucleation sites. The superheated liquid would intermittently flash, setting up a slug-flow pattern which then resulted in poor heat transfer characteristics.

2) Deconditioning is due to a low boiler heat transfer rate that results from inadequate wetting which is caused by the presence of contaminants, such as air, water, or oil.

$$
\text { TRW-690-32 }
$$




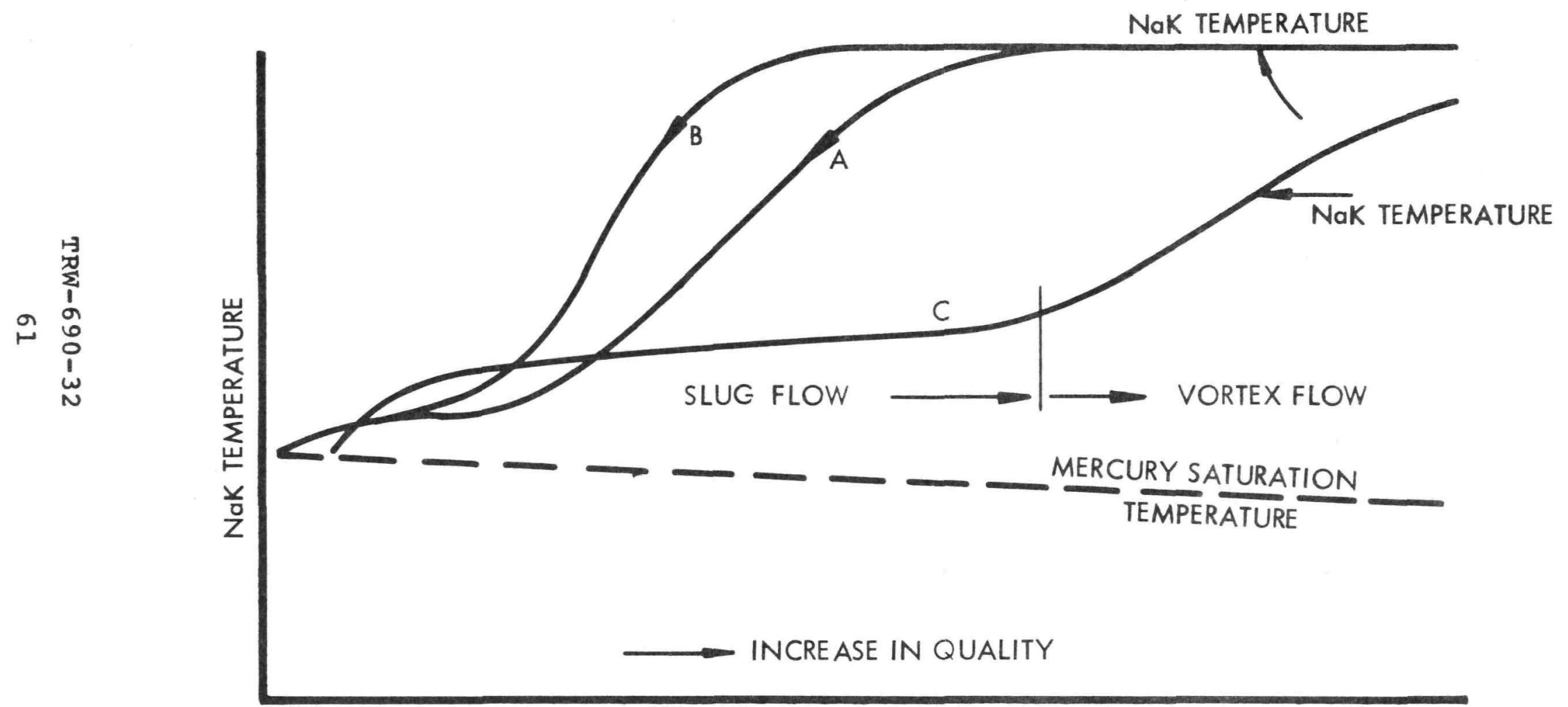

BOILER TUBE LENGTH OR QUALITY

FIGURE 29. NaK TEMPERATURE PROFILES FOR THREE DIFFERENT HEAT TRANSFER MODES 
The non-wetting characteristic of mercury does not contradict either postulate. If deconditioning were a surface chemistry phenomenon, the additional resistance to heat transfer would be offset by the increased mass velocity over the surface due to the insert. If deconditioning were a flow establishment problem, the following probable flow pattern would exist with no insert in a $1 \mathrm{~g}$ environment: Liquid mercury leaves the preheat section and boiling begins. Upon gereration of only 1\% vapor ( $x$ $=0.01$ ), approximately $90 \%$ of the tube volume is occupied by the vapor phase. The vapor velocity is too low to entrain the liquid and make it follow the swirl wire. The liquid therefore collects on the bottom of the tube, is dammed up by the swirl wire, and spills over the wire in a "caterpillar flow" pattern. Since heat transfer is between the tube wall and the mercury liquid (heat transfer to the vapor is negligible), and since low velocity flow is occurring over a small fraction of the tube surface, heat transfer is very poor. Addition of the tube insert, forces the mercury to follow the swirl wire in an annular passage that utilizes the entire available heat transfer surface.

The critical velocity required to break up caterpillar flow and establish turbulent flow is

$$
P_{v} \mu_{\text {crit }}^{2}=142 \frac{\mathrm{lb} \text { (force) }}{\mathrm{ft} \mathrm{sec}^{2}}
$$

Thus vortex flow is established when the vapor quality exceeds $13.3 \%$ and the insert tube therefore sized on the basis of 15\% minimum quality at the exit of the insert.

Although the forced-flow pattern and increased velocity created by the use of tube inserts reduced the severity of the deconditioning problem, Model $5 \mathrm{C}$ and 7 boiler performance continued to be erratic at times. (Details of the test experience are found in section IV.)

A conditioning-deconditioning research program was conducted to determine the cause of deconditioning and techniques to avoid deconditioning problems. The program included a single-tube boiler test program at TRW to evaluate the liquid superheat-slug flow hypothesis and a pool boiling program at Atomics International to evaluate the effects of surface contaminants on wetting.

\section{Single Tube Boiler Tests}

The single tube tests were conducted with a Model 7 boiler tube, as shown schematically in Figure 30. Pressure, temperature, and flow measuring instrumentation was provided. $X-$ ray image amplification apparatus was provided to observe the flow pattern in the tube along with movie film to preserve the

$$
\text { TRW-690-32 }
$$




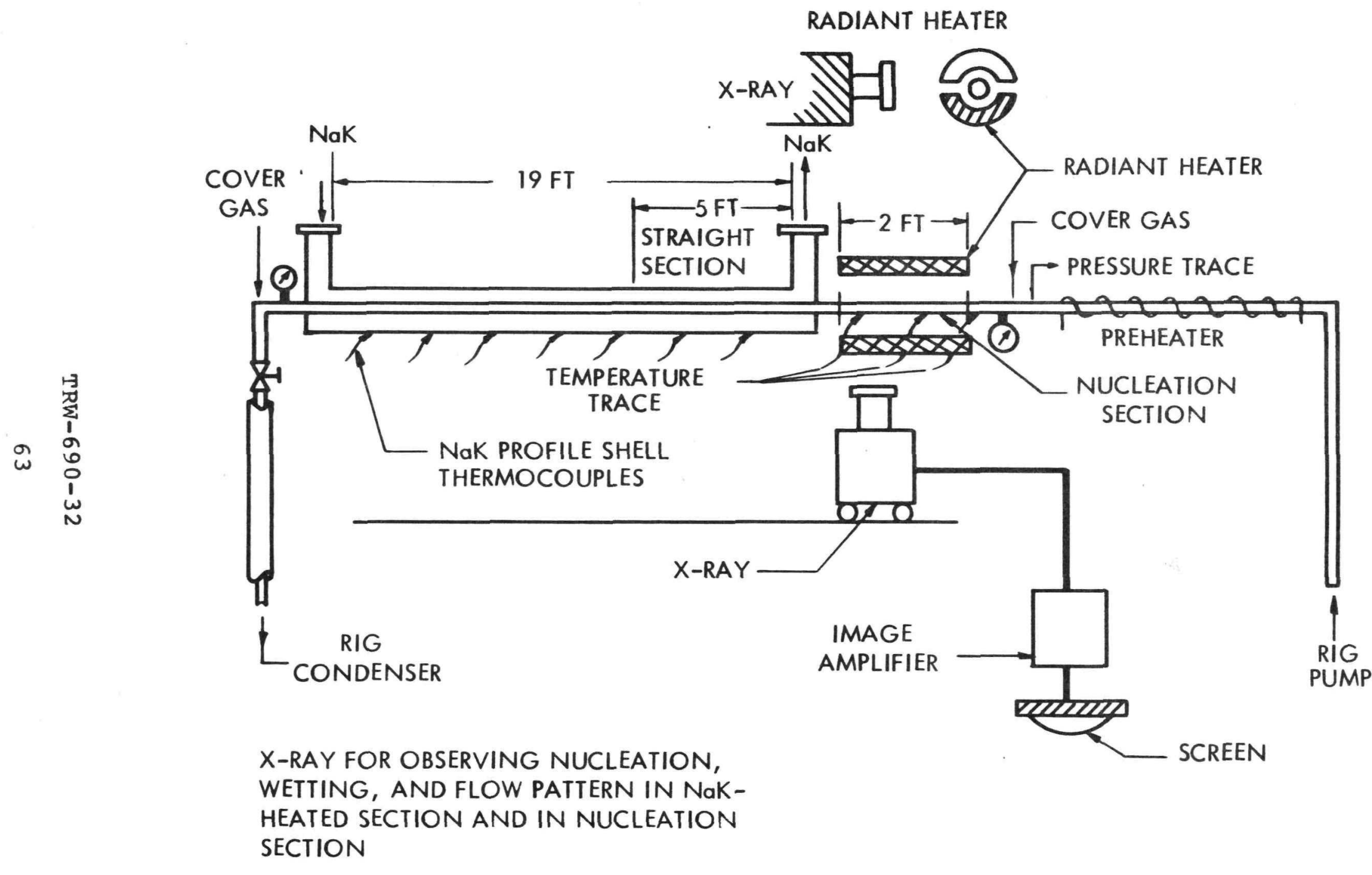

FIGURE 30. SCHEMATIC DIAGRAM OF THE BOILER DECONDITIONING TEST RIG 
data. Boiling sounds were recorded on tape and analyzed in (8) and (15). The Phase I testing began with a conditioned profile but degraded in a short time to deconditioned performance. The most important observation made during the Phase I tests was that the low heat transfer rates associated with deconditioning could be attributed to a liquid slug-type flow pattern. It was observed that liquid would agglomerate and form liquid slugs, leaving relatively large areas of the heating surface in contact with dry vapor. To support this observation made with the $\mathrm{X}$-rayimage amplifier, a detailed mathematical analysis of the boiling heat transfer mechanics as defined by the liquid slug-flow pattern was made (8).

Figure 31 shows a typical NaK profile measured during the Phase I deconditioning tests and depicts a deconditioned heat transfer state for approximately the first 12 feet of boiling length measured from the boiler inlet. Beyond the 12-foot point, the NaK temperature gradient becomes very steep with a "wetting type" gradient of approximately $50^{\circ} \mathrm{F} / \mathrm{ft}$.

An important feature of the NaK temperature profile of Figure 31 is the existence of a transition point between a deconditioned boiling region and a high heat flux (conditioned) region. The transition is attributed to the "break-up" of the liquid slugs or "caterpillars" by the vapor velocity generated during slug flow boiling. The transition between slug or "caterpillar" flow and spray flow was first studied in the adiabatic mercury-nitrogen flow tests, and the flow regime map, shown in Figure 32, was constructed from these observations. A critical value of $\rho_{V} \mu_{V}^{2}=142$ was estimated to define the point of transition.

The NaK temperature profile for slug flow, as computed by the mathematical model, is compared with a measured profile in Figure 33. A NaK heat loss gradient of $1.3 \mathrm{oF} / \mathrm{ft}$ (measured during heat loss calibration) is also taken into account. The computed transitional length (LC) to the termination of slug flow regime using $P_{v} \mu_{v}=142$ (mercury-nitrogen data) is, $L_{c}=13$ feet which compares favorably with a measured length of approximately 15 feet.

It was determined from the results of the phase I testing and analysis that the boiling heat transfer rate in the slug flow (complete bridging of the tube diameter) regime could be increased by means of a plug insert with properly designed passages. This formed the basis for the Phase II testing. A ten-channel insert section was designed which provided a significantly increased heat transfer area such that, even if slug flow were present, sufficient heat would be transferred to ensure a $P_{V} \mu^{2}$ greater than 142 at the exit of the insert. Safeguards against adverse corrosion and erosion effects were included in the plug design in accordance with the criteria established in (19).

$$
\text { TRW-690-32 }
$$




\begin{tabular}{|c|c|c|c|c|c|c|c|c|}
\hline & & & NO & $6-4-8$ & ATE 4-1 & $13-65$ & & 10 \\
\hline & & & $\overline{A P O}$ & DINT OBSERVER & F. W- & $E N$ & 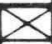 & \\
\hline & & & $\triangle P O$ & INT NUMBER & & 9 & 1 & \\
\hline & & & $A P O$ & INT TIME & & 5:00 & 2 & \\
\hline & & & PSED & HOURS FROM START & & $5: 00$ & 3 & \\
\hline & & & $\frac{A L E}{N_{0}}$ & $\begin{array}{l}\text { LAPSED HOURS AT DESIGN } \\
\text { K HEATER ELECTRICAL }\end{array}$ & & & 4 & \\
\hline & & & & $\begin{array}{l}\text { W. HEAER ELECTRICAL } \\
\text { WER INPUT }\end{array}$ & $\mathrm{kw}$ & 26 & 5 & \\
\hline & & & T34 & $\begin{array}{l}\text { NaK HEATER OUTLET } \\
\text { LINE } \mathrm{U} / \mathrm{C} 3-10 \text {. SKIN }\end{array}$ & ${ }^{\circ} \mathrm{F}$ & - & 6 & \\
\hline & & & T41 & $\begin{array}{l}\text { Nak FLOWMETER } \\
T^{\prime \prime C} 4-5 \text {. SKIN }\end{array}$ & ${ }^{\circ} \mathrm{F}$ & - & 7 & \\
\hline & & & 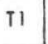 & MERCURY INLET . T/C 5-1 & ${ }^{\circ} \mathrm{F}$ & 712 & 8 & \\
\hline & & & $\mathrm{T2}$ & $\begin{array}{l}\text { HG INLET TUBE SHEE T SHELL } \\
\text { T/C } 5-2 \text {. }\end{array}$ & ${ }^{\circ} \mathrm{F}$ & 884 & 9 & \\
\hline & & 爱 & т3 & NoK OUTLET LINE T/C 5.3 & $\bullet^{\circ} \mathrm{F}$ & 985 & 10 & \\
\hline & & & เฉ2 & NOK INLET LINE T/C 5-2 ${ }^{\text {ND }} 11$ & • $\mathrm{F}$ & 1199 & 11 & \\
\hline & & 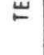 & T2! & $\begin{array}{l}\text { HG OUTLET TUBE SHEET } \\
\text { T/C } 5-2 \text { NDD10 }\end{array}$ & ${ }^{\circ} \mathrm{F}$ & 1186 & 12 & \\
\hline & & & & & ${ }^{\circ} \mathrm{F}$ & & & 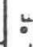 \\
\hline$\sum_{1}^{\pi}$ & & & 123 & $\begin{array}{l}\text { HG OUTLET LINE IMM. } \\
\text { T/C S-2ND } 12\end{array}$ & - $\mathrm{F}$ & 1018 & 14 & $\underline{a}$ \\
\hline जิ & : & & T12 & $\begin{array}{l}\text { CONDENSER HG VAPOR } \\
\text { LINE T/C I-12. IMM. } \\
\end{array}$ & ${ }^{\circ} \mathrm{F}$ & 470 & 15 & s \\
\hline$\underset{N}{\omega}$ & & 3 & F1 & $\begin{array}{l}\text { BOILER MERCURY } \\
\text { WEIGHT FLOW - RATE }\end{array}$ & & & 16 & \\
\hline & & $\frac{0}{4}$ & $\mathrm{~F}_{2}$ & $\begin{array}{l}\text { BOILER NOK WEIGHT } \\
\text { FLOW - RATE }\end{array}$ & & & 17 & $a^{2}$ \\
\hline & & & P8 & BOILER MERCURY INLET & & & 18 & \\
\hline & & & $P Q$ & $\begin{array}{l}\text { BOILER MERCURY } \\
\text { VAPOR DISCHARGE }\end{array}$ & & & 19 & \\
\hline & & & P11 & BOILER NOK OUTLET & $y$ & & 20 & \\
\hline & & 㲵 & P12 & BOILER NaK INLET & besia & & 21 & \\
\hline & & & (B) & BOILER STATIC NOK $\triangle P$ & PSI & - & 22 & \\
\hline & & & (c) & BOILER NOK $\triangle P$ PRESSURE & PS1/ & 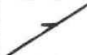 & 23 & \\
\hline & & & & $\begin{array}{l}\text { BOILER NoK FLOW } \Delta P= \\
(B)-(C)\end{array}$ & PSI & - & 24 & \\
\hline & & & & NOZZLE HG FLOW CHART & PPM & 27 & 25 & \\
\hline
\end{tabular}

SINGSE TUEC BOILER PREF RECORD

T/C NUMBER AND TEMPERATURE LOGGER READOUT SEQUENCE:
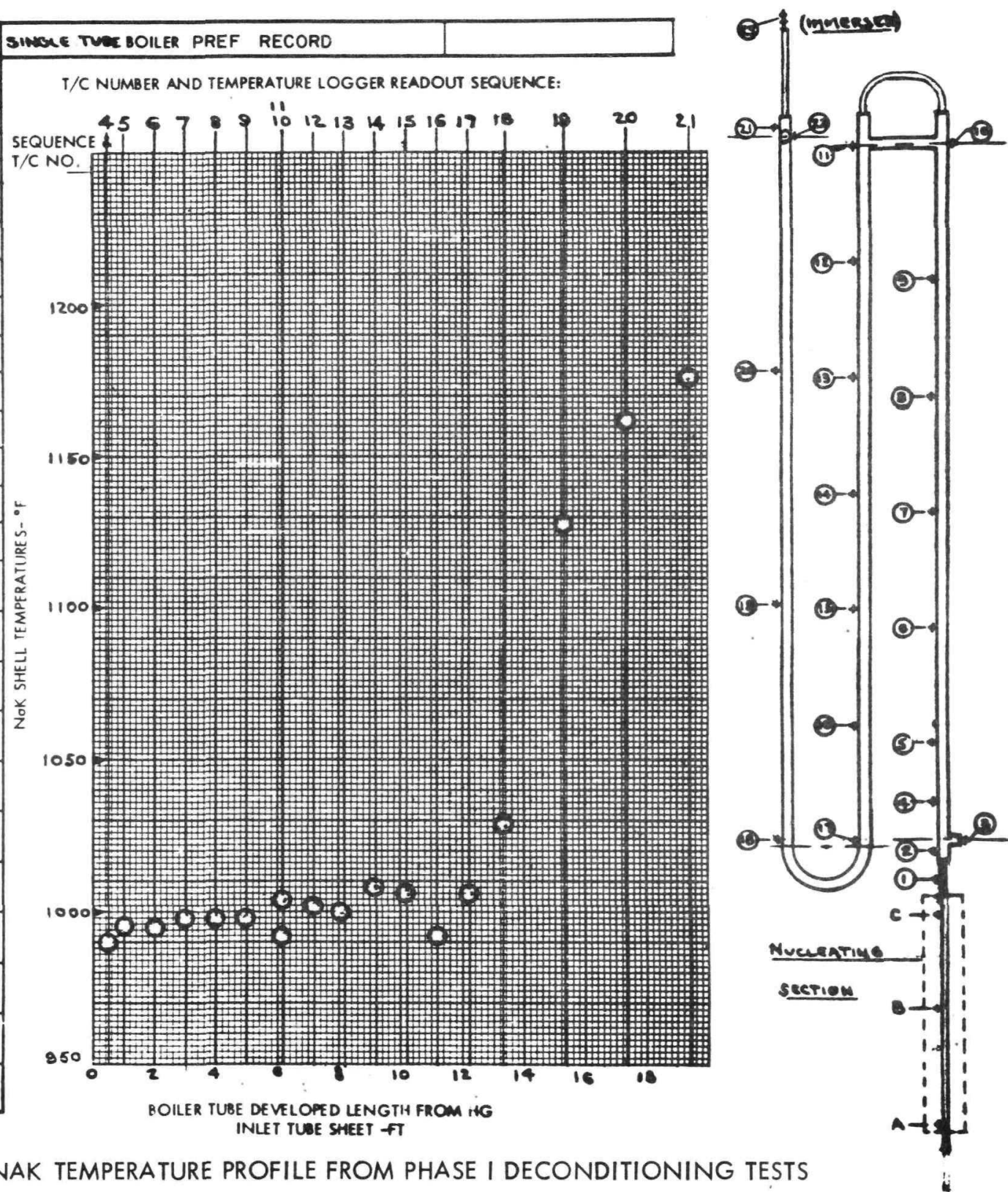

FIGURE 31 TYPICAL MEASURED NAK TEMPERATURE PROFILE FROM PHASE I DECONDITIONING TESTS 

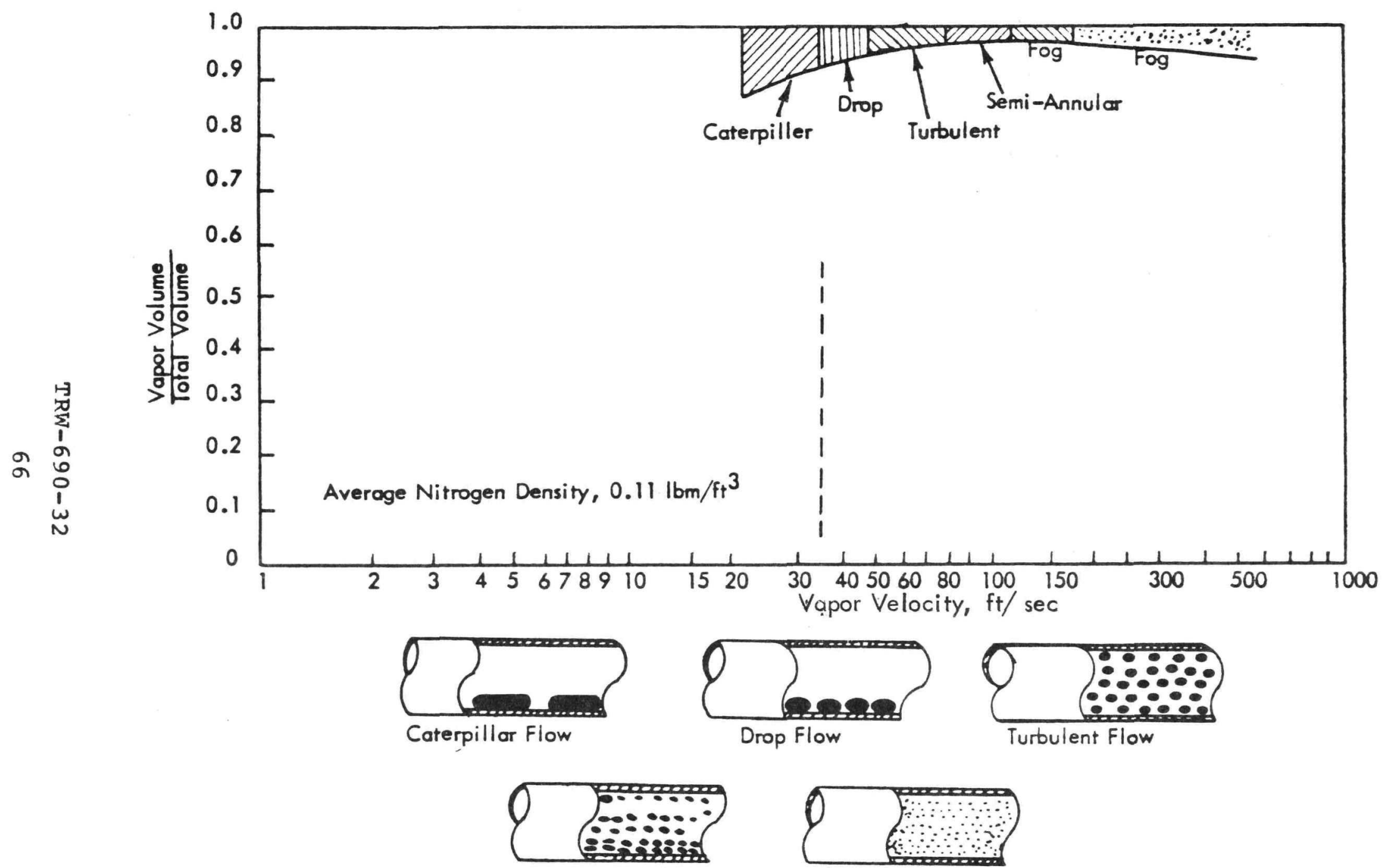

Semi-Annular Flow

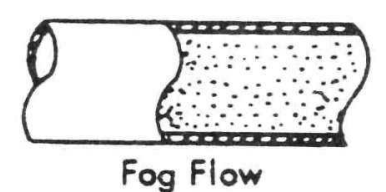

FIGURE 32. FLOW REGIMES FOR NON-WETTING MERCURY FLOWING WITH NITROGEN IN GLASS TUBES 


\begin{tabular}{|c|c|c|c|c|c|}
\hline \multirow{2}{*}{\multicolumn{3}{|c|}{$\frac{\text { IEST NO } 6.4-5}{\text { DATA POINT OBSERVER }}$}} & \multicolumn{3}{|c|}{ DATE 4-6-65 } \\
\hline & & INT OSERVER & GK & & 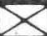 \\
\hline \multicolumn{3}{|c|}{ DATA POINT NUMBER } & \multicolumn{2}{|c|}{7} & 1 \\
\hline \multicolumn{3}{|c|}{ DATA POINT TIME } & \multicolumn{2}{|c|}{1300} & 2 \\
\hline \multicolumn{5}{|c|}{ ELAPSED HOURS FROM START } & 3 \\
\hline \multicolumn{5}{|c|}{ TOTAL ELAPSED HOURS AT DESIGN } & 4 \\
\hline \multicolumn{3}{|c|}{$\begin{array}{l}\text { NOK HEATER ELECTRKCAL } \\
\text { POWER INPUT }\end{array}$} & KW & 26 & 5 \\
\hline \multirow{9}{*}{ 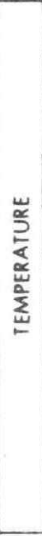 } & $\mathrm{T} 34$ & $\begin{array}{l}\text { NaK HEATER OUTLET } \\
\text { LINE I/C } 3-10 . \text { SKIN }\end{array}$ & ${ }^{\circ} \mathrm{F}$ & - & 6 \\
\hline & T41 & $\begin{array}{l}\text { NoK FLOWMETER } \\
\text { T'C 4-5. SKIN }\end{array}$ & • $F$ & - & 7 \\
\hline & $\Pi$ & MERCURY INLET , T/C 5-1 & $\bullet^{\bullet} F$ & 692 & 8 \\
\hline & 12 & $\begin{array}{l}\text { HG INLET TUBE SHEET SHELL } \\
\text { T/C } 5-2\end{array}$ & • $\mathrm{F}$ & 858 & 9 \\
\hline & 13 & NaK OUTLET LINE T/C 5-3 & $\bullet F$ & 970 & 10 \\
\hline & iथ2 & NaK INLET LINE T/C 5-2 ND 11 & • $\mathrm{F}$ & 1185 & 11 \\
\hline & 121 & $\begin{array}{l}\text { HG OUTLET TUBE SHEET } \\
T / C 5-2 \text { ND } 10\end{array}$ & ${ }^{\bullet} \mathrm{F}$ & 1128 & 12 \\
\hline & 129 & $\begin{array}{l}\text { HG OUTLET LINE IMM. } \\
\text { T/C 5-2 ND } 12\end{array}$ & $\bullet^{F}$ & 930 & 14 \\
\hline & $T 12$ & $\begin{array}{l}\text { CONDENSER HG VAPOR } \\
\text { LINE } T / C \quad 1-12.1 \mathrm{MM} \text {. }\end{array}$ & ${ }^{\circ} \mathrm{F}$ & 460 & 15 \\
\hline \multirow{2}{*}{$\frac{3}{4}$} & FI & $\begin{array}{l}\text { BOILER MERCURY } \\
\text { WEIGHT FLOW - RATE }\end{array}$ & & & 16 \\
\hline & $F_{2}$ & $\begin{array}{l}\text { BOILER NaK WEIGHT } \\
\text { FLOW - RATE }\end{array}$ & & & 17 \\
\hline \multirow{8}{*}{ 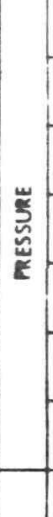 } & P8 & BOILER MERCURY INLET & & & 18 \\
\hline & $P Q$ & $\begin{array}{l}\text { BOILER MERCURY } \\
\text { VAPOR DISCHARGE }\end{array}$ & & & 19 \\
\hline & PII & BOILER NoK OUTLET & & & 20 \\
\hline & P12 & BOILER NaK INLET & & & 21 \\
\hline & (B) & BOILER STATIC NOK $\triangle P$ & PSI & & 22 \\
\hline & (C) & BOILER NOK $\triangle P$ REESSURE & & & 23 \\
\hline & & $\begin{array}{l}\text { BOILER NoK FLOW } \Delta P= \\
\text { (B) }- \text { (C) }\end{array}$ & PSI & & 24 \\
\hline & & NOZZLE HG FLOW CHART & PPM & 30 & 25 \\
\hline
\end{tabular}

Sintole TUE BOLER PER RECORD

T/C NUMBER AND TEMPERATURE LOGGER READOUT SEQUENCE:

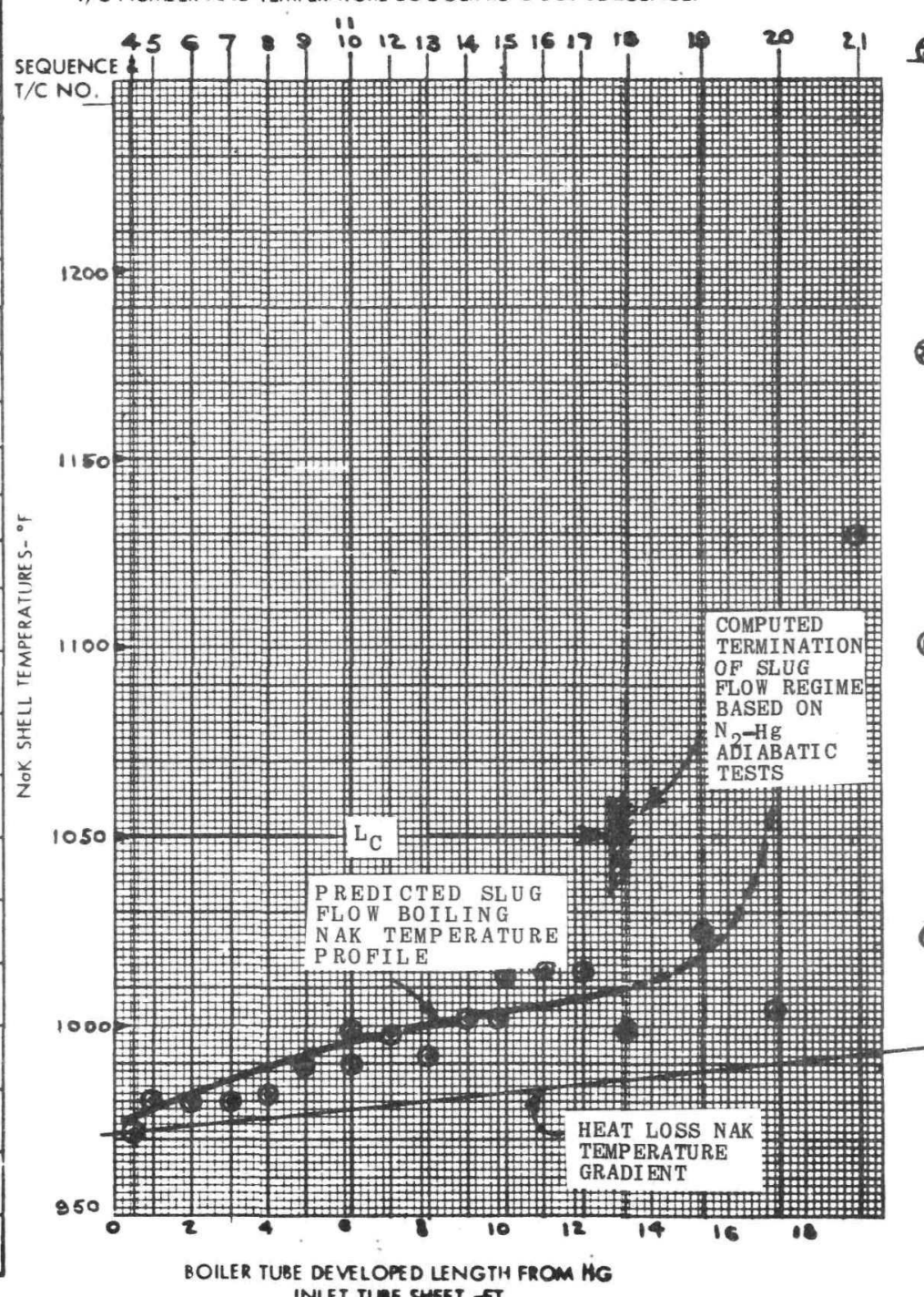

BE DEVELOPED LENGTH
INLET TUBE SHEET $\rightarrow T$

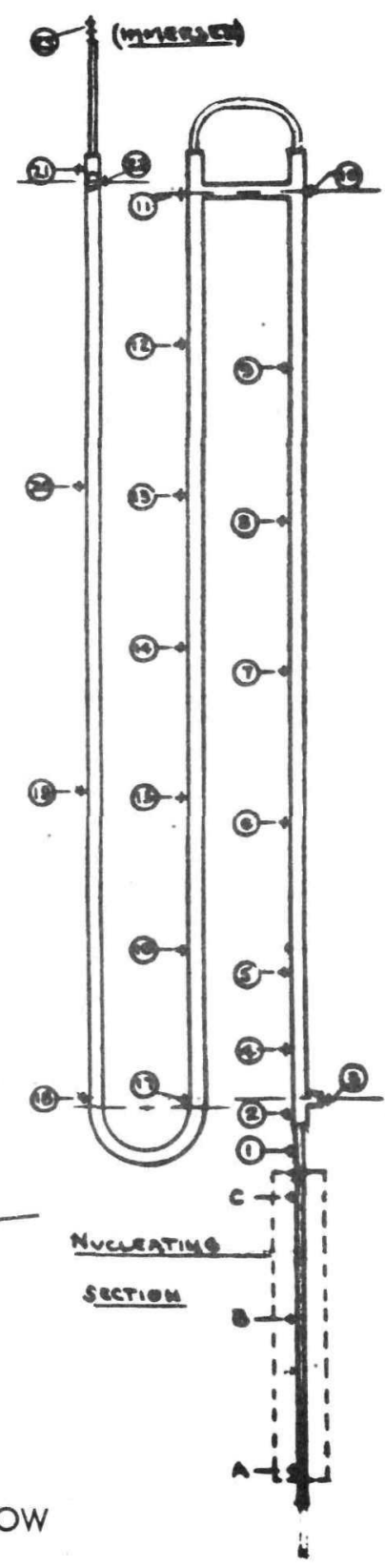

FIGURE 33 COMPARISON OF NAK TEMPERATURES WITH COMPUTED CURVE FOR SLUG FLOW ADJUSTED FOR HEAT LOSS 
The plug and boiler tubing were made from Haynes alloy 25: In Figure 34 are macrographs of sections of the multi-channel plug insert as brazed into the boiler tube, magnified by a factor of 10. The slots of the plug forming part of the heat conducting passages are shown in Figure 35. The plug section was 30 inches long with provision on the NaK side to heat all or $1 / 2$ of the length and on the mercury side to flow through all or $1 / 2$ of the passages or to bypass the section completely. Rig modifications for the Phase II testing are shown in Figure 36. Pressure, temperature, flow, $\mathrm{X}-\mathrm{ray}$, and sound measurements were made in the same manner as in the phase I testing. Movie film acquisition was improved in having the camera mounted to the $\mathrm{X}$-ray head rather than at the TV monitor screen.

The multi-channel slug was tested during both wetting and nonwetting conditions. However, the mode of operation experienced in Figure 33 having the 13 to 15 feet of slug flow, for which the plug was specifically designed was not encountered. The differences experienced in the two phases are as follows. In the Phase I tests, deconditioning was attributed to liquid slugs separated by large vapor spaces. In the phase II tests, deconditioning was the result of large liquid spheroids or "caterpillars" riding on a vapor film. It can be expected that the multichannel plug should improve the thermal performance in the caterpillar flow regime because the liquid phase agglomeration is reduced by the configuration of the flow passages. This in fact was observed to be the case.

Figure 37 shows the effect of an 18 inch plug on performance when operating in the wetting mode. The only effect was an upstream shift of the high boiling flux region into the plug.

Figure 38 shows NaK temperature profiles measured during non-wetting vapor film spheroidal boiling for performance with and without a 36 inch plug. It is in this regime that the plug is most effective. After correcting for heat loss to the ambient, more heat is found to be transferred in the 3 foot plugged section than is transferred in the entire 19 feet of the unplugged boiler.

Figure 39 shows temperature profiles during non-wetting contact spheroidal boiling for performance with and without an 18 inch plug. Intermediate plug effectiveness is noted. This trend is desirable in minimizing the effects of deconditioning which is the design objective of plug type inserts.

of particular interest is the plug performance shown in Figures 38 and 39. Both are characterized by a very steep inlet slope which tapers off considerably at the downstream end of the plug. This was found to be the general case for operation with either the 18 or 36 inch plug length. An analysis, supported by the data in (14), treated each passage in the plug as a small diameter bare tube. It was found that critical conditions for

$$
\text { TRW-690-32 }
$$




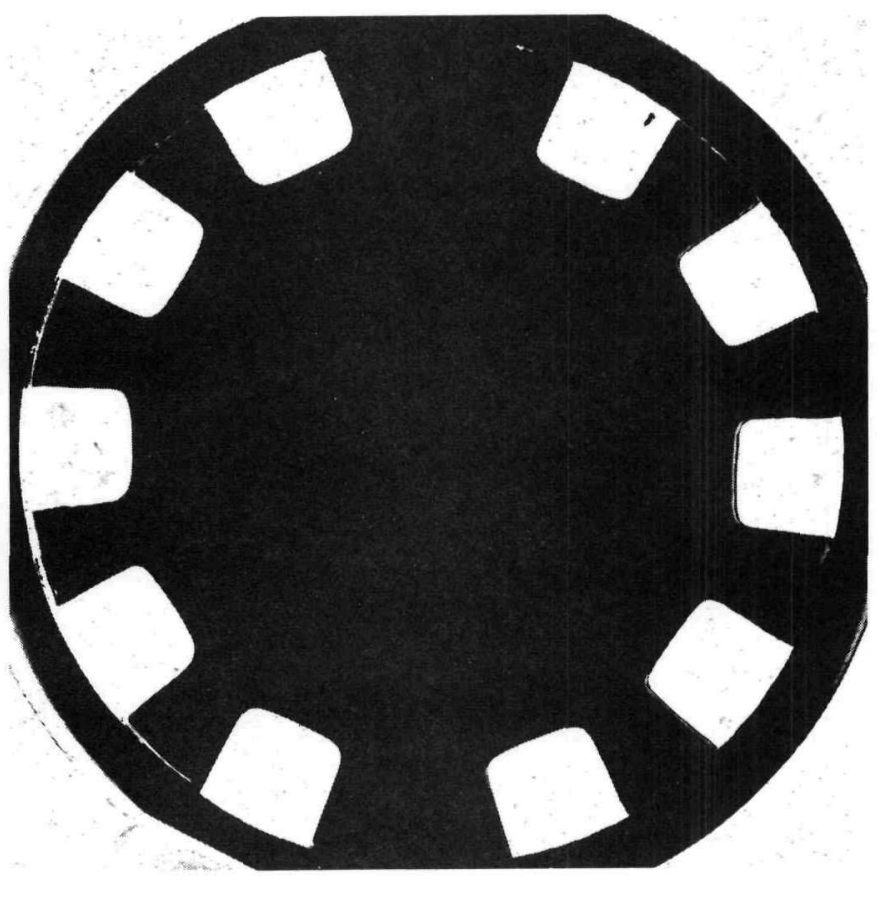

Section 1

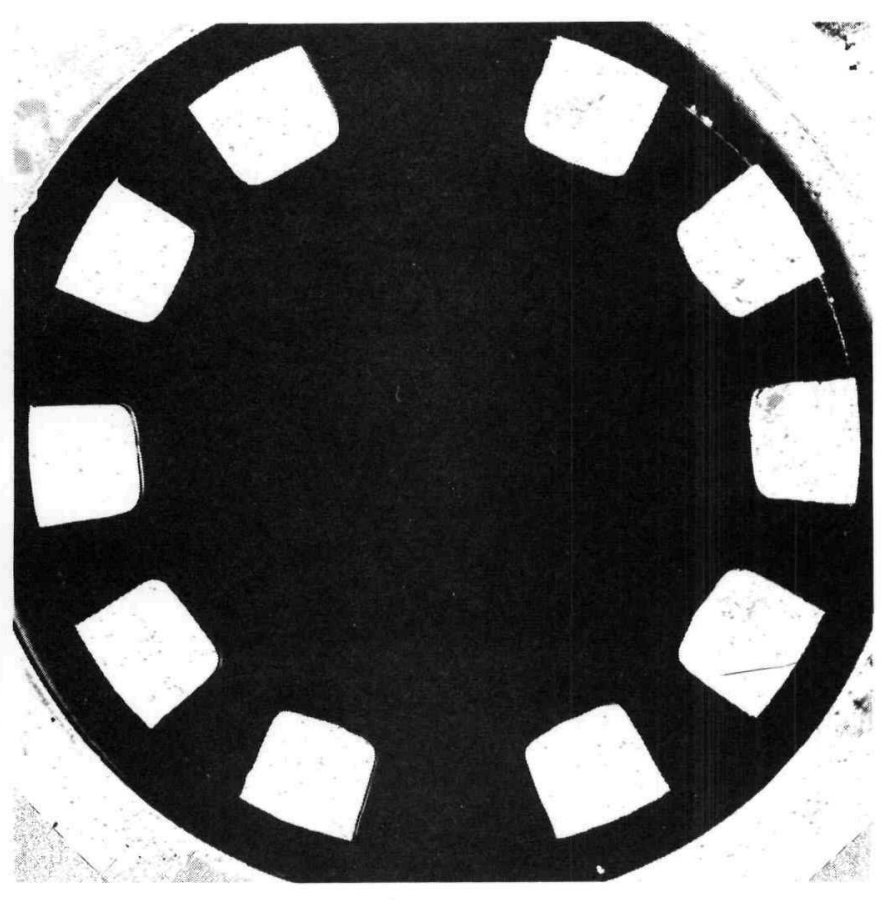

Section 3

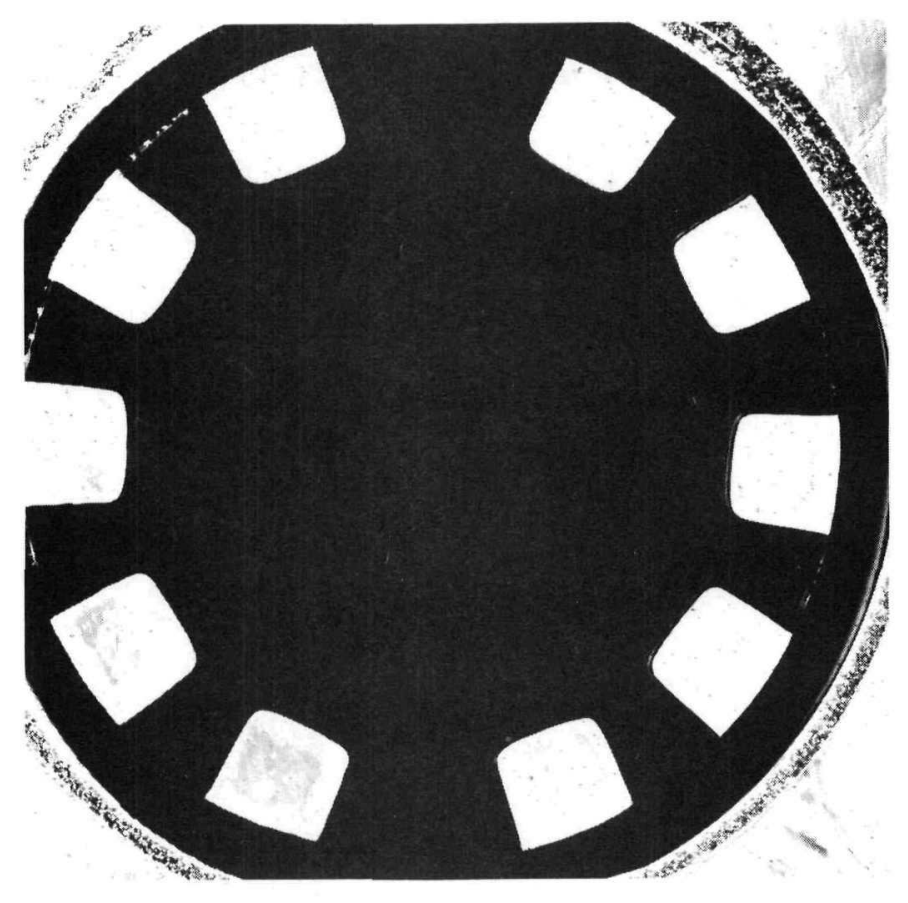

Section 2

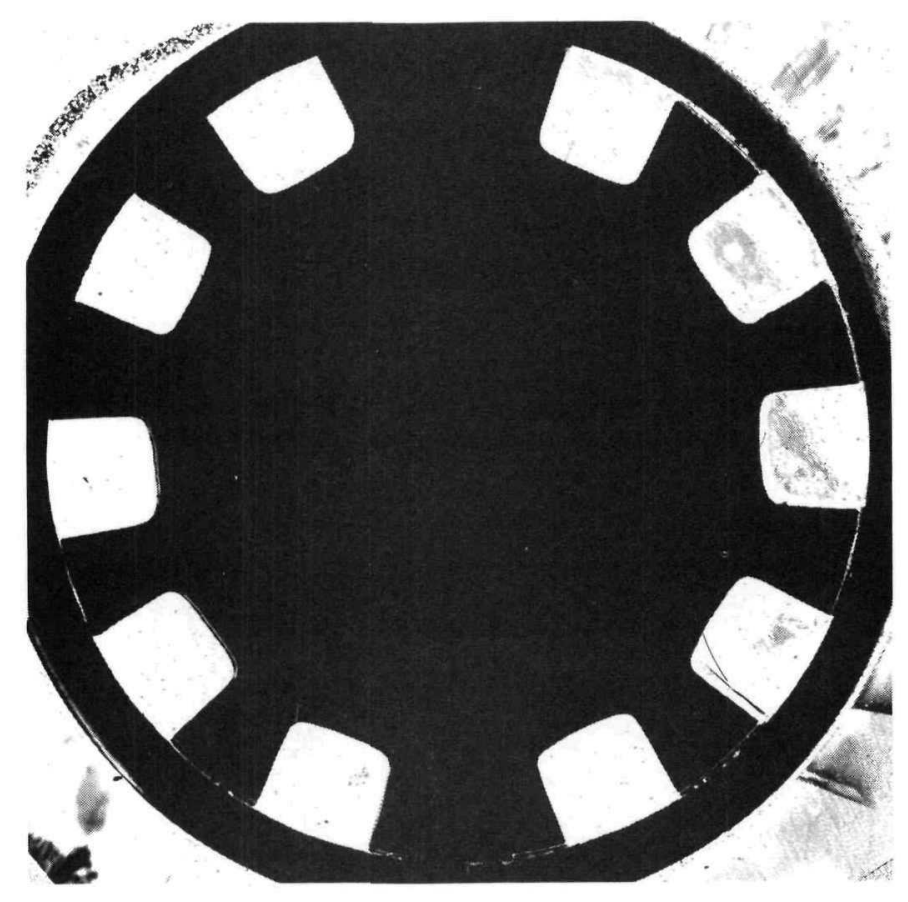

Section 4

FIGURE 34 MACROGRAPHS OF MULTI-CHANNEL PLUG TRW-690-32

69 


\section{0}

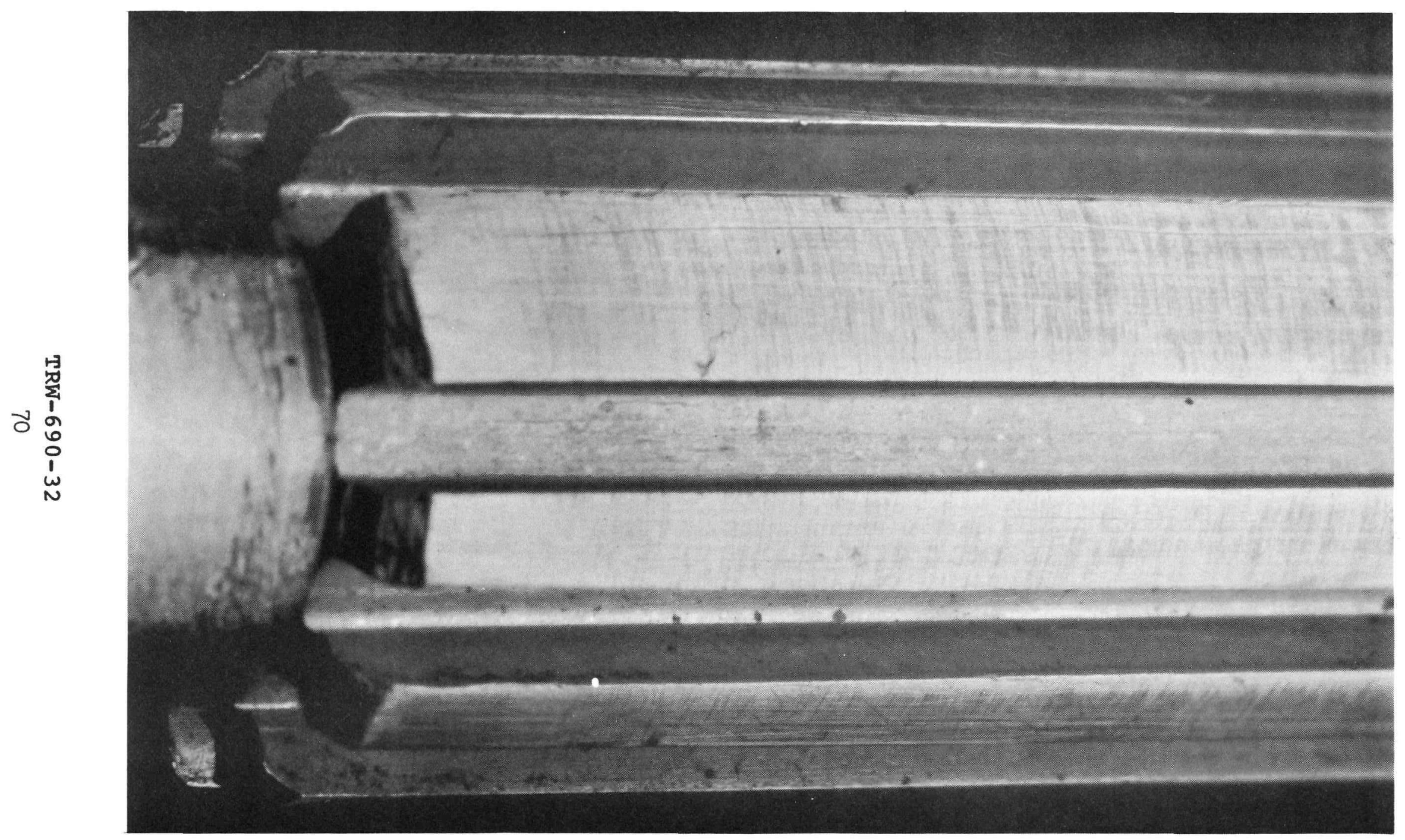

FIGURE 35 FLOW PASSAGES OF MULTI-CHANNEL PLUG 


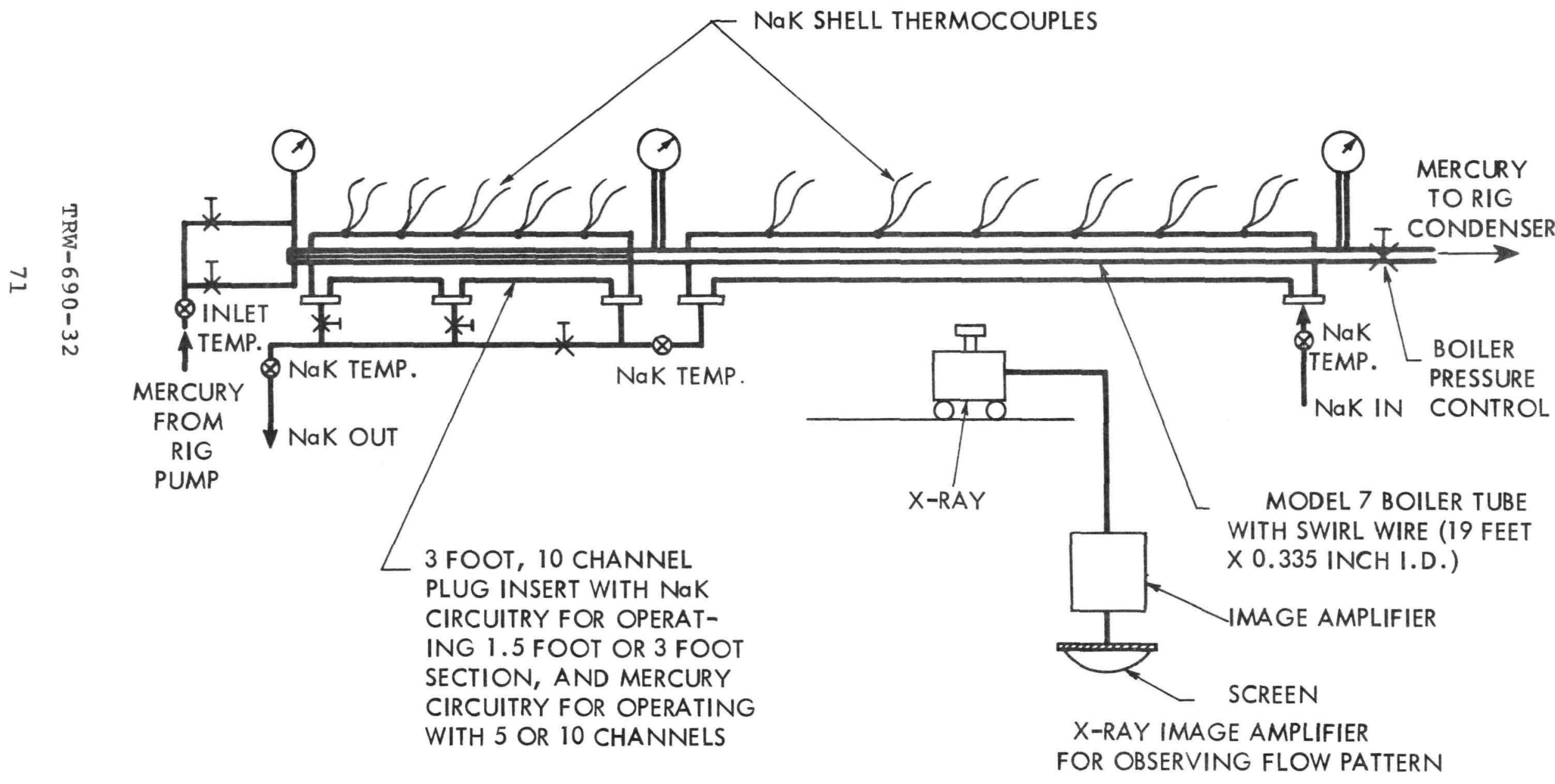

FIGURE 36. SCHEMATIC DIAGRAM OF BOILER TEST RIG FOR PHASE II CONDITIONING TESTS 


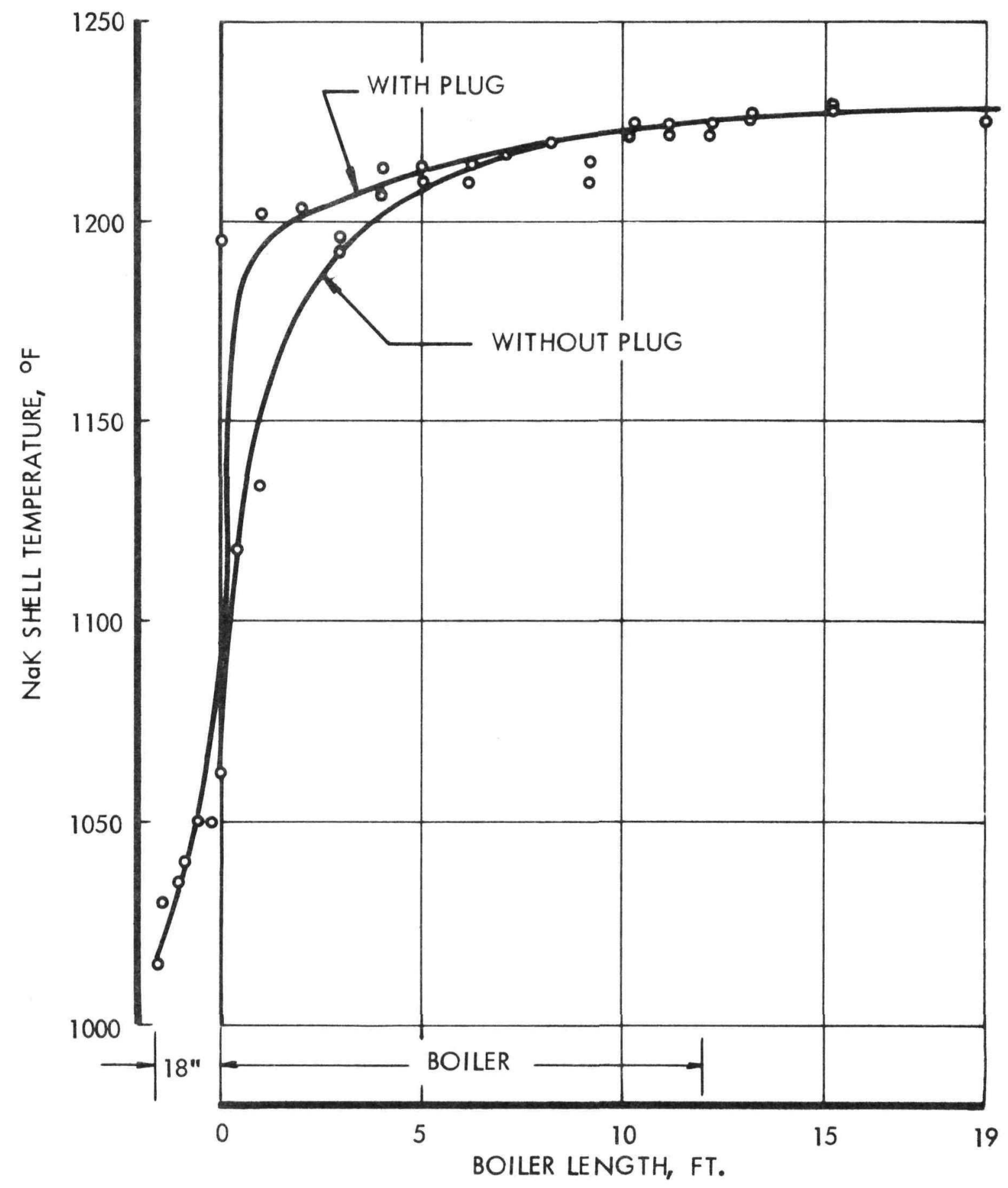

FIGURE 37 NaK SHELL TEMPERATURE PROFILE DURING WETTING

TRW-690-32 


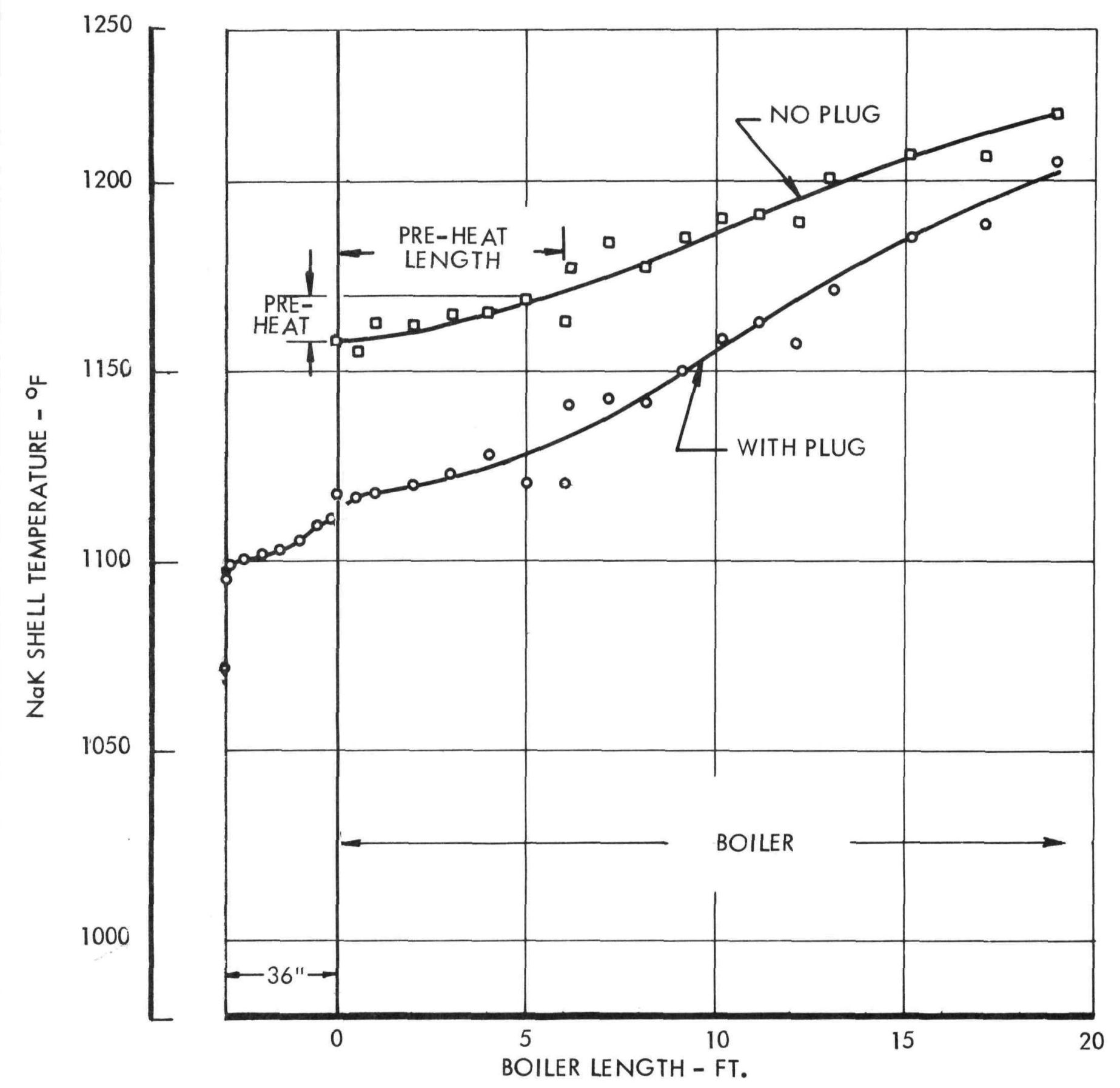

FIGURE 38 NaK SHELL TEMPERATURE PROFILE DURING NON-WETTING VAPOR FILM SPHEROIDAL BOILING

TRW-690-32 


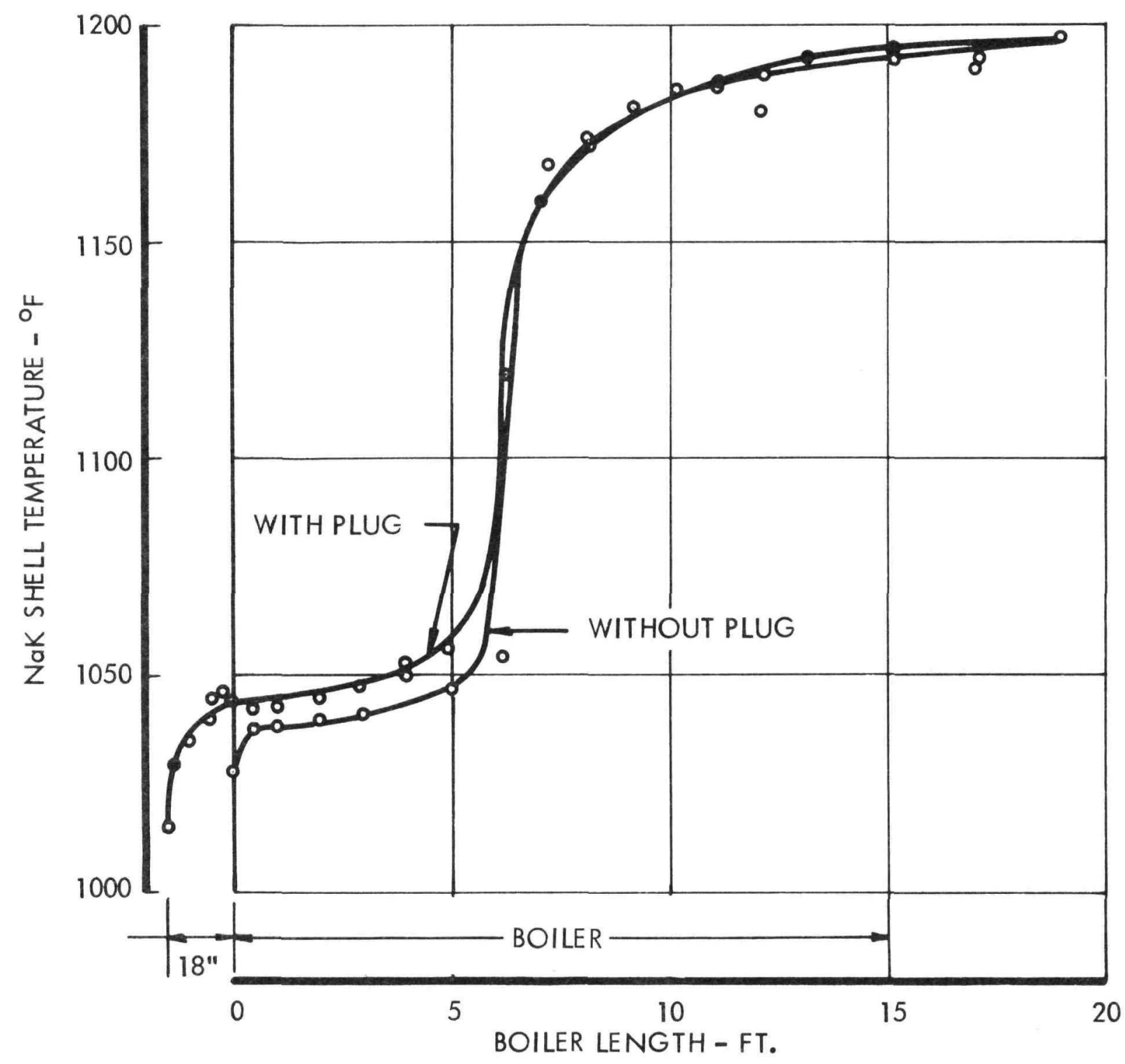

FIGURE 39 NaK SHELL TEMPERATURE PROFILE DURING NON-WETTING CONTACT SPHEROIDAL BOILING

TRW-690-32 
the breakup of liquid slugs occurs at approximately 10\% quality. At this point the liquid phase is entrained by the vapor with very little of the non-wetting liquid particles contacting the heated wall which results in a low heat transfer coefficient in the downstream portions of the plug. This suggests that a prototype plug insert for non-wetting boiling may consist of a short multi-channel plug which boot straps the quality from zero to approximately $10 \%$ after which a plug with swirl passages takes over. The quality is then increased to that required for unagglomerated vortex flow in the unplugged section of the boiler tube. The program did not permit continued development in this area.

An unexpected boiler response was encountered during the non-wetting deconditioned investigations. It was found that the boiler input variables (NaK and mercury flow, NaK temperature, and boiler pressure) could be so manipulated as to obtain what appeared to be a conditioned boiler. The situation, referred to as instantaneous boiler conditioning and deconditioning, is illustrated by the boiler pressure effect in the sequence of data sheets presented in Figures 40 through 43. A typical non-wetting vapor film boiling profile is shown in Figure 40 . By increasing boiler pressure to approximately 175 psia and then adjusting downward to 90 psia, the conditioned profile. of Figure 41 was obtained. In both figures, boiling was initiated at the entrance of the multichannel plug using 10 channels and the full 36 inch length. Without further adjustments, the plug was bypassed resulting in the deconditioned profile of Figure 42. Reactivating the plug (Figure 43) did not restore the conditioning profile. Figure 44 shows the results of mapping experiments in which NaK inlet temperature was the independent variable. The two states of high and low heat transfer were repeatably achieved and identified as contact spheroidal boiling and film spheroidal boiling, respectively. The process was found to be irreversible and proceeding in a clockwise manner. After a transition from contact to film boiling, a return to contact boiling could be made only after the $\Delta \mathrm{T}$ was reduced to a value near $100 \circ \mathrm{F}$. Reference (9) deals with this phenomenon in detail and discusses the role that increased wetting plays in delaying the transition from contact to film boiling. It also shows that the difference in mean heat transfer coefficient between the two non-wetting boiling modes for mercury is sufficient to account for deconditioning as experienced in the SNAP 2 boilers.

\section{Pool Boiling Tests}

The effect of some surface and system contaminants on mercury pool boiling heat transfer was investigated at AI and reported in (15). The results, summarized in Figure 45, showed that the degree of wetting is an important parameter in mercury pool boiling heat transfer. Nucleate boiling and high departure from nucleate boiling (DNB) heat flux are obtained with a well wetted surface. At the other extreme, only film boiling is

$$
\text { TRW-690-32 }
$$



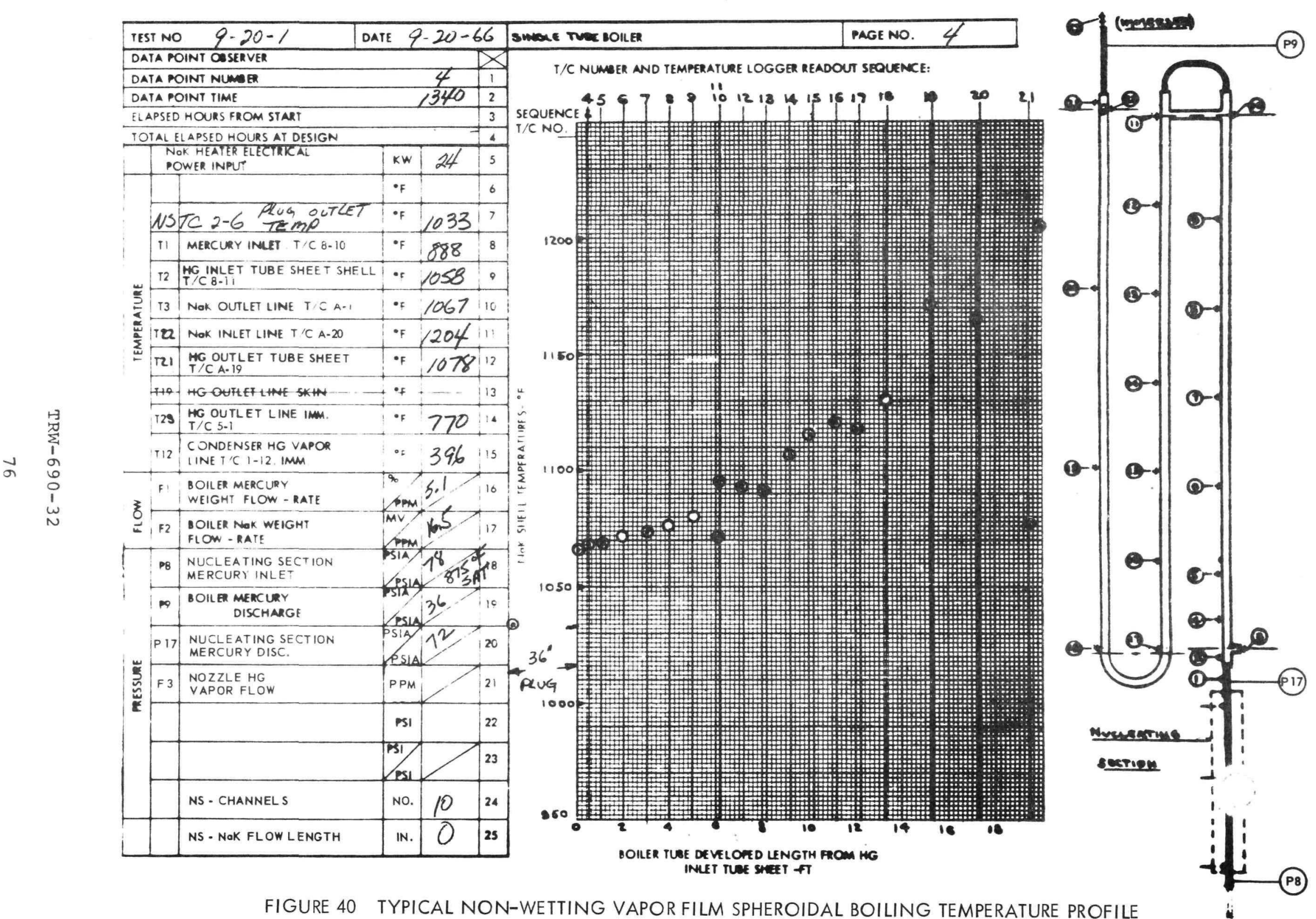

FIGURE 40 TYPICAL NON-WETTING VAPOR FILM SPHEROIDAL BOILING TEMPERATURE PROFILE 


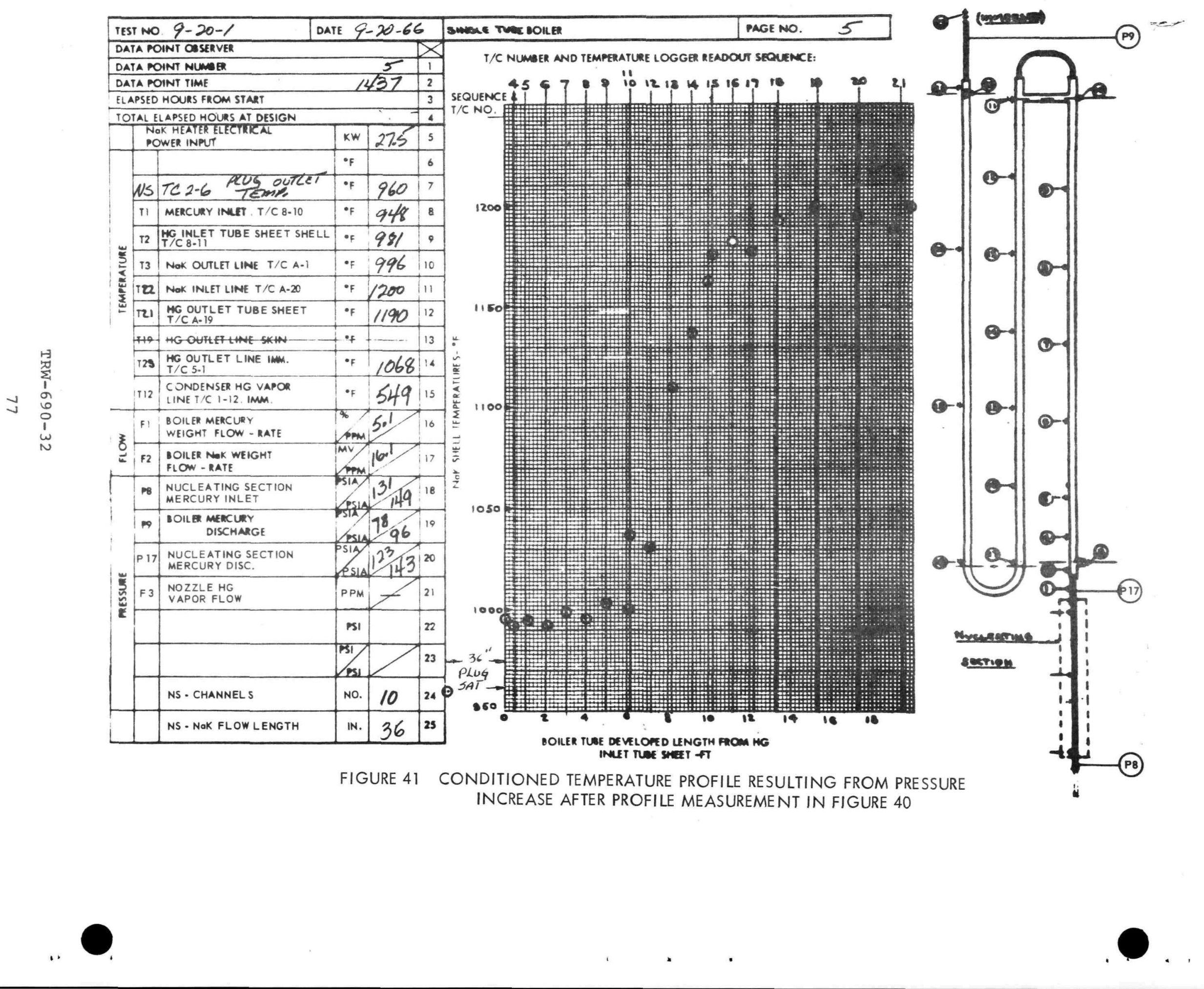




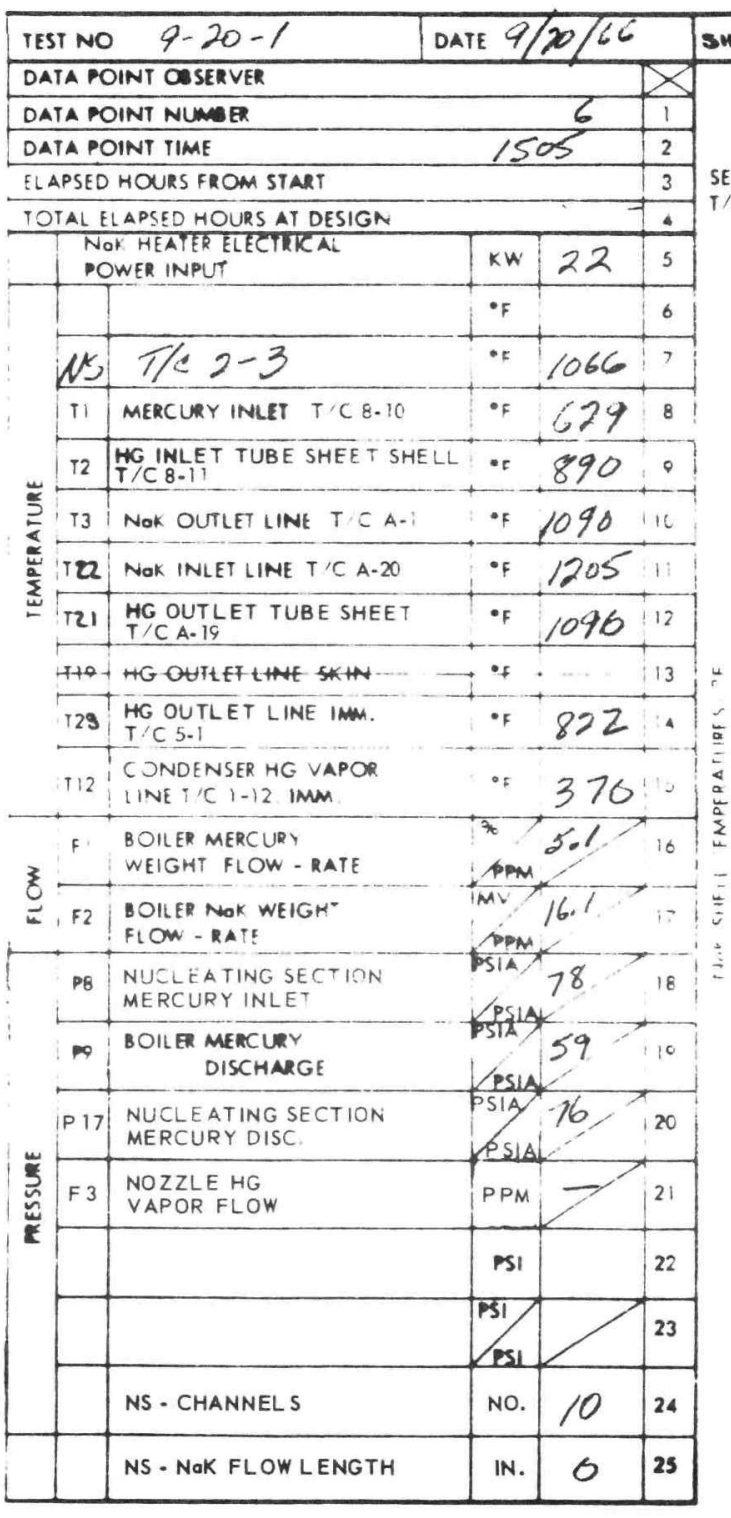

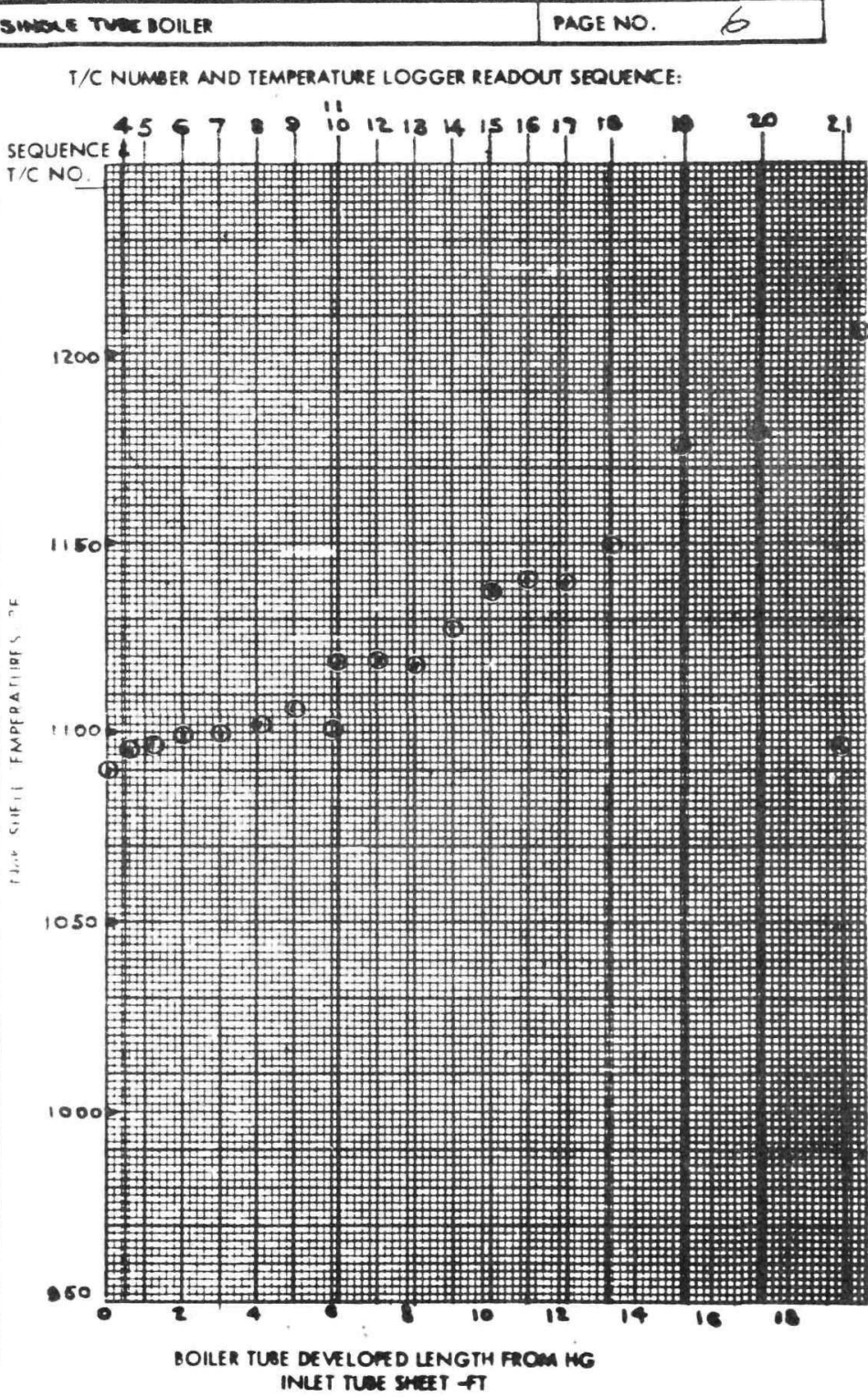
INLET TUE SHET $\rightarrow$ T

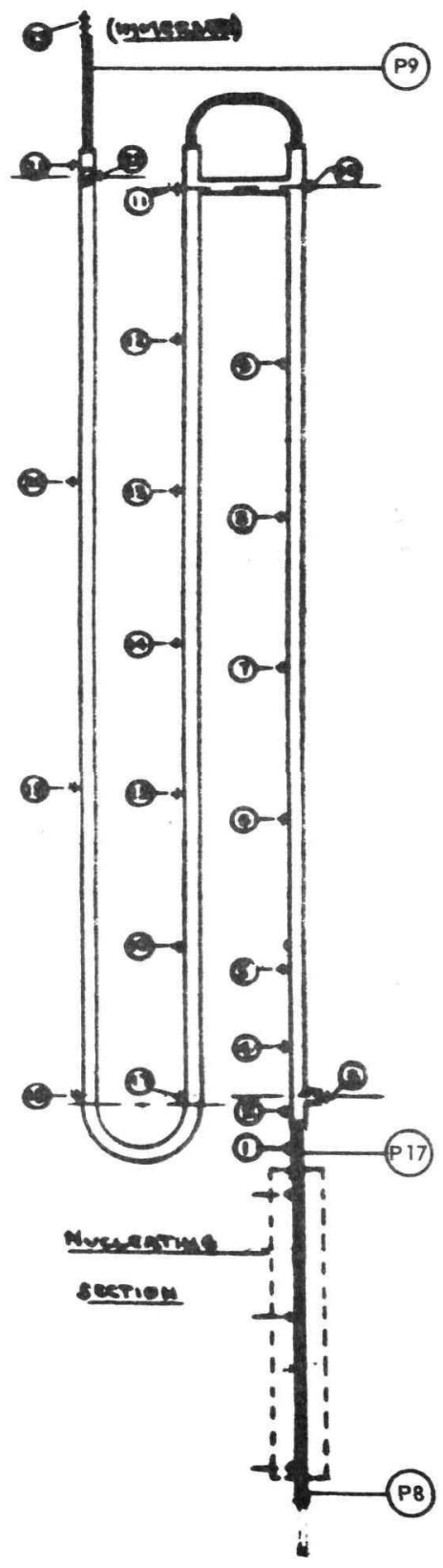



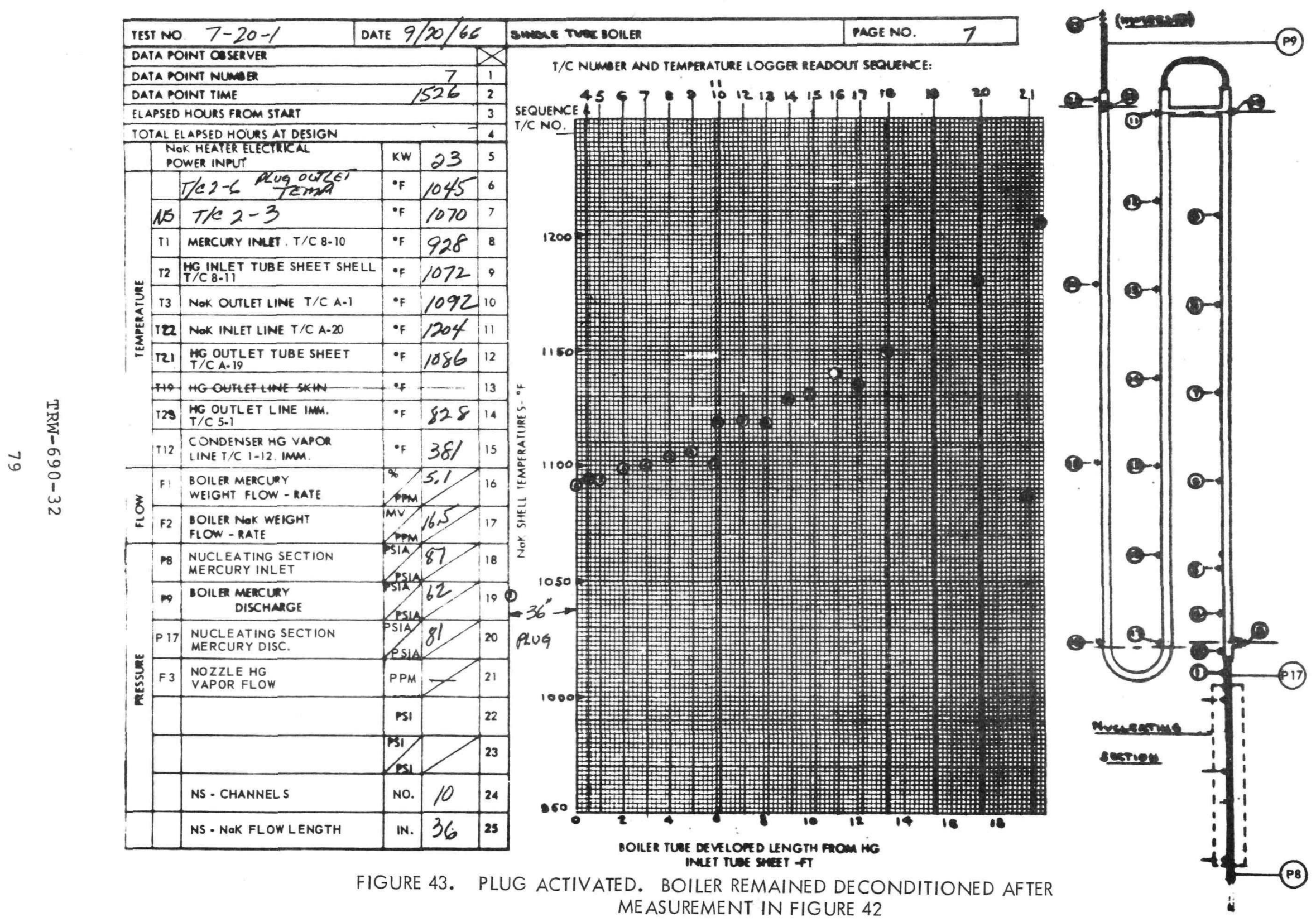

MEASUREMENT IN FIGURE 42 


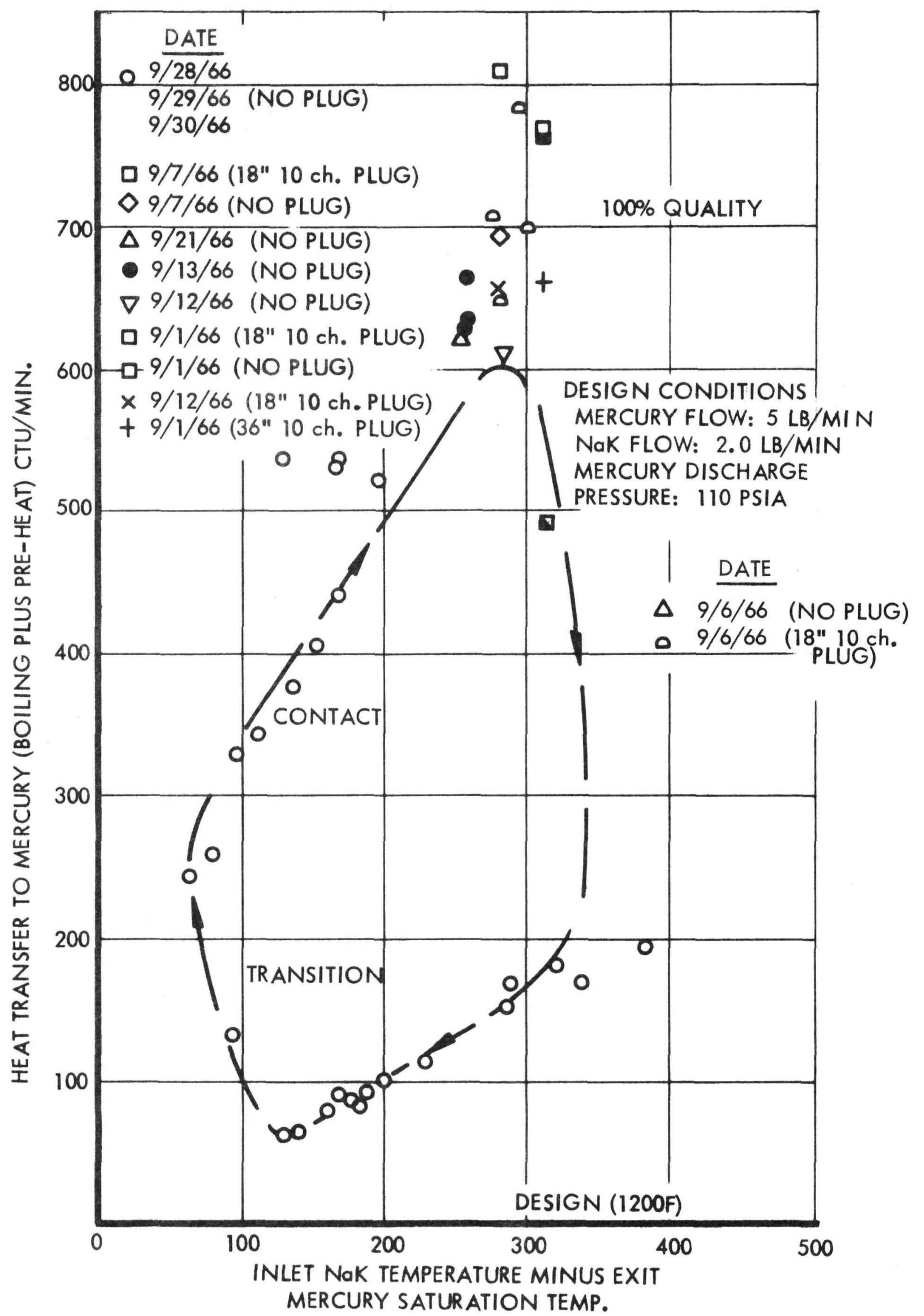

FIGURE 44 MAPPING RESULT OF DECONDITIONING PHENOMENON (INSTANTANEOUS CONDITIONING AND DECONDITIONING)

TRW-690-32 


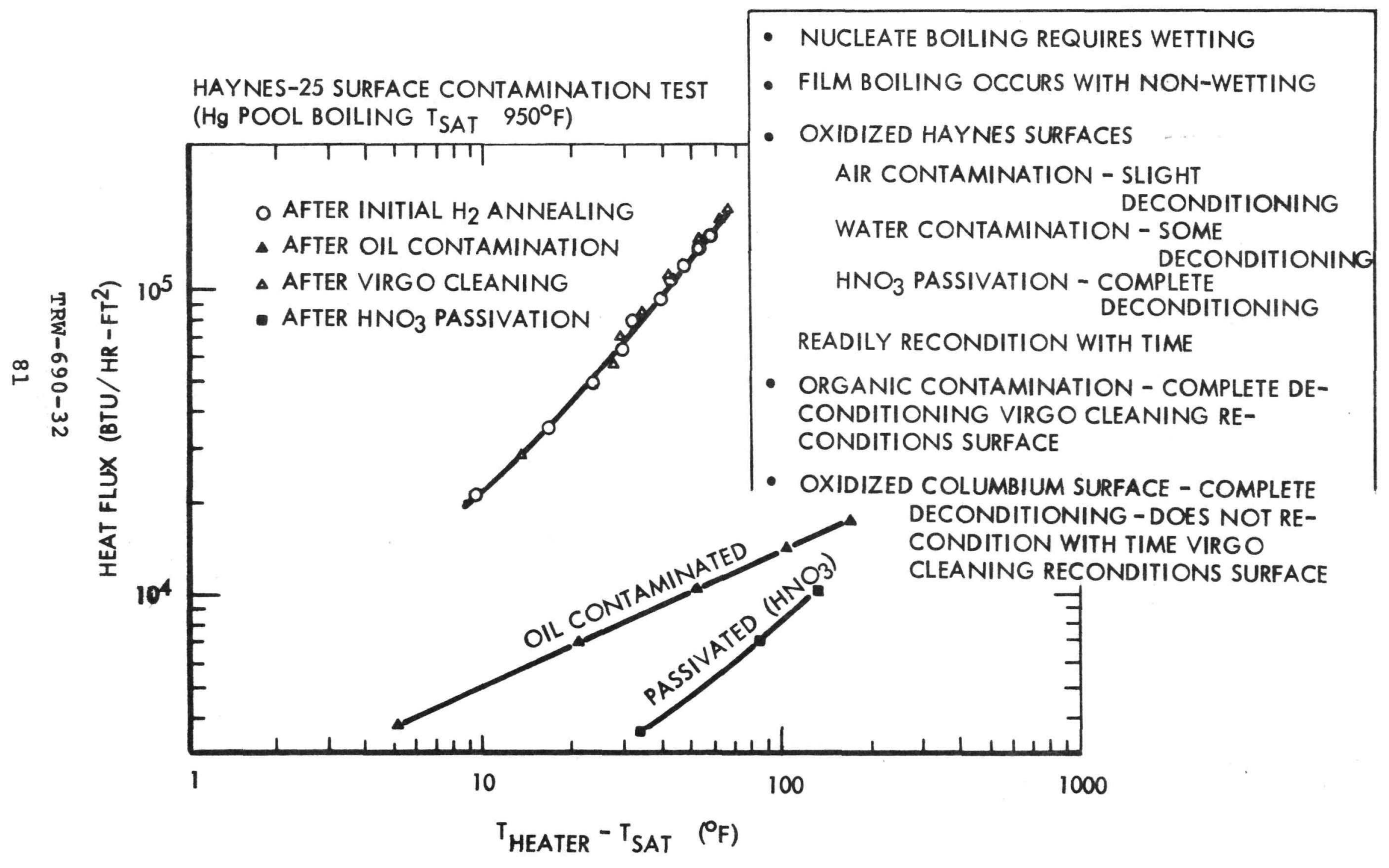
FIGURE 45. EFFECT OF CONTAMINATION ON POOL BOILING HEAT TRANSFER WITH MERCURY 
obtained with a highly unwetted surface. The pool boiling heat transfer coefficients for wetted and unwetted surfaces correspond closely to the convection boiling heat transfer coefficients observed in the conditioned and deconditioned SNAP 2 boilers, respectively. This suggests that SNAP 2 boiler deconditioning is due to loss of adequate wetting.

Experiences with oil, water, and air contamination in the single tube boiler and the prototype boilers agree well with the pool boiler results tabulated in Figure 45. Oil contamination inflicts severe and long lasting performance degradation. Oil had entered some of the test rigs through the vacuum pumping system and, in one case, from the failure of a rig mercury circulation pump. Chemical cleaning of the entire mercury system is required to restore boiler performance. There is no source of oil contamination in the flight system configuration.

Air and water contamination had resulted in various degrees of performance degradation. In most cases, continued operation restored performance. The source of water in a typical test rig setup is from a watercooled condenser. Air contamination results from loss of inert gas purge during rig modifications. Good lab practice can eliminate the difficulties with contaminants.

\section{Conditioning Conclusions}

The causes of deconditioning are not yet fully understood. The single tube boiler and the pool boiler have each supplied data which can be interpreted to explain the deconditioning phenomena. The explanations, however, cannot be considered conclusive. It is suspected that deconditioning is the result of subtle interconnections among such phenomena as wetting, nucleation, liquid superheat, and aging of the liquid-wall interface.

Progress has been made toward the control of deconditioning in the application of plug type inserts which control the hydrodynamics of the two-phase flow and decrease the sensitivity of the boiler to deconditioning tendencies. The rod insert in the compact boilers marks the first step. The multichannel plug in the single tube boiler marks the second step. The third step has not been taken due to termination of the program. It would have been a combination of the two earlier steps with the multichannel section upstream of the rod section.

Conditioning and deconditioning have been discussed in
several reports. See (8), (9), (10), (12), (15), (17), (18),
(20) and (21).

\section{E. GRAVITY CONSIDERATIONS}

The SNAP 2 system was intended for space application wherein the external body forces would be essentially zero gravity.

$$
\text { TRW-690-32 }
$$


The selection of the once-through boiler concept was based on many considerations of which facilitation of two-phase flow control was of major importance. By boiling to complete dryness (100\% quality), the need for a moisture separator and a liquid return system is eliminated. By boiling inside of tubes from 0 to $100 \%$ quality using swirl wire inserts, artificial gravity forces are created which if sufficiently high desensitize the boiler to the external environment. Figure 46, taken from (10), shows the magnitude of the forces developed on the mercury drops in the Model $5 \mathrm{C}$ and 7 boilers. In the rod insert area of 0 to approximately 15\% quality, the forces are actually higher than shown. Reference (9) discusses the conditions to be satisfied to insure satisfactory operation of a multi-channel plug in gravity and zero gravity. These are dependent upon the passage size being less than the critical diameter so that capillary forces dominate in the gravity environment.

Zero gravity simulation experiments were conducted in 1960 in the "Orbital Force Field Boiling and condensing Experiments" program which are reported in (5). The simulated zero-gravity environment was obtained by flying an Air Force KC-135 aircraft through a parabolic zero-gravity maneuver, known as a keplerian trajectory. which provided a force field varying from 2.5 to 0 $g^{\prime} \mathrm{s}$ with 32 seconds at zero gravity. The mercury boiler in the test package was an electrically heated, single stepped tube,

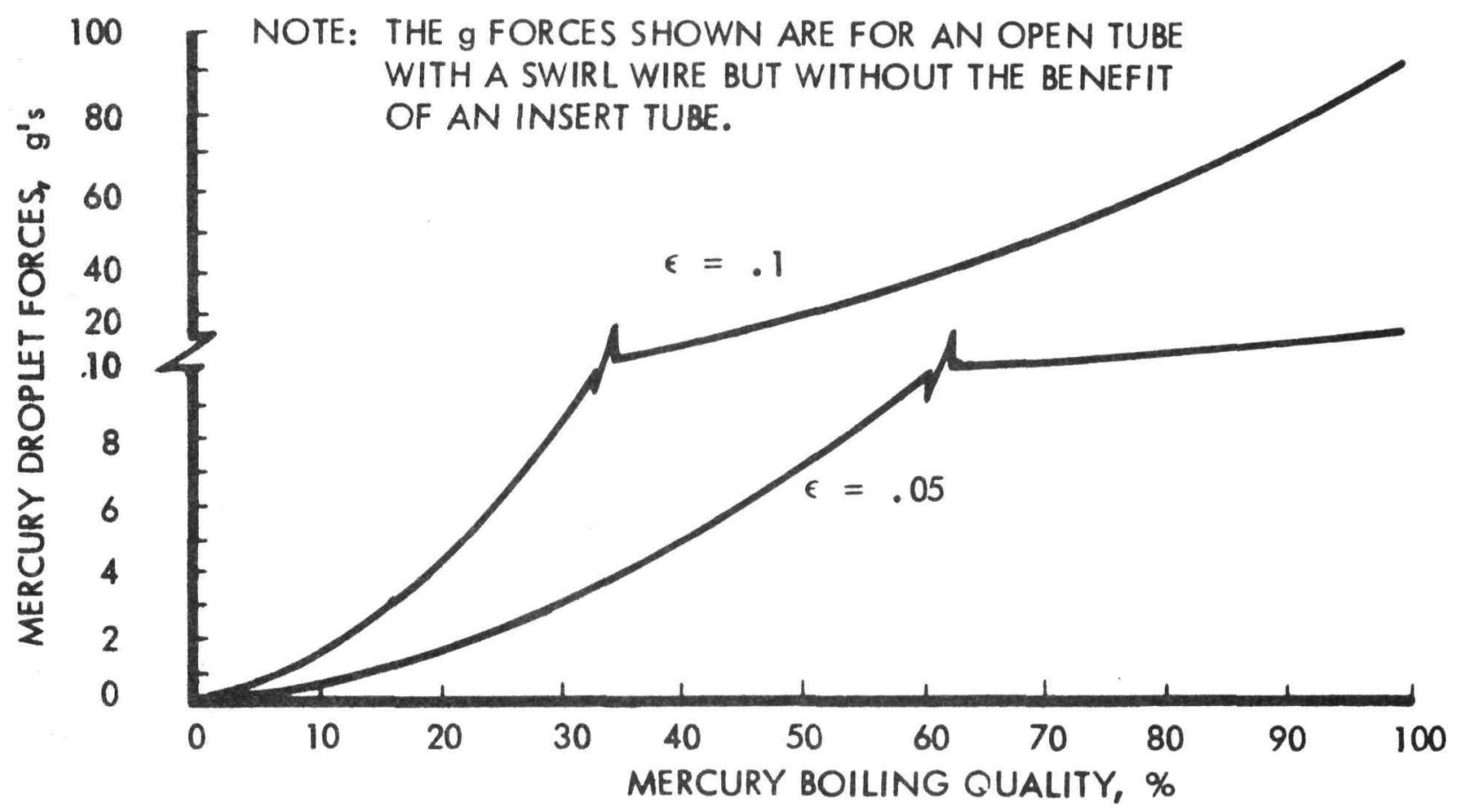

FIGURE 46 DEVELOPED ' $g$ ' FORCES IN THE BOILING MERCURY

TRW $-690-32$ 
helically formed coil, equipped with a swirl wire insert. The boiler operated in the film boiling mode in ground and flight tests. It was concluded from the results that the external gravity environment played a negligible role in boiler heat transfer.

Tests conducted in 1964 on the Model 7 boiler, (22) involved laboratory operation in the one-gravity environment with mercury flow through the boiler in the vertical upflow orientation followed by inverting the boiler for mercury flow in the vertical downflow orientation. Boiler performance was unaffected demonstrating the insensitivity to the external gravity environment.

The boiler design utilizes the relatively large available pressure drop to overcome gravity and instability sensitivities and to improve heat transfer. 


\section{MECHANICAL DESIGN FEATURES}

\section{A. REQUIREMENTS}

The boiler performance requirements were listed in Table 1. The flight qualification environmental requirements are stated in section IIT-G. Other requirements which significantly influenced the mechanical design are enumerated below:

1) The boiler performance life was 10,000 hours at a nominal temperature level of $1200^{\circ} \mathrm{F}$ in a space environment. The boiler would not be operating during the vehicle launch.

2) A flight system boiler would be subjected to thermal shock, thermal endurance, and environmental shock and vibration testing prior to launch.

3) Maximum operating pressures to be experienced are 250 psia on the $\mathrm{Hg}$ side and 25 psia on the NaK side.

4) The weight objective was 45 pounds which included the boiler, mounting brackets, insulation, and fluid inventories at operating conditions.

5) The boiler configuration was to lend itself to easy vehicle integration.

6) No net disturbing torque was to be imposed on the vehicle due to boiler operation.

Major emphasis was placed on mechanical design features and fabrication and inspection procedures to insure boiler reliability.

\section{B. CONFIGURATION}

All of the boilers were of the shell and tube configuration having large ratios of tube length to diameter. The large ratios were dictated by heat transfer requirements and had a beneficial mechanical design effect in minimizing the number of tube to tube sheet joints.

The early boilers, up through Model 4, had the tubes concentric with the shell and the whole assembly formed into a helical coil as shown in Figures 3 and 4 . The mean coil diameters varied to accommodate integration with the system and the vehicle nose cone. Coil diameters of 19.5, 39 and 52 inches were used in the Models 1 through 4 boilers. The larger diameter boilers mounted directly to the radiator-condenser. The $180^{\circ}$ 
reversal in the helix direction shown in Figure 4 is the technique used to eliminate the rotational torque due to NaK and mercury flow.

The compact boilers, Models $5 \mathrm{C}$ and 7 , resulted from a redesign objective to reduce both boiler weight and Nak side pressure drop. The compact configuration cross section provides increased NaK flow area. The shorter shell decreases the NaK flow length. The inner cylindrical container is evacuated and displaces sufficient $\mathrm{NaK}$ to contribute to a weight savings. Although the NaK wetted perimeter is increased, the net effect of the changes was a substantial NaK pressure drop reduction. The tubes are longer than the shell and are accommodated by helically coiling the tubes as shown in Figure 5. Note that $180^{\circ}$ reversal in each tube at the boiler midpoint in Figure 5. The slender compact configuration was easily integrated into the system. Mounting was directly to the radiator-condenser. The reduced surface area of the shell eased the insulation requirements.

\section{SELECTION OF MATERIALS}

The prime criteria for selection of materials were 1) compatibility with the working fluids and 2) high temperature strength. Workability and cost were also considerations, but the corrosiveness of mercury in conjunction with a closed system and the lightweight, longlife requirements made the enumerated considerations of major importance. Haynes 25 and Type 316 stainless steel were selected as the materials of construction for the SNAP 2 boilers.

Type 316 stainless steel was selected as the material for the shell side of the boiler because a multitude of data was available for NaK service. Type 316 stainless steel is partially stabilized and thus resists sigma phase formation in the SNAP 2 boiler temperature range. Also, the NaK loop in the PCS system was made of Type 316 stainless steel, so use of this material in the boiler was consistent with the Nak system plumbing.

All parts in contact with mercury such as the tubes, tube sheets, swirl wire, insert tubes, and inlet and outlet conical adaptors were made from Haynes 25.

Haynes 25 was selected for the following reasons:

1) Corrosion resistance: Extensive mercury corrosion test work had been carried on at TRW from which Haynes 25 had been classified as a class 2 material (class 1 is considered best, Class 5 very poor.) This rating considers both material removal and depth of penetration. class 1 materials generally were refractories which had fabrication and environmental problems which were undesirable.

TRW-690-32 
2) High Temperature Strength: Haynes 25, a ductile material, has strength properties approximately double those of type 316 stainless steel in the temperature range of the SNAP 2 boilers.

3) Weight: Haynes 25 is slightly more dense than stainless steel $\left(0.33 \mathrm{lb} / \mathrm{in.}^{3} \mathrm{vs} .0 .29 \mathrm{in.}{ }^{3}\right)$. The higher strength properties of Haynes 25 permitted lighter gauge wall thickness and resulted in a lighter over-all heat exchanger weight.

4) Fabricability: Machining, forming, and welding of Haynes 25 is processed with the same ease as stainless steel except that it has a higher "work hardening coefficient."

5) Availability: Sheet, bar stock, wire, and tubing in sizes of interest for SNAP 2 boilers were all commercially available. Tubing was not an off-the-shelf item and therefore usually required a longer lead time than stainless steel.

At the time the Model 5c fabrication began there was incomplete information on the embrittling characteristics of Haynes 25. The available data indicated sufficient ductility for the SNAP 2 application. The mechanical design (see section III-D) was directed toward the elimination of notches and other stress raisers. The failure of the $5 \mathrm{C}-1$ boiler (see section $\mathrm{V}$ ) coincided with a more complete understanding of the relationship of initial material hardness and subsequent loss of ductility with time at temperature.

As a result of the 5c-1 tube leaks, a solution anneal at $2250^{\circ} \mathrm{F}$ for 15 minutes in a hydrogen atmosphere was required on all Haynes 25 parts (tubes, tube sheets and swirl wire) after each cold-forming operation.

D. THERMAL STRESS

From a mechanical design viewpoint, a most critical consideration was thermal stress. Severe thermal stress producing conditions in the SNAP 2 boilers could exist due to thermal shocks, at joints of dissimilar metals and due to differential expansion between tubes and shell. The severity of these conditions was minimized by design.

To achieve light weight as well as flexibility rather than rigidity under thermal operating conditions, thin-walled sections were used in SNAP 2 boiler designs. In using this approach, however. fatigue life of the critical areas had to be investigated for the number of expected cycles. 
Areas of maximum thermally induced stresses exist in the vicinity of each of the two tube sheets. Here dissimilar metal joints, changes in shape and thickness and tube to tube sheet joints occur. Throughout the boiler design gradual changes in shapes and wall thicknesses were used to minimize stress levels.

In sizing wall thicknesses, mercury and/or NaK corrosive action in addition to operating pressure and thermally induced loads, were taken into account.

The computed wall thicknesses for the SNAP 2 boiler parts were normally so thin that the final sizes were dictated by availability and ease of welding, handling and coiling. This was especially true for the tube wall thickness where strength and corrosion requirements could be satisfied by a wall thickness of several thousands of an inch. Typical tube walls used, however, ranged from .020 to .035 inch thick.

To ease discontinuity stresses in the tube sheet to shell region, cylindrical extensions were retained integral with both sides of each tube sheet, thus making weld joint stresses independent of tube sheet stresses. In the Models $5 \mathrm{C}$ and 7 compact boilers, internal extensions were also used to join the individual tubes to the tube sheet using an internal butt welding technique. A detailed discussion of this method of tube attachment is found in section III-E.

Stress levels due to differential expansion between tubes and shell were kept at safe values by designing for relative motion. This was more easily accomplished in the helical type boiler, since the tubes and shell form basically concentric helically coiled U-tubes making relative motion possible. properly spaced tube supports further allowed for relative tube movement in a radial direction of the shell.

In the compact type boiler the coiled tube assembly and the shell were solidly connected through the load ring at the trunnion support and, of course, at both inlet and outlet tube sheets. Differential expansion on the mercury inlet side of the load ring was taken up by the approximate right angle bends in the tubes. Sufficient clearance of the coiled tubes in the scalloped tube supports and of the coil assembly within the shell allowed for differential expansion on the NaK inlet side of the load ring.

Reference (10) contains a good summary analysis of the thermal stresses in the compact boiler. Additional details are reported in references (23) through (27).

Two problems occurred with the compact boilers that were related to thermal stress. The first was a mercury tube fracture 
caused by rapid age hardening at elevated temperature of the Haynes 25 tubing that was put into service having high residual stresses from the cold working during fabrication. This was solved by in process annealing. Details are discussed in section V.

The second problem was one of collapse of the evacuated cylindrical inner container in four of the Model 5c boilers. This did not impair the thermal performance but it would cause a $\mathrm{NaK}$ inventory problem in a flight system. The collapse was caused by thermally induced relative motion of the support discs inside of the cylinder. Three support discs were fixed relative to each other by a length of small tubing. The heat transfer path caused a thermal $\mathrm{lag}$ in the support structure, resulting in buckling of the discs and support tubing during rapid heatup and cooldown of the boiler, leading to eventual collapse of the cylinder from the external NaK pressure. Ring type supports, brazed to the cylinder, and elimination of the support tube solved the problem.

\section{E. INTERNAL BUTT WELD}

The conventional method of making a welded tube to tube sheet connection is to pass each tube through a hole in the tube sheet, then weld the end of each tube in place at the tube sheet front face, similar to the joint design illustrated in Figure 47. In joints of this nature a crevice is formed between the tube and tube sheet which provides a source for accelerated corrosion and stress concentration.

Prior to design of the $5 \mathrm{C}$ boiler, the SNAP 2 tube joints had been of the above design, and performed satisfactorily for 1500 hours in tests, however, there was some concern over the ability of this joint to survive severe thermal shocks and last for the 10,000 hour design life.

Several alternatives such as back brazing and tube sheet front face extensions were evaluated and found to be inferior to internal butt welding to tube sheet backface extensions as shown in Figure 48. The concept had been shown to be feasible for larger diameter tubing, references (28) and (29). Significant advantages of the internal butt weld joint are:

1) The joint was crevice-free and the need for backbrazing was eliminated.

2) The welds, could be 100 percent inspected by radiography and fully evaluated, whereas interpretation of trepan weld edge-type $X$-rays was indefinite. 

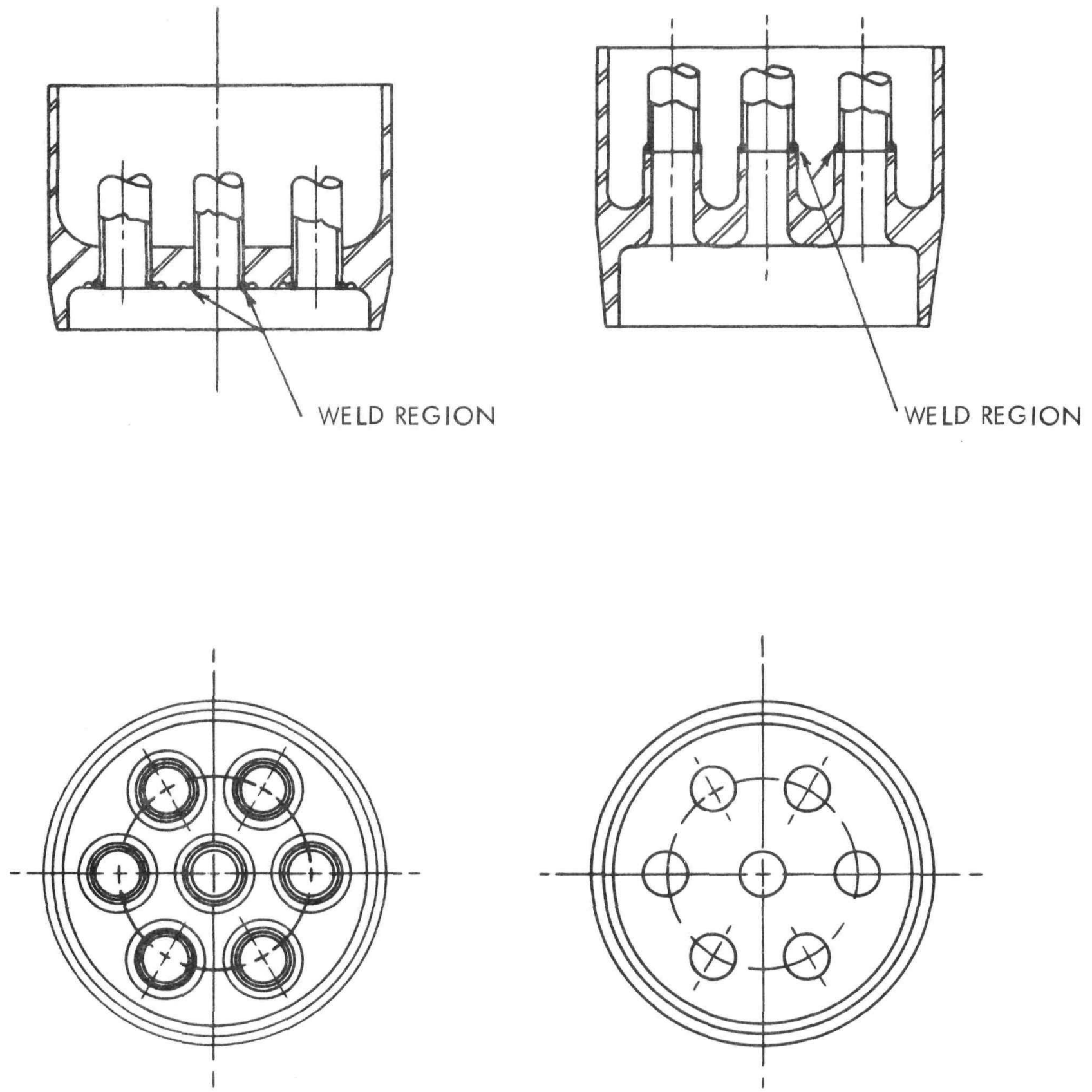

FIGURE 47 TREPAN GROVE TUBE SHEET CONFIGURATION

FIGURE 48 INTERNAL BUTT WELD TUBE SHEET CONFIGURATION

$$
\begin{gathered}
\text { TRW- } 690-32 \\
90
\end{gathered}
$$


3) The joint was located in an area of minimum thermal and mechanical stress whereas the edge weld was in an area of high stress.

To verify the feasibility of joining small diameter tubing to tube sheet extensions by an internal butt weld technique, TRW developed and built an internal welding torch and designed and tested a suitable joint configuration. Detailed torch design and test results are reported in (10).

The testing demonstrated that the internal tube butt welding process for welding small inside diameter tubing to simulated headers was feasible. The torch design and parameters developed did consistently produce quality welds in simulated tube-toheader joints fabricated from Type 316 stainless steel and Haynes 25. A joint efficiency of approximately $96 \%$ was achieved on Type 316 stainless steel material and tensile strength equivalent to the producer's specifications was obtained on Haynes 25. Each alloy was fully ductile in the as-welded condition.

All Model $5 \mathrm{C}$ and Model 7 boilers were built using the internal butt welding method. Post-test inspections of the tube to tube-sheet welds in the above boilers revealed no failures.

\section{F. FABRICATION}

The helical type SNAP 2 boilers (Models 1 to 4 ) consisted of 13 tubes (Model 1) or 7 tubes (Model 2-4) inside nominal two inch diameter shells. One half of the total length of the tube and shell assembly was formed into a right hand helical coil while the other half was formed into a left hand helix. The two coils were connected by a short U-bend section to satisfy the zero net torque requirement. To keep individual tube lengths constant, the tube bundle was twisted through $180^{\circ}$ (with respect to the shell).

Each tube and shell assembly for the helical design boiler was formed on a mandrel specifically constructed for the required configuration (specific helix diameter and coil number). A major fabrication problem in this type of boiler was maintaining proper tube spacing during coiling. Granulated sugar had been used as packing material for tube spacing with moderate success. Predicting axial and radial spring-back was highly speculative. The spring-back was a complex function of the seven or thirteen Haynes 25 tubes and Type 316 stainless steel shell and was empirically determined from test samples at least one circumference long. Mandrels were eventually made that were capable of some adjustment in coil diameter.

Wrinkling of the shell wall on the inside of the coil during coiling was not an uncommon occurrence. While this problem did 
not affect thermal performance of the boiler, difficulties in the application of the thermal control coating (gold foil) was anticipated.

Refinements in fabricating techniques for the helical boiler were never finalized since the concept was discarded in favor of the compact models.

In the compact SNAP 2 boilers, four tubes are coiled in parallel to form a tight 3.25 inch diameter helical coil assembly. Tests showed that this 3.25 inch diameter coil could be fabricated without a mandrel or filler for $3 / 8$ inch $0 . D$. by .020 inch wall Haynes 25 tubing. Coil forming was therefore fast and tooling inexpensive.

The number of welds pex individual boiler tube in a Model $5 \mathrm{C}$ was one-half that in a Model 4 or earlier boiler. The 180 degree flow reversal was accomplished in a continuous tube in the Model 5c, resulting in tube welds only at the tube-to-tube sheet joint, an increase in boiler reliability.

An important process in the fabrication of the SNAP 2 boilers was the technique of inserting the turbulating devices into the boiler tubes which were inserted prior to any tube coiling operation. These devices consisted of helically coiled swirl wires in the Model 1 through 4 boilers and similar swirl wires plus tubular centerbodies (at the mercury inlet end) in the Model $5 \mathrm{C}$ and 7 boilers. The swirl wire insert was helically coiled wire having a helix outside diameter slightly greater than the boiler tube inside diameter. In early fabrication, the coiled wire insert was pulled into position. A tack weld at the tube ends plus the spring action of the coils held the wire in place. Uniformity of swirl wire spacing was not precise with this technique which was resolved by tack welding the wire to the centerbody every $720^{\circ}$; tension winding the balance of the wire on a brass mandrel for insertion into the tube; releasing tension and unscrewing the mandrel; and final check of the position by radiography.

Throughout the fabrication of any SNAP 2 boiler, adherence to rigid material acceptance and manufacturing specifications as well as to proper cleaning procedures were maintained. Also elaborate inspection techniques of all parts, subassemblies and assemblies were employed.

\section{G. FLIGHT QUALIFICATION TESTS}

The Snap 2 boiler was subjected to a series of shock, vibration, and hydrostatic pressure tests as required by the flight qualification structural specifications. 
The specifications of the various tests were as follows: Shock Test

Magnitude:

$$
\begin{array}{ll}
\text { Lateral and normal axes: } & 10 \mathrm{~g}^{\prime} \mathrm{s} \\
\text { Longitudinal axis: } & 20 \mathrm{~g}^{\prime} \mathrm{s}
\end{array}
$$

Number and Direction: twice in each direction along the mutually perpendicular axes (total of 12 shocks)

Shock Waveform: half sine wave

Duration: 6 milliseconds (measured at base of sine wave).

Sequence: Lateral and normal axes before longitudinal axis.

\section{Vibration Test}

Longitudinal axis

Vibration Input:

$$
\begin{array}{ll}
\text { Frequency } & \multicolumn{1}{l}{\text { Level }} \\
5-9 \mathrm{cps} & 0.50 \mathrm{inch} \text { double amplitude } \\
9-250 \mathrm{cps} & 2.0 \mathrm{~g} \\
250-400 \mathrm{cps} & 3.5 \mathrm{~g} \\
400-2000 \mathrm{cps} & 7.5 \mathrm{~g} \\
\text { Type of Sweep - Constant Octave sweep rate from } \\
\text { Low Frequency to High Frequency. } \\
\text { Sweep Speed - 4.0 degrees/min. (45 min. total } \\
\text { time of Sweep) }
\end{array}
$$

Lateral and Normal Axes

Vibration Input:

Frequency

5-7.5 cps

$7.5-250 \mathrm{cps}$

\section{Level}

0.50 inch double amplitude

$1.5 \mathrm{~g}$

$$
\text { TRW-690-32 }
$$




$$
\begin{array}{ll}
250-400 \mathrm{cps} & 2.0 \mathrm{~g} \\
400-2000 \mathrm{cps} & 7.5 \mathrm{~g}
\end{array}
$$

Type of Sweep - Constant Octave sweep rate from Low Frequency to High Frequency.

Sweep speed - 4.0 degrees/min. (45 min. total time of Sweep)

\section{Hydrostatic Pressure Test}

Magnitude: 1.25 times maximum operating pressure (adjusted for thermal loading where applicable).

Duration: 5 minutes

The helical type snap 2 boiler designs had not been structurally refined to a point where flight qualification testing was undertaken. Tube support methods were not judged adequate to withstand the shock and vibration requirements. Improvements in design were under way, but were terminated upon selection of the compact boiler as the reference design for the system.

The problem of supporting the tubes adequately, without adversely affecting the NaK side pressure drop was more easily accomplished in the compact boiler design. The tube coil assembly was supported inside the annulus formed by the boiler shell and inner can by pairs of scalloped support straps (see Figure 5) equally spaced at $90^{\circ}$ intervals circumferentially. A tight fit of the scalloped straps inside the annulus was insured by individually hand fitting each coil assembly to a shell. The fit, however, still allowed for relative thermal expansion.

By welding the lower tube support ends (mercury inlet end) to the load ring, longitudinal loading due to the coil assembly mass was directly transferred through the load ring to the external trunnion supports. The evacuation tube for the inner cylinder inside the NaK outlet line and the span of mercury inlet tubing upstream of the load ring were supported by wire straps.

The Model 5c-9 boiler underwent flight qualification testing and was subjected to the shock, vibration and hydrostatic pressure tests conducted according to the above specifications. Post test inspections showed that the $5 \mathrm{C}$ boiler was not damaged as a result of the structural flight qualification testing. 


\section{A. INSTRUMENTATION}

All of the development boilers, including the preliminary test sections, in both the component test rigs and in system test rigs had similar instrumentation and data recording equipment. The hot plate test rigs, boiler research test section, and the single tube conditioning test section had additional instrumentation as was discussed in section II. The most noteworthy of the special instrumentation was the $\mathrm{X}$-ray image amplifier with the television monitor screen and movie camera apparatus which is covered in detail in references (8) (9) and (17).

Pressures, temperatures, and flow rates were measured in the development boilex tests by instrumentation generally considered typical of liquid metal systems.

Mercury pressures were measured with Bourdon gages. Primary fluid pressures ( $\mathrm{Na}$ or $\mathrm{NaK}$ ) were measured with diaphragm type transmitters with the readout on continuous strip chart as required by certain tests. Pressure taps in both fluids were located at the boiler terminals.

Terminal temperatures were measured by immersed shielded thermocouples. Local temperatures along the mercury tube length were not measured directly but were inferred from thermocouple readings taken from the surface of the shell of the boiler. This was a pioneering effort at the time which proved highly successful and has since been adapted by most experimenters doing liquid metal boiler work. The technique is useful in defining the temperature distribution of the primary fluid which permits an approximate determination of:

1) The distribution of heat transfer surface into preheating, boiling, and superheating regions;

2) The heat transfer coefficients between the primary fluid and mercury during preheating, boiling, and superheating:

3) Mercury side hydrodynamic stability; and

4) Startup and shutdown characteristics.

The relationship of primary fluid temperature distribution with length to the above factors is noted in Figures 51, 52, and 55.

Surface thermocouple installation does not compromise boiler reliability nor complicate boiler fabrication as would internal

$$
\text { TRW-690-32 }
$$


thermocouples.

Temperatures were usually readout on multipoint chart recorders with selected temperatures recorded on continuous strip charts as required by certain tests.

Primary fluid flow was measured with a permanent magnet flowmeter. Mercury flow was determined by a calibrated liquid orifice. For 100 percent vapor generation, a choked nozzle was used on boiler component tests as a check on the liquid flow. In system tests, turbine performance was used as a check on the liquid flow.

\section{B. NaK TEMPERATURE PROFILES}

The shell surface temperature profile came to be regarded as the prime criterion for determining boiler performance. At least one sample of a temperature versus length profile for each of the development boilers is included in Figures 49 through 58.

Figure 59 is a rare plot of a Model $5 \mathrm{C}$ boiler that was operating in an unstable manner apparently in transitional boiling. The heavy bars indicate the regions of high frequency oscillation for the individual thermocouples. The upper locus is a region of low heat flux. The individual thermocouples would occupy either the upper or lower locus transferring from one to another in an unpredictable random pattern. This mode of operation is related to the conditioning phenomenon which is discussed in section II-C.

\section{TEST PROBLEMS}

Difficulties with boiler conditioning caused the most significant problems in testing. Conditioning has already been discussed in section II-D.

Other test problems were minor in nature being more nuisances than problems. These fell into the general categories of leaks and contamination.

on the Nak side, NaK oxide plugging problems were encountered with the compact boilers, however, complete plugging never occurred. The degree of plugging was insufficient to affect the pressure drop readings but sufficient to affect the $\mathrm{NaK}$ temperature profile. Several steps were taken to eliminate difficulties with NaK oxides:

1) Reliance upon the existing practice of cold trapping and hot dumping the $\mathrm{NaK}$ in the system was abandoned.

2) The purity of the NaK was upgraded in the initial filling of the system from $300 \mathrm{ppm}$ oxygen to $50 \mathrm{ppm}$.

$$
\text { TRW-690-32 }
$$




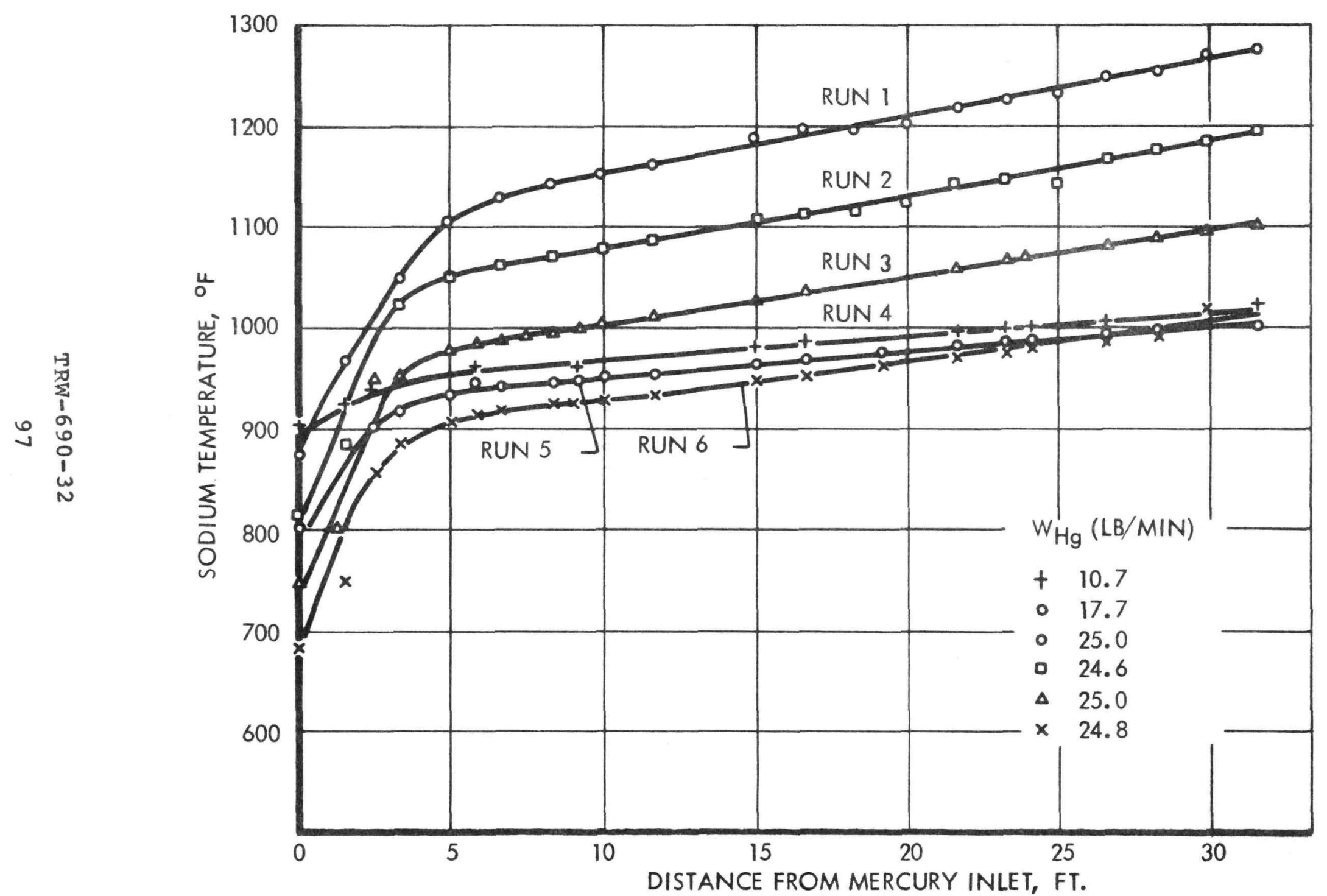

FIGURE 49. VARIATION OF TNa WITH DISTANCE FOR PRELIMINARY TEST SECTION I-0.402"I.D. × 34' LONG 


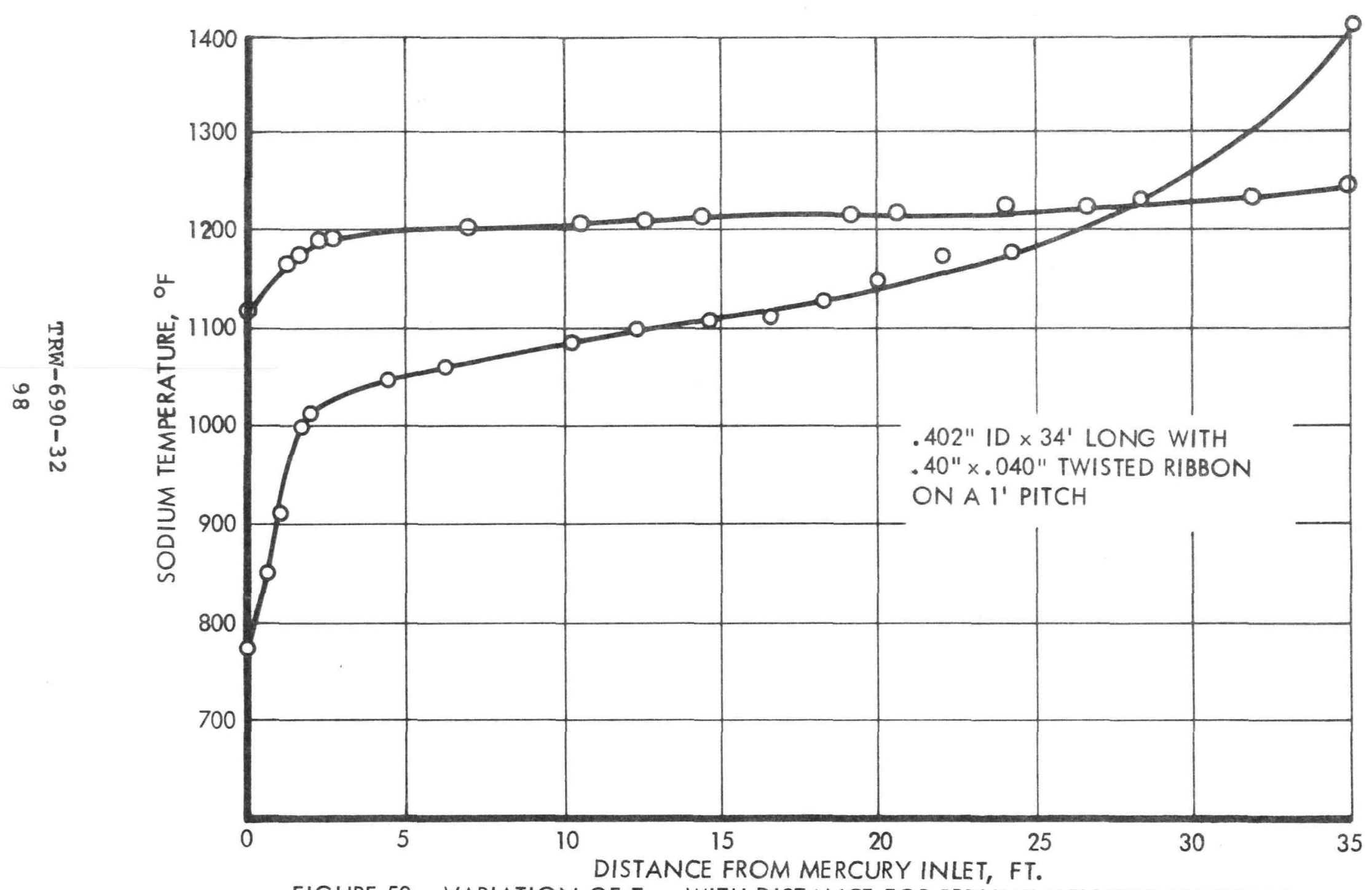

FIGURE 50. VARIATION OF TNa WITH DISTANCE FOR PRELIMINARY TEST SECTION 2 


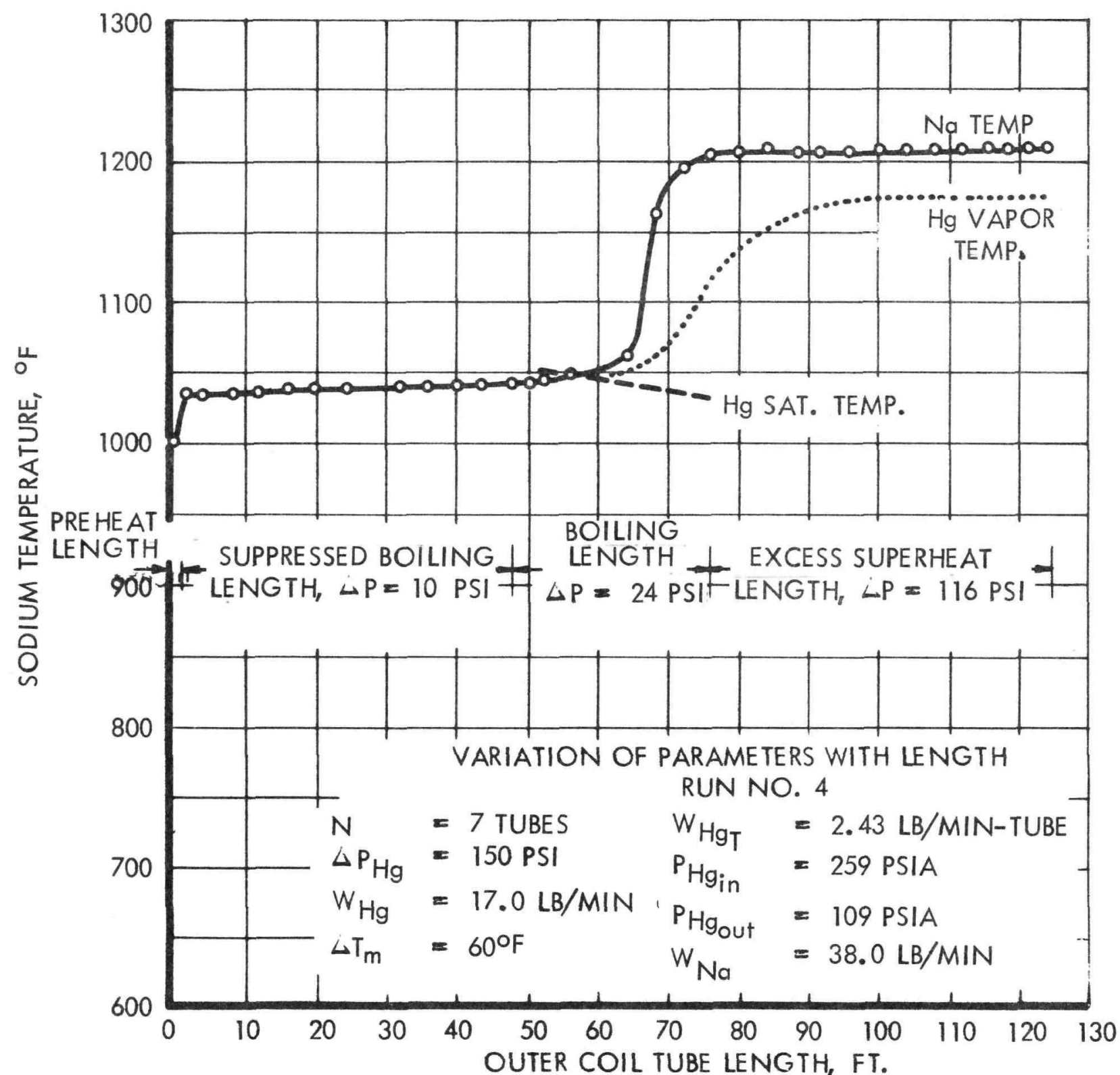

FIGURE 51. SODIUM \& ESTIMATED MERCURY EQUILIBRIUM TEMPERATURE DISTRIBUTION IN THE MODEL 1 BOILER 


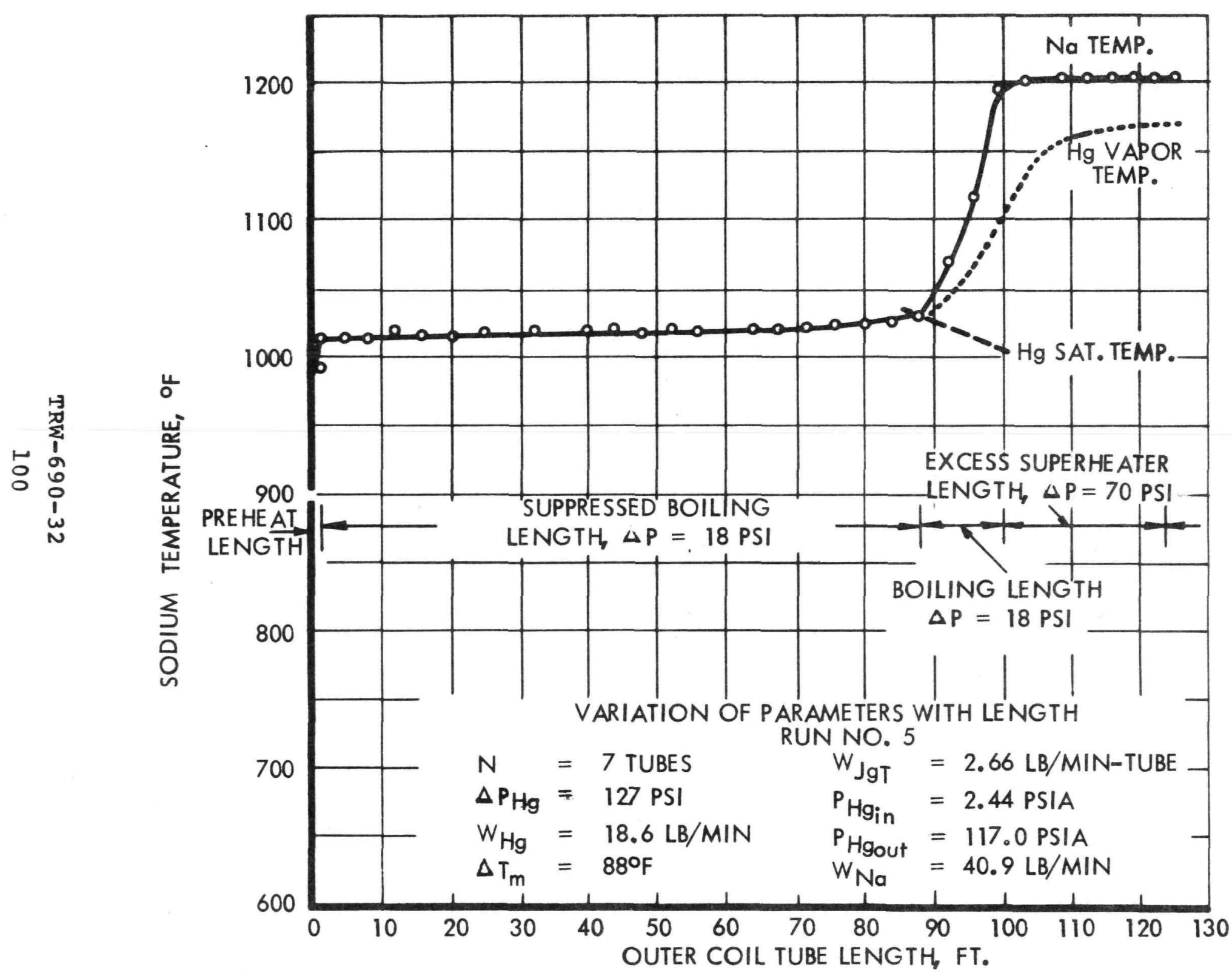

FIGURE 52. SODIUM AND ESTIMATED MERCURY EQUILIBRIUM TEMPERATURE DISTRIBUTION IN THE MODEL I BOILER 


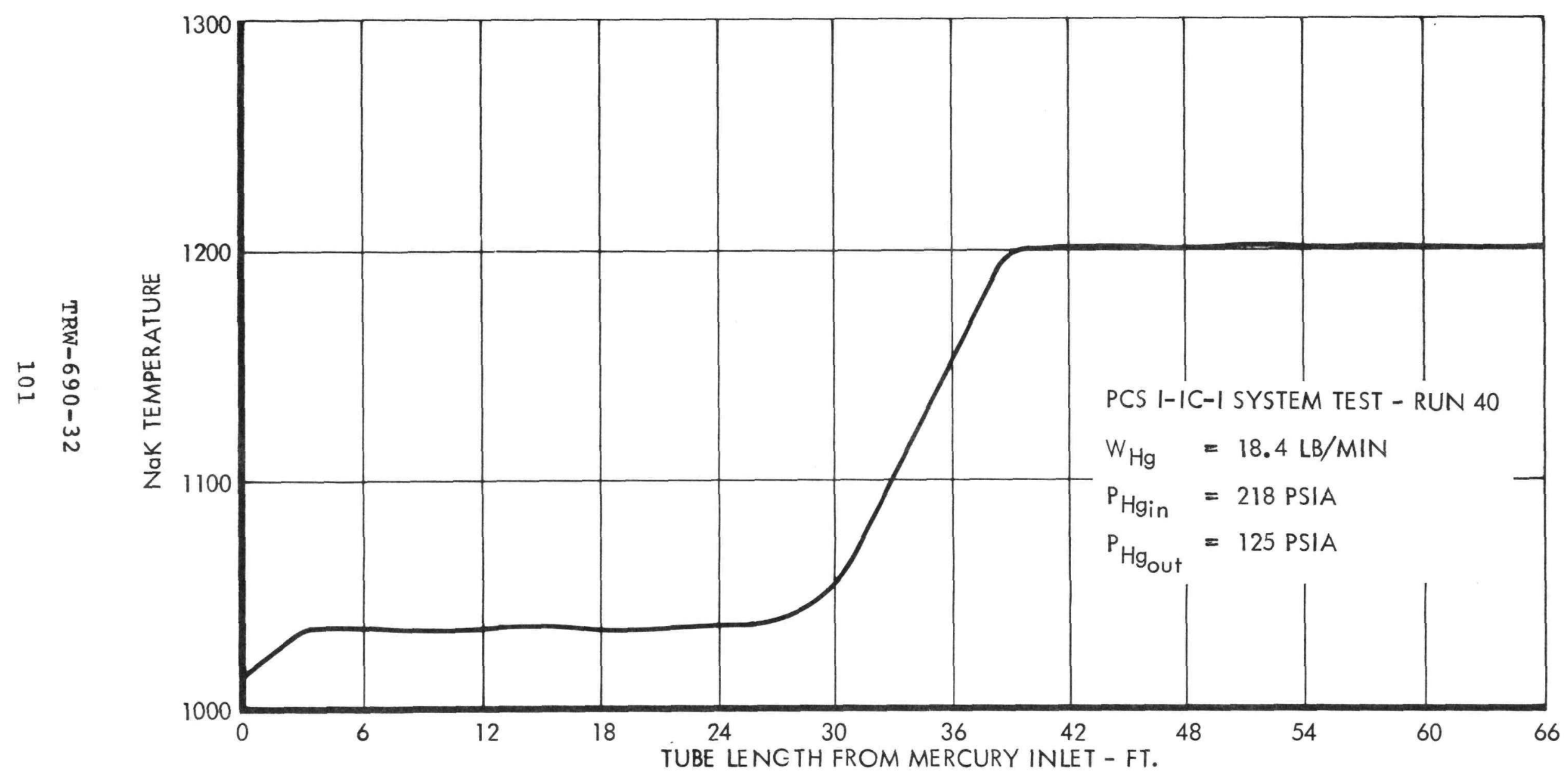

FIGURE 53. NaK TEMPERATURE VERSUS LENGTH FOR THE MODEL 2 BOILER 


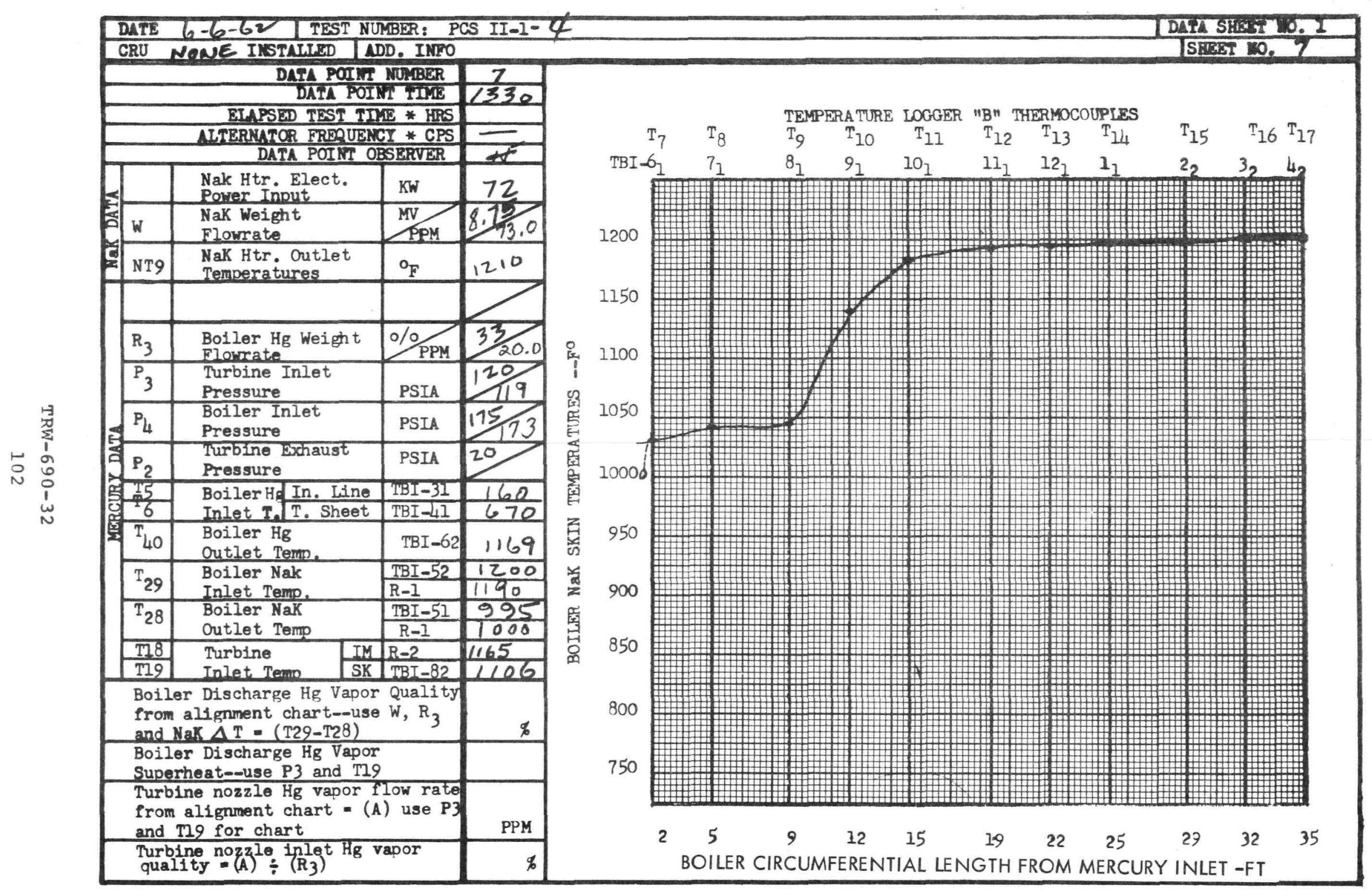

FIGURE 54 NAK TEMPERATURE VERSUS LENGTH FOR THE MODEL 3 BOILER 


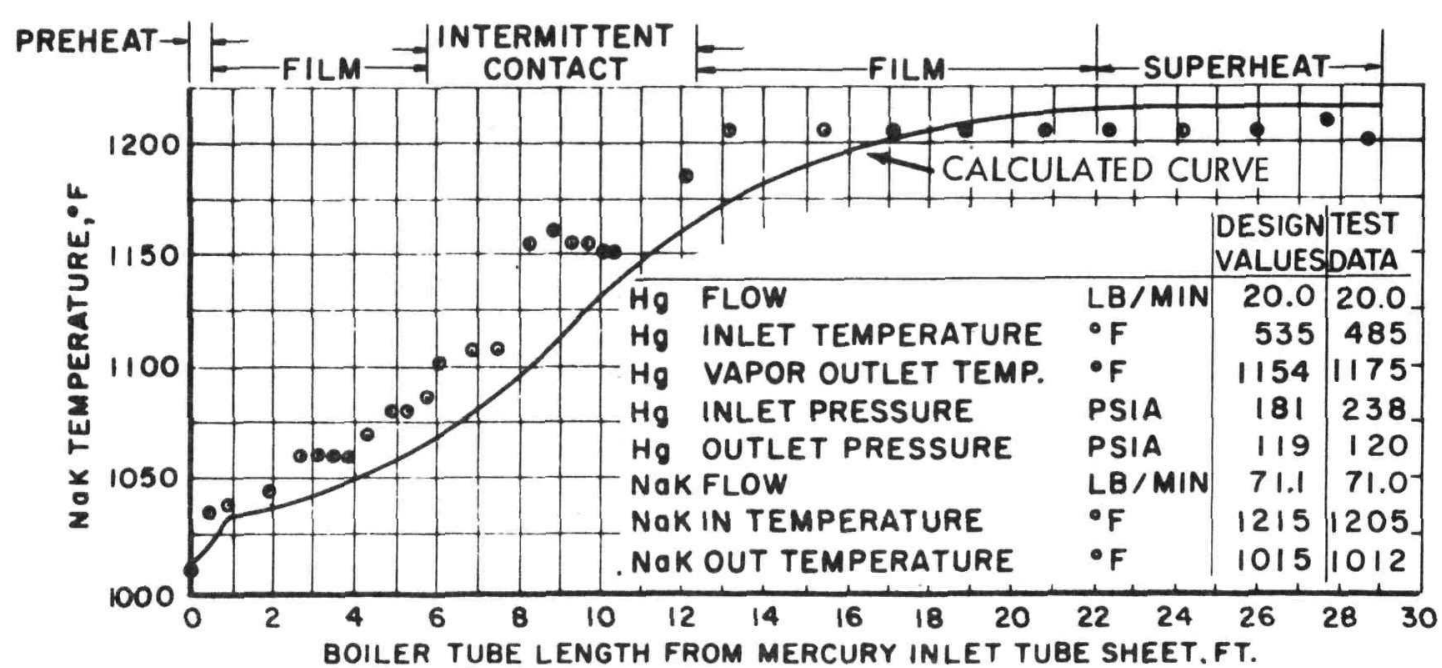

FIGURE 55 COMPARISON BETWEEN CALCULATED AND MEASURED BOILER PERFORMANCE MODEL 5 C

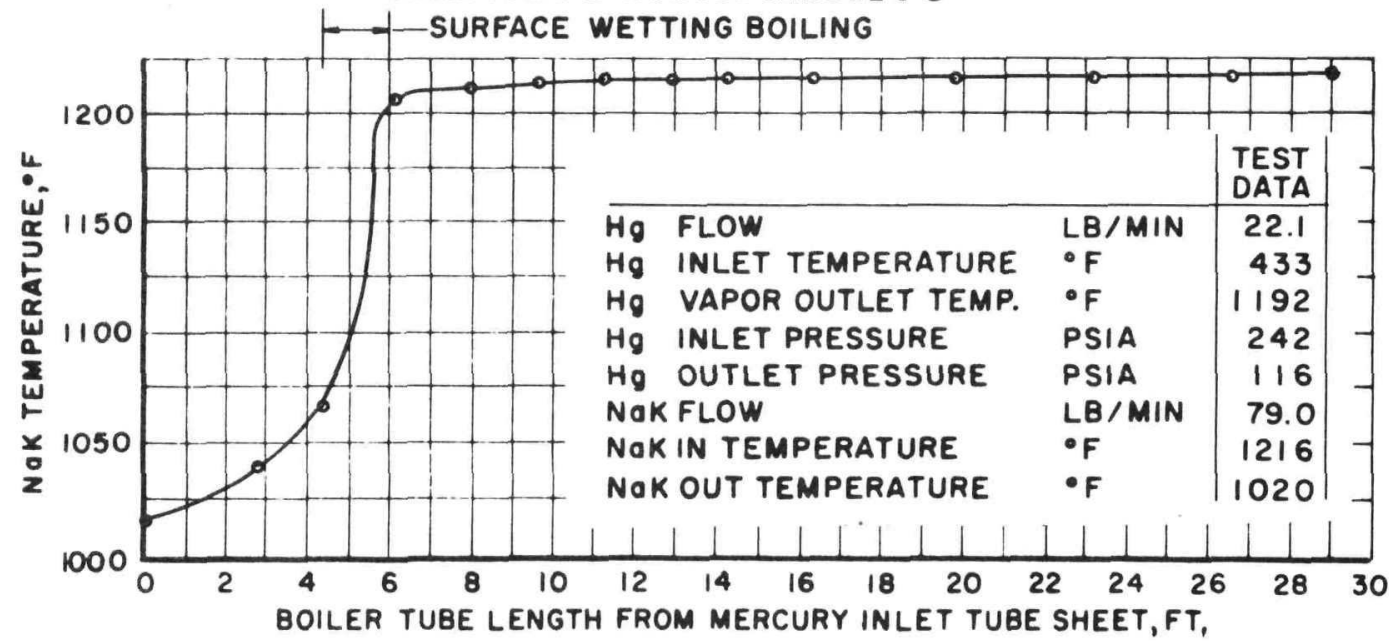

FIGURE 56 MEASURED BOILER PERFORMANCE WITH PROBABLE WETTING MOUEL 5 C

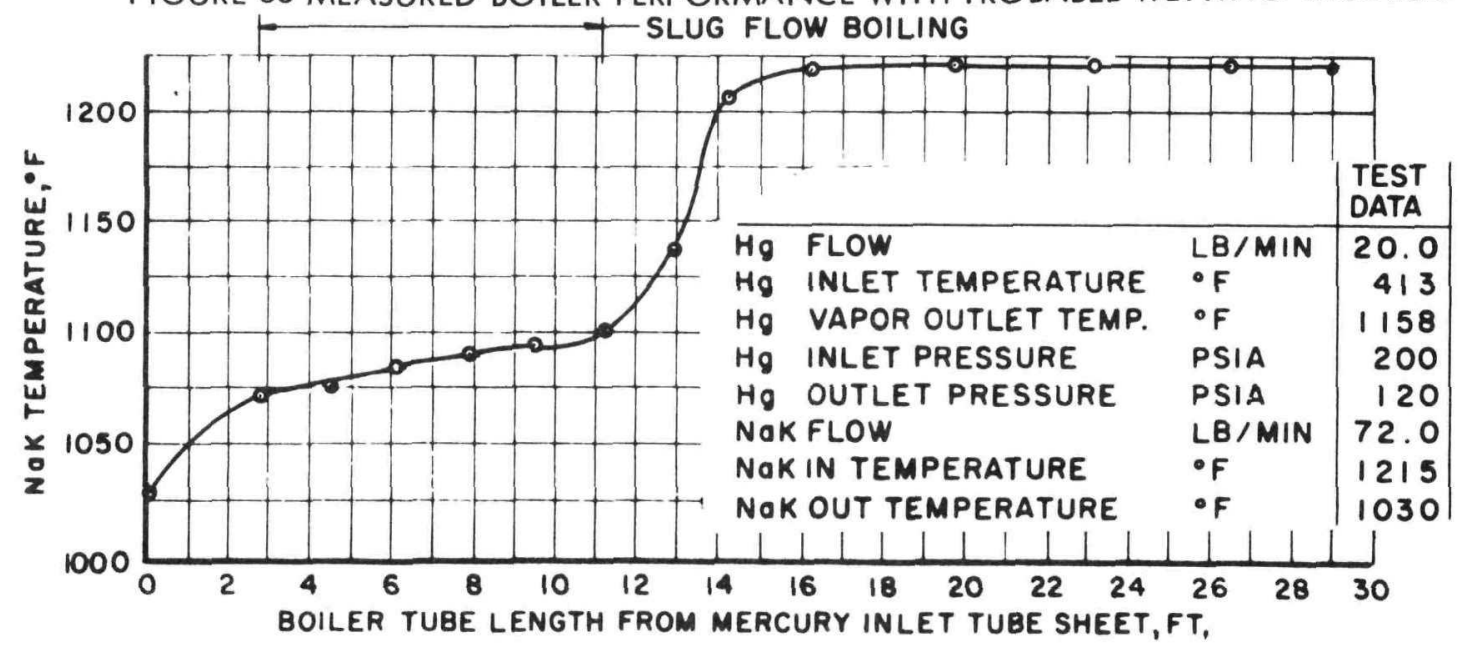

FIGURE 57 MEASURED BOILER PERFORMANCE WITH PROBABLE SLUG FLOW MODEL 5 C 


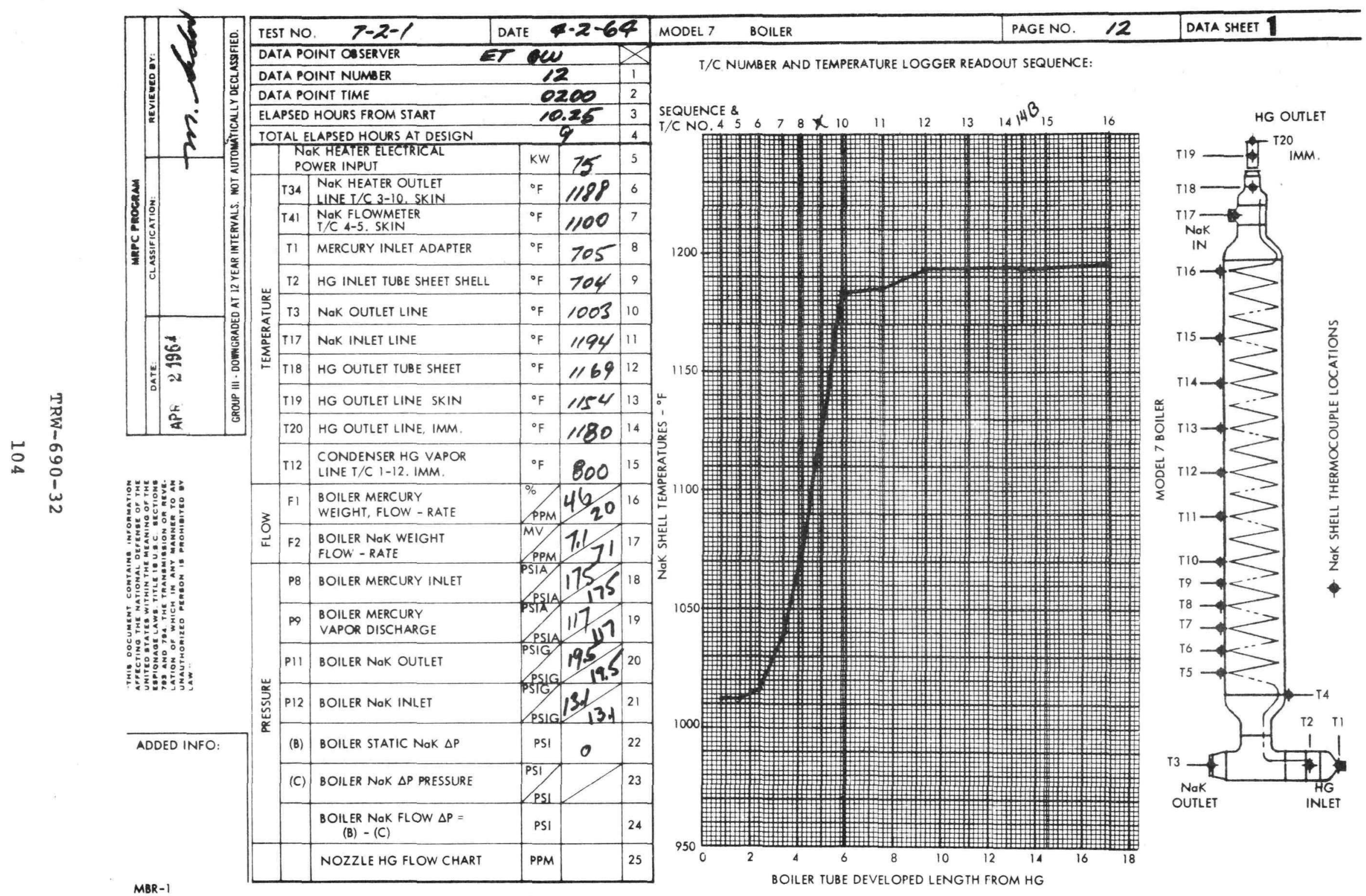

FIGURE 58 NAK TEMPERATURE VS. LENGTH FOR THE MODEL 7 BOILER 
TEMPERATURE DATA IS UNCORRECTED, REFER TO CAL IBRATION ER FOR CORRECTION.

\begin{tabular}{|c|c|c|c|c|}
\hline \multicolumn{3}{|c|}{ TEST NO. CRU V-40-46 } & \multicolumn{2}{|l|}{ DATE } \\
\hline \multicolumn{3}{|c|}{ DATA POINT OBSERVER } & $\mathrm{AO}$ & \\
\hline \multicolumn{3}{|c|}{ DATA POINT NUMBER } & & \\
\hline \multicolumn{3}{|c|}{ DATA POINT TIME } & 1400 & \\
\hline \multicolumn{3}{|c|}{ ELAPSED HOURS FROM CRU START } & & \\
\hline \multicolumn{3}{|c|}{ ALTERNATOR FREQUENCY - CPS } & & \\
\hline $\begin{array}{l}P 1 \\
G\end{array}$ & \begin{tabular}{l|} 
TURBINE INLET \\
NOZZLE PRESSURE
\end{tabular} & PSIA & & \\
\hline $\begin{array}{c}P 16 \\
G\end{array}$ & $\begin{array}{l}\text { BOILER CAVITATING } \\
\text { VENTURI INLET PRESSURE }\end{array}$ & PSIA & & \\
\hline $\begin{array}{ll}P 13 \\
G\end{array}$ & $\begin{array}{l}\text { BOILER MERCURY } \\
\text { INLET PRESSURE }\end{array}$ & PSIA & & \\
\hline $\begin{array}{l}F 5 \\
G\end{array}$ & $\begin{array}{l}\text { BOILER HG INLET } \\
\text { FLOW } \triangle P \text { GAGE }\end{array}$ & $\triangle P P M$ & & \\
\hline $\begin{array}{l}\text { F5 } \\
T\end{array}$ & $\begin{array}{l}\text { METER READOUT A5, } \\
\text { BOILER HG INLET FLOW }\end{array}$ & $\%$ & & \\
\hline $\begin{array}{c}T \\
118\end{array}$ & $\begin{array}{l}\text { NAK FLOWMETER BODY } \\
\text { TEMPERATURE - USE W/NF6 }\end{array}$ & $D-1$ & ${ }^{\circ} \mathrm{F}$ & 1 \\
\hline \multirow[t]{2}{*}{$\begin{array}{c}\mathrm{NF} \\
6\end{array}$} & $\begin{array}{l}\text { BOILER NAK WEIGHT॰ } \\
\text { FLOW-RATE, RECORDER E }\end{array}$ & MV / $/$ PPM & & \\
\hline & NAK HEATER POWER• & KW & & 1 \\
\hline $\begin{array}{c}\top \\
229\end{array}$ & $\begin{array}{l}\text { BOILER NAK IN ALARM } \\
\text { TEMPERATURE INSTR. LI }\end{array}$ & & ${ }^{\circ} \mathrm{F}$ & 1 \\
\hline \begin{tabular}{c|c} 
\\
231
\end{tabular} & $\begin{array}{l}\text { BOILER NAK IN SHUTDOOWN } \\
\text { TEMPERATURE INSTR. L2 }\end{array}$ & & ${ }^{\circ} \mathrm{F}$ & \\
\hline \begin{tabular}{c|c} 
\\
179
\end{tabular} & $\begin{array}{l}\text { MERCURY INLET LINE } \\
\text { TEMPERATURE }\end{array}$ & $12-1$ & ${ }^{\circ} \mathrm{F}$ & 1 \\
\hline \begin{tabular}{c|}
$T$ \\
173
\end{tabular} & $\begin{array}{l}\text { HG INLET TUBE } \\
\text { SHEET SHELL TEMPERATURE }\end{array}$ & $12-2$ & ${ }^{\circ} \mathrm{F}$ & 1 \\
\hline \begin{tabular}{c|}
$T$ \\
175
\end{tabular} & $\begin{array}{l}\text { NAK OUTLET LINE } \\
\text { TEMPERATURE }\end{array}$ & $12-3$ & ${ }^{\circ} \mathrm{F}$ & 1 \\
\hline $\begin{array}{c}T \\
143\end{array}$ & $\begin{array}{l}\text { NAK INLET LINE } \\
\text { TEMPERATURE }\end{array}$ & $12-52$ & ${ }^{\circ} \mathrm{F}$ & 1 \\
\hline $\begin{array}{c}\mathrm{T} \\
183\end{array}$ & $\begin{array}{l}\text { BOILER HG DISCH. LINE } \\
\text { TEMPERATURE (IMM. } 3.5 \mathrm{FT})\end{array}$ & $12-6_{2}$ & ${ }^{\circ} \mathrm{F}$ & \\
\hline
\end{tabular}

NOTE:

"UNCORRECIED DATA USED FOR MONITORING REFER TO CALIBRATION ER FOR CORRECTED VALUES.

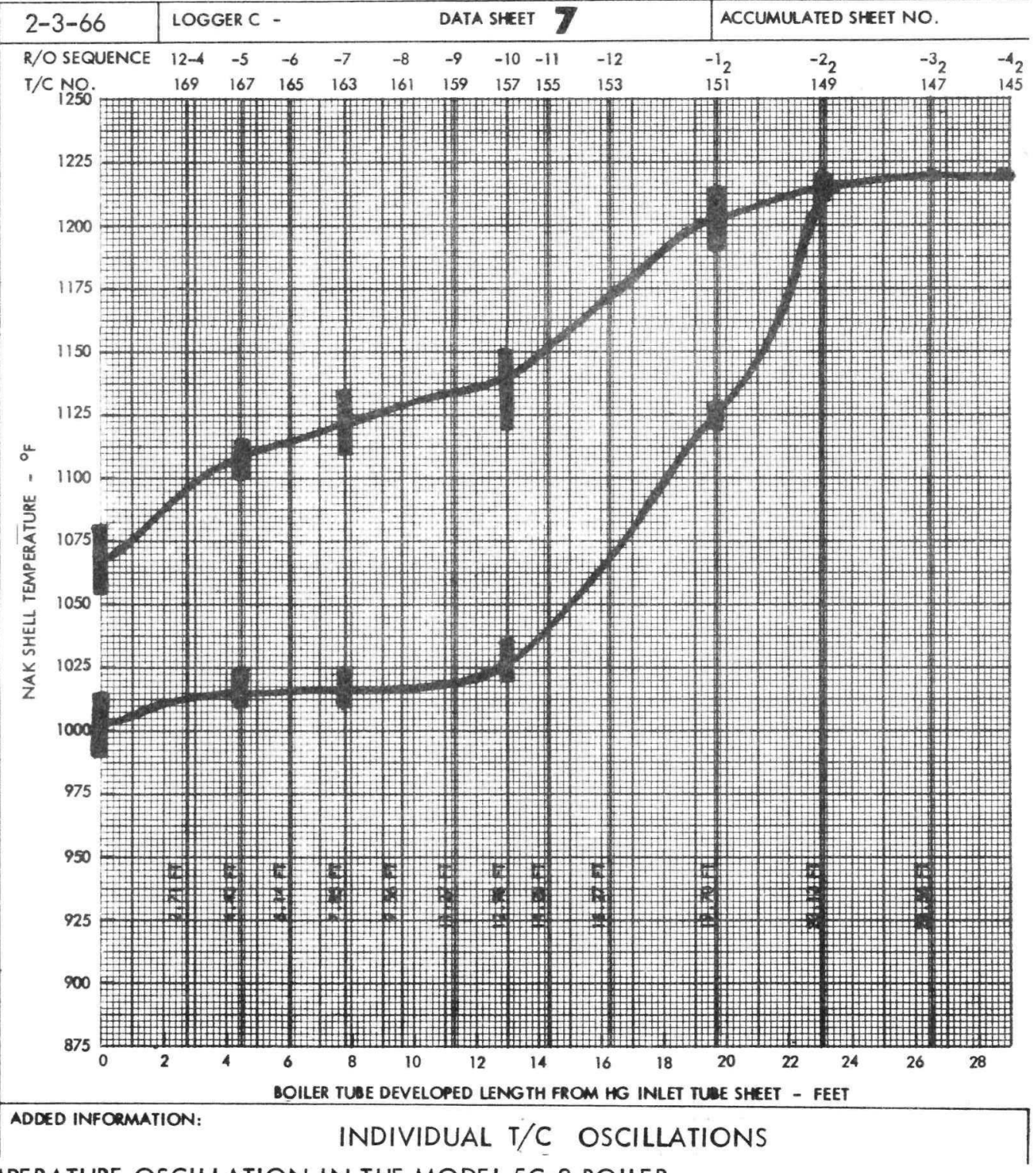


3) Leak tightness of the NaK system as determined by vacuum measurements prior to loop filling was improved.

4) The purity of inert cover gases which may be admitted into the system was improved, and

5) A commercial oxide control and Indicating System (OCI) to provide continuous purification and measurement of oxide content without withdrawing samples was installed.

Leaks on the mercury side at one time or another had permitted air, water, and oil to enter the system. All of these contaminants have a bearing upon conditioning as discussed in Section II-D.

Air in-leakage was a possibility any time the system was opened for equipment installation, removal, or maintenance. The air in-leakage probability was minimized by continuous purging with inert gas during these activities. Air in-leakage was also possible during system evacuation prior to thermal operation. The most common leak sources were the mechanical connectors in the plumbing which would loosen somewhat after thermal shocking. The remedy was to seal weld the joints.

During periods of shutdown, an inert gas blanket was maintained in the mercury system at a pressure above atmospheric.

The test rig condensers were water cooled. On at least one occasion a condenser leak permitted water to enter the mercury system. Later condenser designs had a mercury filled jacket between the condensing passage and the cooling passage which eliminated further water contamination problems.

oil contamination occurred from two sources. In some test rigs, the main mercury circulating pump had oil jackets which, if ruptured, resulted in oil entering the mercury system. Preventative maintenance practices were successful in eliminating this difficulty. Boilers operating in systems with CRU's (combined rotating units) did not have the pump-oil problem with which to contend.

The vacuum pumps in all of the test rigs had oil seals which were the other source of oil contamination. The redesign of the vacuum plumbing lines and inclusion of fail safe devices eliminated the probability of oil backstreaming into the mercury system. Cleaning procedures had also been developed for refurbishing a test rig that became contaminated with oil.

Three Nak to mercury leaks had occurred in the program, two in compact boilers and one in a helical boiler. These leaks were all related to Haynes 25 embrittlement problems which were solved by proper heat treating (See section $V-C$ for a discussion of the metallurgical aspects). Two of the leaks were severe and required extensive rebuilding of the test rigs before further 
testing could be conducted. For a comprehensive discussion of test cell experience
covering the complete power conversion system over the entire program, see (30). 
Boiler materials selection was based on factors such as corrosion resistance, high temperature strength, weight, fabricability, and availability as discussed in section III-D.

No problems were foreseen with the type 316 stainless steel or Haynes Alloy 25 ( $(-605)$ components in NaK service, (31) and none had developed.

The evaluation of materials behavior in a mercury environment was extensively investigated in support of the entire SNAP 2 system. Topical reports, references $(30,32,33,34)$ will provide the reader a chronological updating of the materials work and lists of references to numerous additional reports.

Corrosion resistance and aging embrittlement of Haynes 25 have been of special interest to the boiler design in these studies. Erosion resistance became an item of intensive investigation following a NaK to mercury tube leak in the $5 \mathrm{C}-5$ boiler. Corrosion product deposition was of primary concern from a system standpoint, but it was also monitored as an additional indicator of boiler performance.

\section{A. CORROSION AND DEPOSITION}

Mercury corrosion studies were made in glass and metal reflux capsule tests, and natural and forced circulation 1oop tests. Mercury corrosion data for both the liquid and vapor phases was obtained from all tests. The reflux capsules had a flow rate of $1 / 2$ pound of mercury per hour.

The thermal convection loop flow rates varied between 10 and 30 pounds per hour. Weight loss and depth of penetration data was gathered.

A total of 1298 glass capsule, 105 metal capsule, 27 thermal convection 100p, and 4 forced circulation loop tests were made. Total operating times were: 1,312,109 hours; 106,116 hours; 38,150 hours; and 18,300 hours respectively. System test rigs provided samples for comparison with the laboratory data.

Over 30,000 hours of boiler test operation was accumulated on the program with the longest run time on one boiler being 8300 hours. Ten boilers were dissected for metallurgical analysis. The results are reported in (35) through (44). steps:

The typical dissection procedure includes the following key

$$
\begin{aligned}
& \text { a) Check argon pressure drop in individual mercury } \\
& \text { tubes for comparison with values obtained during }
\end{aligned}
$$


fabrication.

b) Take metallographic specimens from each tube at approximately 2 foot intervals.

c) Examine all samples and obtain corrosion and deposition measurements.

d) Conduct electron beam microprobe analysis of samples, usually from one tube only.

Figure 60 shows a representative corrosion and deposition pattern. The results in Figure 60 were obtained from the 5c-9 boiler after 2200 hours of operation. Corrosion attack is most severe at the inlet and low quality end of the boiler and corrosion product deposition greatest in the high heat flux, middle quality sections of the boiler. Corrosion progressed by selective leaching of various elements in the alloys. Deposition cross sections showed layers reflecting the transport of products selectively leached. Figure 61 depicts these composition profiles.

Figure 62 shows the agreement between corrosion rates experienced in the boilers and the rates obtained from the capsule and loop tests.

The thinnest tubing used in boiler construction, .020" wall in the 5c and 7 models, has far more than adequate corrosion allowance for the 10,000 hour design life.

Corrosion product deposition did not restrict flow passages nor inhibit heat transfer. The exception to this statement was the experience with the $5 \mathrm{C}-2$ boiler (37). The swirl wire from the insert section and the swirl wire from the down stream section of one tube had an end of each wire welded to the insert in an overlapping rather than butting position. A small flow passage was created which plugged up with corrosion products during operation. A revision in assembly procedures prevented a recurrence.

The deposition profile is an indicator of the various heat transfer regimes in the boiler. The corrosion products are transported in the liquid droplets and deposited on the tube wall as the droplets evaporate. The superheat section of the boiler begins where the deposition terminates.

\section{B. EROSION}

One erosion failure was experienced in the program in the 5c-5 boiler which was operated approximately 850 hours. A swirl wire misalignment near the downstream end of the insert tube resulted in an order of magnitude reduction in flow area and velocities in the restriction estimated as high as $1000 \mathrm{fps}$. The damaged area is shown in Figure 63. A revision in assembly 


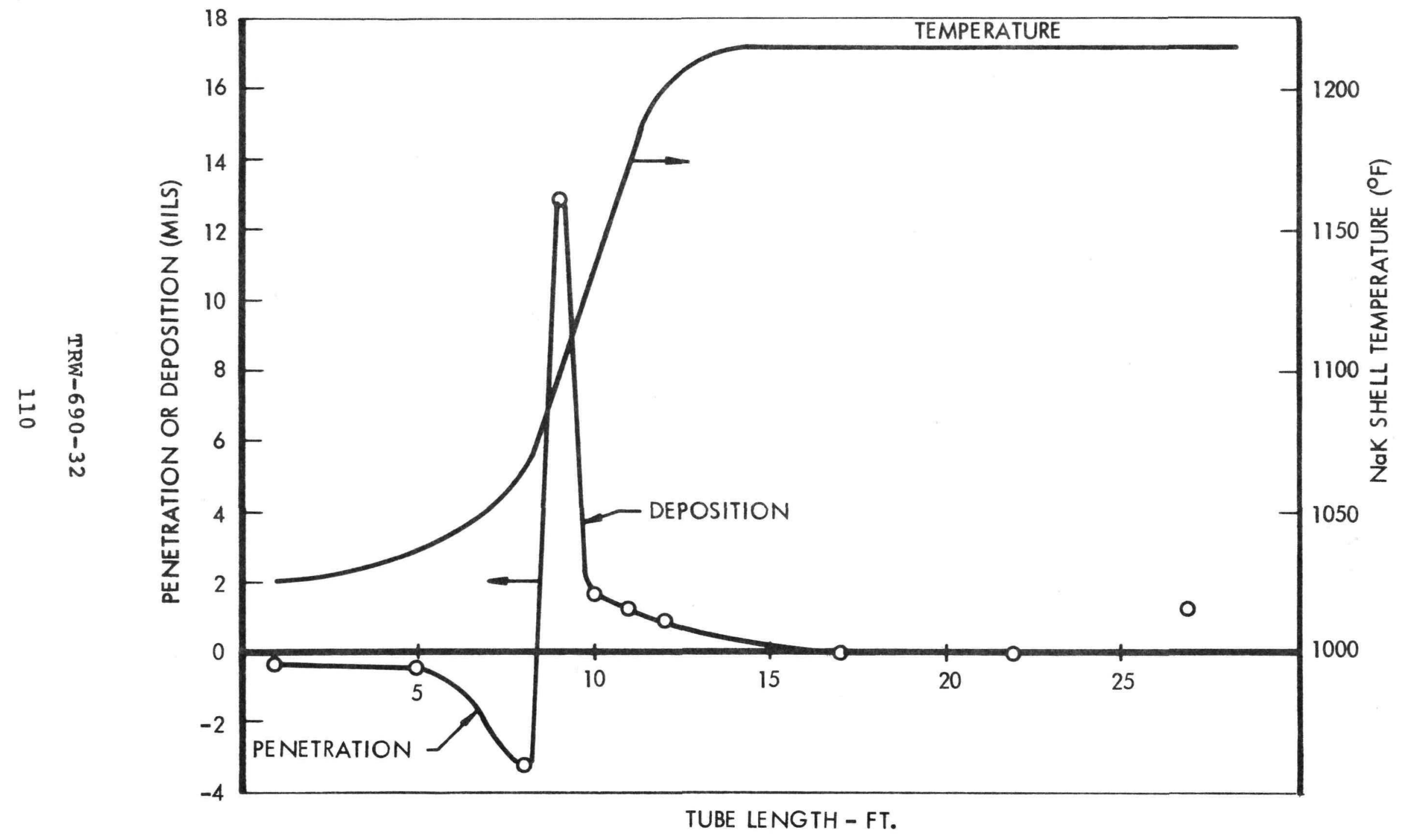

FIGURE 60. PENETRATION, DEPOSITION (TUBE 2), AND NaK SHELL TEMPERATURE VERSUS TUBE LENGTH - 5C-9 BOILER 


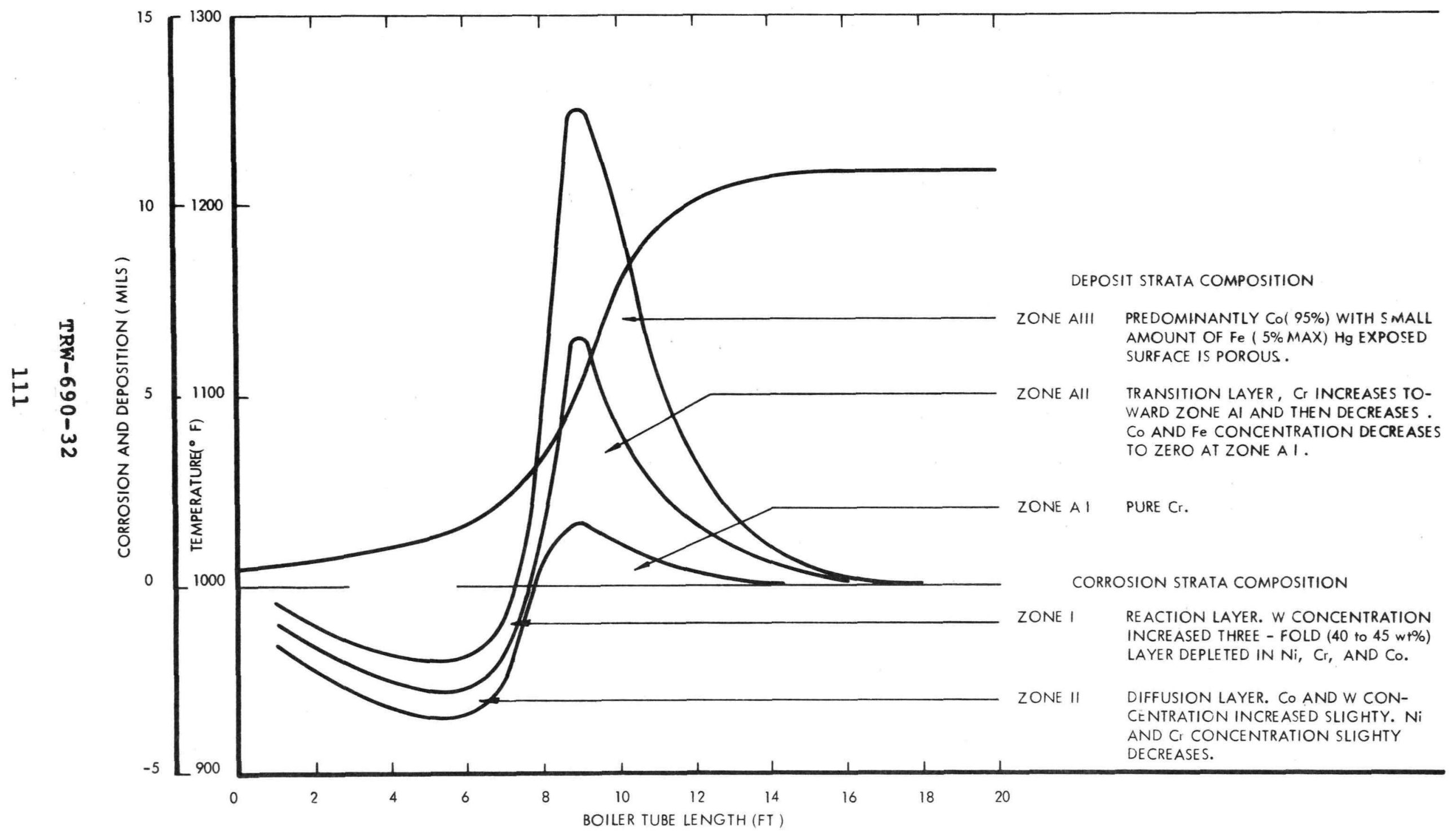

FIGURE 61 BOILER COMPOSITION AND DEPOSITION PROFILES 


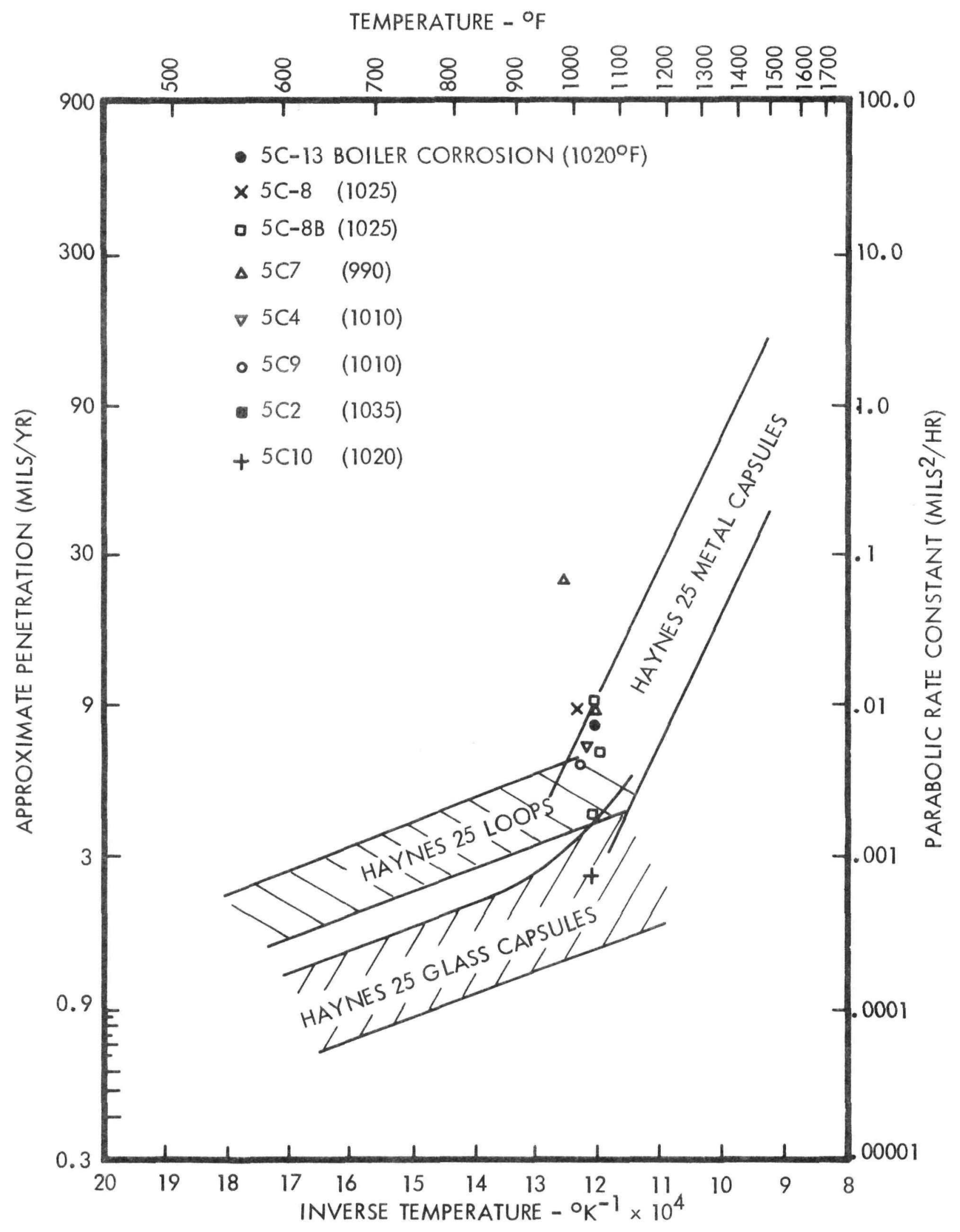

FIGURE 62. COMPARISON OF CORROSION RATE CONSTANT AT MAXIMUM PENETRATION WITH LABORATORY DATA ON HAYNES 25 CORROSION

TRW $-690-32$ 


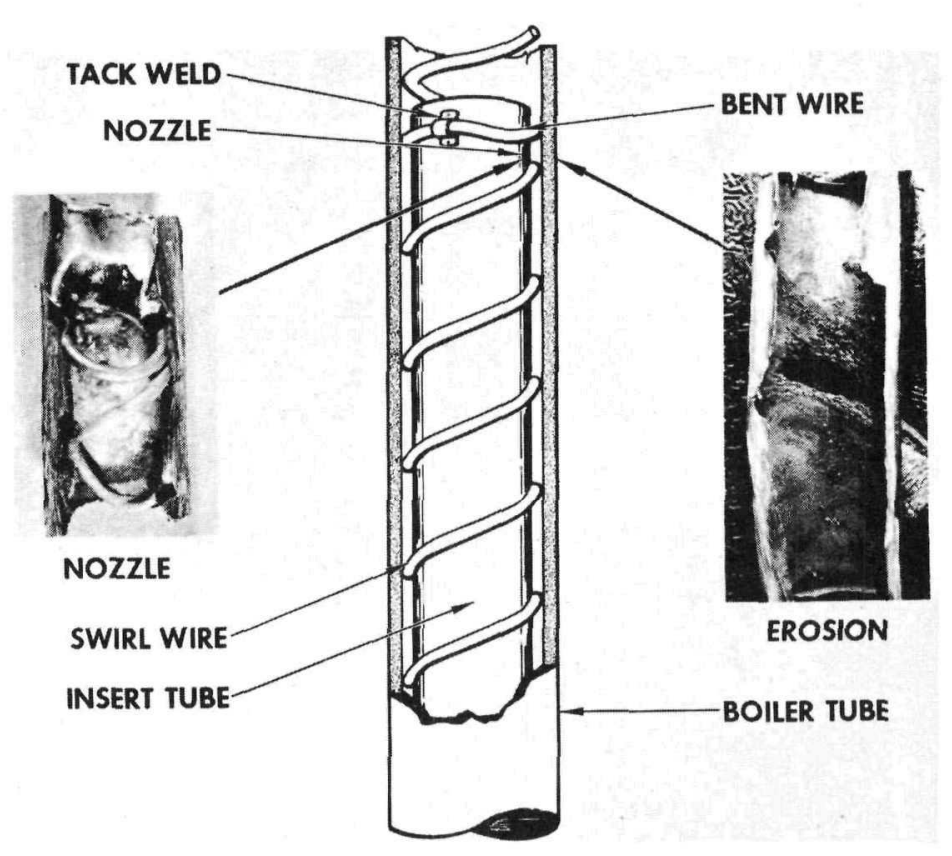

FIGURE 63 BENT MODEL 5C-5 SWIRL WIRE AND EROSION FAILURE

procedures prevented a recurrence. An analysis was performed in (19) to establish the threshold of erosion damage in SNAP 2 Haynes 25 boiler tubes. Results were expressed in terms of velocity as a function of tube metal temperature and material strength. At $1000^{\circ} \mathrm{F}$ the predicted damage threshold velocity ranges from 500 to 1600 fps for yield strength values ranging from the annealed to the work hardened condition respectively. These values are far above those normally encountered in the various boiler passages. The maximum velocity encountered in existing or contemplated boiler passages occurs in an anticipated prototype multi-channel plug operating in the fully conditioned mode. Based on a maximum velocity of $165 \mathrm{fps}$, no appreciable erosion damage is anticipated.

\section{EMBRITTLEMENT}

Haynes alloy 25 ( $L-605)$ was used in boiler construction before complete information on its embrittling characteristics was generated. In July and August 1962, tube fractures in the PCS II-0 (Model 3) and the 5C-1 boilers occurred. Swirl wire fractures also occurred. These problems were found to be due to an embrittlment situation. Fortunately, the results of an embrittlement investigation program were made available in August 1962, (45), which enabled the rapid resolution of the boiler problem.

Reference (36) presents the details of the boiler tubing and swirl wire fracture and resolution. It was determined that the boiler tubing was received with high residual stresses which 
resulted from a straightening operation performed for inspection. Severe cold working of the tubing and wire resulted from the coilforming processes in fabrication. It is possible that fine cracking started at this time. Rapid age hardening occurred at boiler operating temperatures accompanied by a loss of material ductility. The decrease in ductility of the embrittled material is an inverse function of operating temperature. It is particularly critical near room temperature. Cracks that may have been present from the fabrication process could have propagated and new cracks might have been initiated during the startup and shutdown transients.

The photomicrographs in Figure 64 show two cracks found out of three that existed in the $5 \mathrm{C}-1$ boiler tuhing. The fractures are intergranular and originated on the $\mathrm{NaK}$ side of the tube. Hardness readings of the tube material after only 172 hours of exposure at about $1000^{\circ} \mathrm{F}$ was 48 to 52 Rc. The hardness for annealed Haynes alloy No. 25 after such a short exposure at this temperature would normally be approximately Rc 30. The effect of accelerating the age hardening of this material because of residual stress from cold work was obvious.

The damage in the swirl wire and in the Model 3 boiler tubing was of an identical nature. The Model $5 \mathrm{C}$ coil received severe cold working in forming the 3-1/2 inch diameter coil. The swirl wire received severe cold working to fit the inner diameter of the mercury tubes. The Model 3 coil diameter of 39 inches was not severe but the tube failure occurred under a tube spacer which cocked during coiling causing severe local cold working.

The need for annealing after each cold forming operation was established in a special experimental program which assessed the effect of various combinations of heat treating and aging. The test samples consisted of sections of tubing prepared using the 5C fabrication tooling. Samples were withdrawn for analysis at various exposure times up to 1000 hours. The metallurgical data and discussion of results is contained in (36). The hardness data is reproduced in Figure 65. The curve fitting the data for Coil B-Series 9 is representative of the conditions experienced in the 5c-1 boiler tubing. The curve fitting the data for coil A-Series 10 is representative of the conditions to be anticipated in all new boilers manufactured beginning with the 5C-4 in 1963 . The corrective action has been proved effective in more than 20,000 hours of subsequent operation.

TRW $-690-32$ 


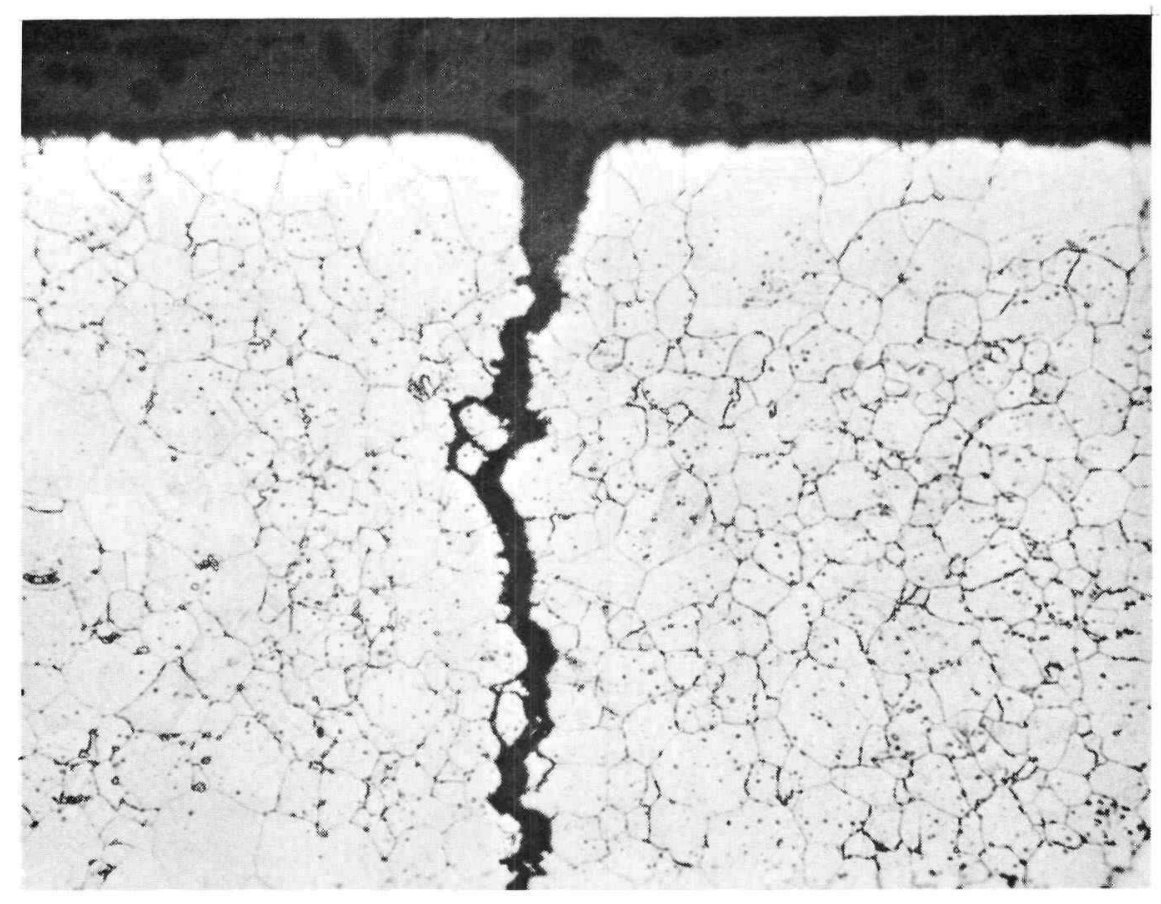

5783

$250 x$

CRACK IN TUBE SECTION 4A

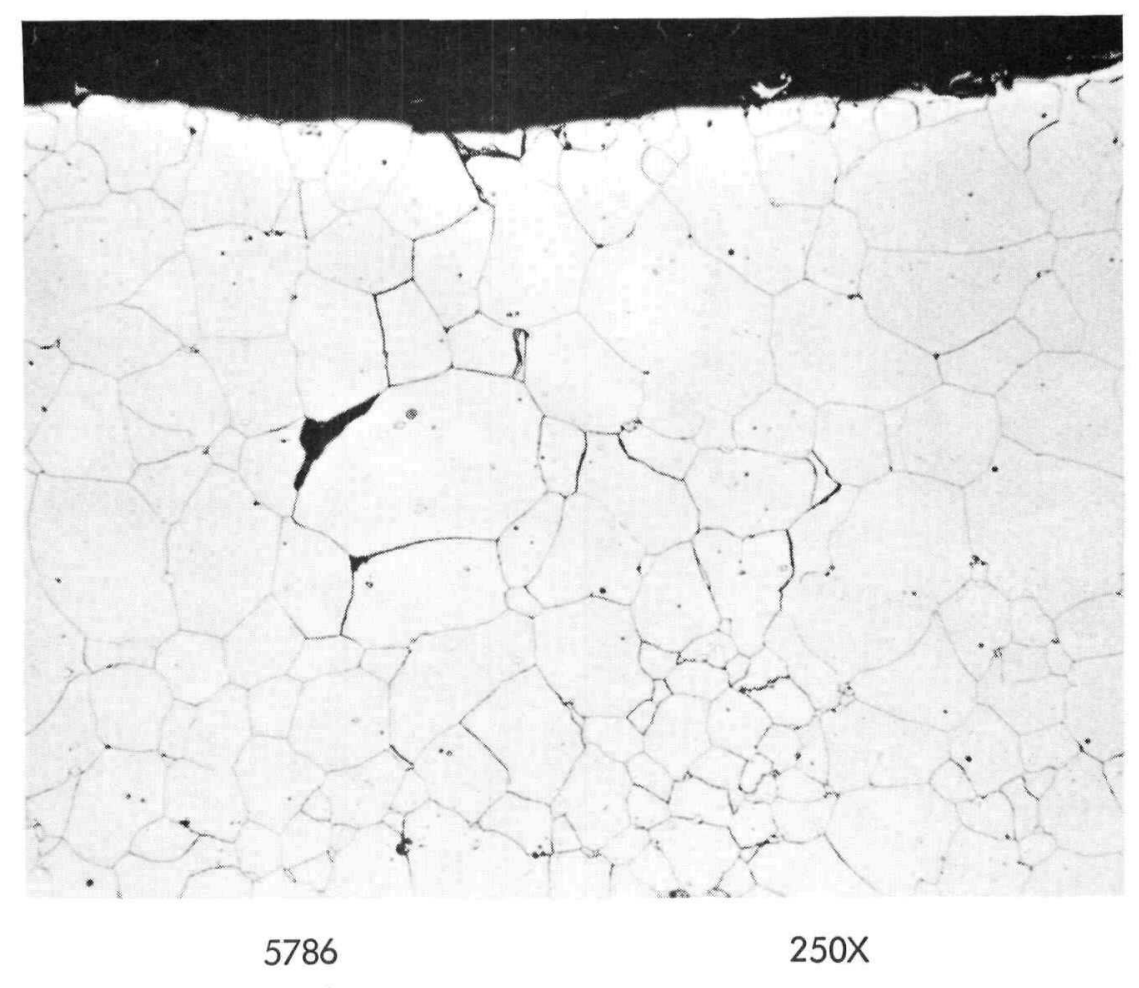

CRACK IN TUBE SECTION 2B

FIGURE 64 PHOTOMICROGRAPHS OF MODEL 5-C TUBE SECTIONS 


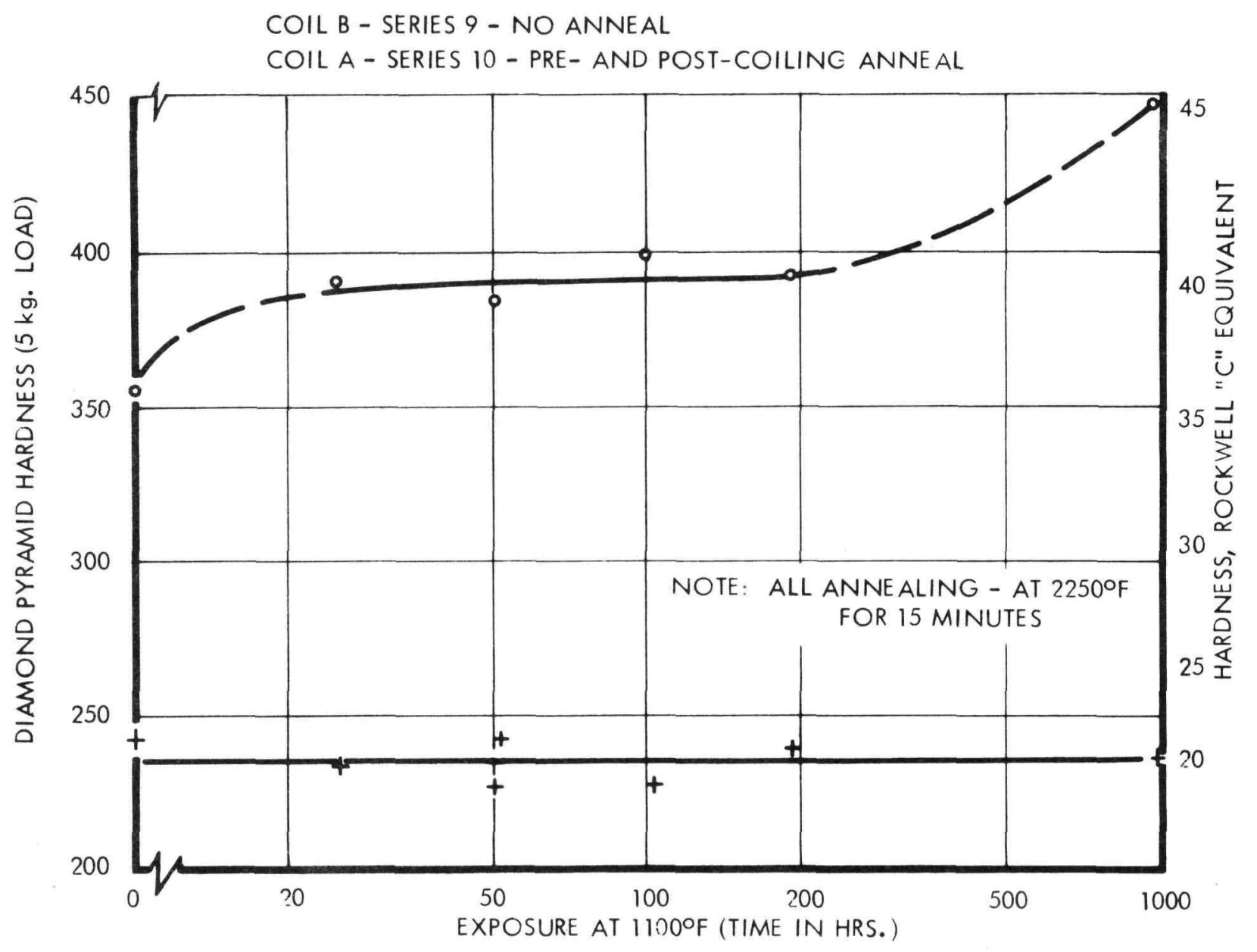

FIGURE 65 BOILER TUBING ANNEALED COILING STUDY

TRW $-690-32$ 


\section{CONCLUSIONS}

The SNAP 2/MRP boiler research and development program resulted in a compact, reliable, once-through boiler which met the requirements of the power conversion system.

Two modes of boiling were encountered which had a marked effect upon boiler design, spheroidal boiling and wetting boiling. The wetting mode results in compact and light weight boilers. However, wetting in pure mercury systems is erratic being influenced by factors such as cleanliness, tube materials, and wall superheat. This requires system controls that are not always possible to insure. In general, spheroidal boiling results in lower heat fluxes than wetting boiling. Spheroidal boiling was extensively investigated on the program and was found to exhibit a wide range of heat flux variations requiring 'local' definition.

The term conditioning has been coined for defining boiling states giving reasonably high heat fluxes which can include both wetting boiling and non-wetting contact spheroidal boiling. The term deconditioning is used to define boiling states of low heat fluxes which are associated with spheroidal vapor film boiling and slug flow boiling.

A conservative and reliable boiler design should accommodate both the spheroidal boiling and the wetting boiling modes of heat transfer since the conditions causing these modes are not well defined. Further work in this area is recommended.

over 30,000 hours of operation have been accumulated on the several development boiler models which have proven the once through boiler concept, demonstrated the insensitivity to the gravity environment, and demonstrated a thermal shock capability during injection startups. The boiler effort ultimately resulted in the development of two flight ready designs, the Model $5 \mathrm{C}$ and Model 7 boilers which bettered the weight and NaK pressure drop specifications. These demonstrated qualification capability during tests in terms of environmental shock, acceleration, and extended thermal endurance.

The cobalt base superalloy used for mercury containment was concluded to be reliable (corrosion) for the 10,000 hour design life. Also, it permitted fabrication (machining, forming, welding) to be as readily accomplished as with the stainless steels. The internal butt welded tube to tube sheet joint was concluded to be superior to conventional joining techniques in surviving mercury inlet thermal shocks.

TRW $-690-32$ 


$$
\begin{aligned}
& \mathrm{A}=\text { area } \\
& \mathrm{C}=\text { conductance } \\
& C_{p}=\text { specific heat } \\
& D=\text { tube diameter } \\
& \mathrm{d}=\text { differential } \\
& G \quad=\quad \text { mass velocity } \\
& \mathrm{g}=\text { acceleration } \\
& \mathrm{g}_{\mathrm{s}}=\text { standard gravitational acceleration } \\
& h=\text { heat transfer coefficient } \\
& K=\text { thermal conductivity } \\
& K_{G}=\text { mass transfer coefficient } \\
& L=\text { tube length } \\
& \mathrm{m}=\text { mass flow rate } \\
& \mathrm{Nu}=\text { Nusselt number } \\
& n=g / g_{s} \\
& \mathrm{~N}=\text { number of tubes } \\
& \mathrm{P}=\text { pressure } \\
& \mathrm{P}_{\mathrm{O}}=\text { ambient pressure of spheroid } \\
& \operatorname{Re}=\text { Reynolds number } \\
& R c=\text { Rockwell "C" } \\
& r_{0}=\text { spheroid radius }
\end{aligned}
$$




$$
\begin{aligned}
& r_{\infty}=\text { initial spheroid radius } \\
& S \quad=\text { ratio of vapor to liquid velocity } \\
& T \quad=\text { Temperature } \\
& u \quad=\text { velocity } \\
& V \quad=\text { volume } \\
& x \quad=\text { flowing vapor quality } \\
& y \quad=\text { vapor film thickness }
\end{aligned}
$$

\section{Greek}

$$
\begin{aligned}
& \alpha \quad=\text { swirl wire angle } \\
& \Delta \quad=\text { difference } \\
& \delta \quad=\text { drop diameter } \\
& \epsilon \quad=\text { slip ratio }=u_{f} / u_{v} \\
& \theta \quad=\text { time } \\
& \lambda \quad=\text { latent heat } \\
& \mu \quad=\text { viscosity } \\
& \rho \quad=\text { density }
\end{aligned}
$$

Subscripts

$$
\begin{aligned}
\delta & =\text { spheroid } \\
\mathrm{E} & =\text { exit } \\
\mathrm{f} & =\text { liquid } \\
\mathrm{i} & =\text { inlet }
\end{aligned}
$$




$$
\begin{aligned}
& l \quad=\text { liquid slug } \\
& \mathrm{m}=\text { mean } \\
& \mathrm{N}=\text { NaK } \\
& \circ \quad=\text { initial } \\
& t \quad=\text { tangential } \\
& \mathrm{v}=\text { vapor } \\
& \mathrm{w}=\text { wall }
\end{aligned}
$$


1. Y. S. Tang, "Iiquid-Metal Boiling Heat Transfer," Nuclear Applications, vol. 1, p.-521, December 1965.

2. E. F. Kamperman, R. A. MCKinnon, "Sunflower Boiler/Heat Storage," TRW ER-4869, April 1963.

3. C. T. Jaenke, "Final Report on Mercury Boiler and Preheater Development Proqram," TRW ER-5421, June 1963.

4. A. J. Sellers, G. M. Thur, M. K. Wong, "Recent Development in Heat Transfer and Development of the Mercury Boiler for the SNAP-8 System," Aerojet-General Corporation, September 1965.

5. C. T. Jaenke, A. Koestel, J. G. Reitz, "Orbital Force Field Boiling and Condensing Experiment (OFFBACE)," TRW EP-4670, october 1962.

6. R. G. Gido, et al.," "Boiler Development," TRW ER-4521, July 1961.

7. R. G. Gido, A. Koestel, "Mercury Boiling Research," TRW ER4833, October 1962 .

8. A. Koestel, "Boiler Conditioning Phase I Results," TRW ER6660 , January 1966.

9. A. Koestel, "Boiler Conditioning Phase II Results," TRW ER6992. November 1966.

10. R. J. Ziobro, D. A. Oberacker, "Compact Boiler Development," TRW ER-5411, February 1964.

11. D. A. Oberacker, "The Model 7 Boiler Design Report," TRW ER6086, October 1964 .

12. R. J. Ziobro, "Model 8 Boiler Design," TRW ER-6439, March 1965.

13. M. K. Wong, Aero-Jet Memorandum AN-SNAP 65-240, April 1965.

14. H. F. Poppendick, et al.. "Annual Technical Report on High Acceleration Field Heat Transfer for Auxiliary Space Nuclear Power Systems," AEC Contract No. AT(04-3)-409, period September 1, 1963 through August 31, 1964, Geoscience Limited.

15. T. T. Shimazaki, "Effects of Some Surface and System Contaminants on Mercury Pool Boiling Heat Transfer," NAASR 11949 , July 1966.

TRW-690-32 
16. R. L. Hungtington, "Concurrent Flow of Nitrogen and Mercury

in Open Sinale Tubes," University of Oklahoma Research Institute Report, February 1961.

17. R. J. Ziobro, "X-Ray Movie Film Report of Flow Patterns in a once-Through Forced Convection Nak Heated Mercury Boiler," ANL-7100 p-633, Sentember 1965.

18. T. J. Vild, P. R. Houser, "Controlled Atmosphere, Mercury Drop Evaporation Experiment," TRW ER-6169, Sentember 1964.

19. A. Koestel, D. A. Oberacker, S. Glickhause, "Pluq Insert Design and Test Plan, Heat Transfer, Hydrodynamics, Corrosion, and Erosion Consideration for the single Tube Boiler," TRW ER-6796, March 1966.

20. A. Koestel, T. T. Shimszaki, "MRP Deconditioning Problem and Planned Investigations," NAA-SR-10860, June 1965.

21. E. B. Baumeister, "Mercury Rankine Program Boiler Development Summary," NAA-SR-12233, January 1967.

22. L. Rizzolla, "Performance Verification Test (7-1) and Acceptance Test (7-2) Report on the Model 7 Boilers," TRT ER-6051, June 1964 .

23. D. A. Oberacker, "Proqress Renort on SNAP 2 Boiler Thermal Shock Testing, March 20, 1962 to June 29, 1962," TPW ER5008, August 1962 .

24. C. P. Pound, "Structural Analysis of PCS II-2 Component Supports (5C Trunnion Mounts)," TRW ER-5140, November 1962.

25. C. P. Pound, "Model 5C Boiler stress Renort," TRW ER-5359, May 1963.

26. R. Kasuba, "Transient and Steady state Stress Analysis of the 5C Boiler Outer Shell," TRW ER-5431, April 1963.

27. F. J. Koenig, "Model 7 Boiler Stress Analysis," TRW ER-6273, Summer 1964 .

28. E. W. Rowlands, Jr., J. C. Cooksey, "Internal Weldina of Tubes to tube sheets," Welding Journal, p 707-710, July 1960 .

29. J. M. Gerken, D. B. Kittle, "TIG Welding Joins Small Stainless Tubes to Thick Tube-Sheets," Welding Enqineer, p 46-48, November 1960 .

30. R. C. Schulze, E. J. Varqo, "Corrosion Products in the MRP/ SNAP 2 System," TRW ER-7253, June 1968. 
31. "Liquid-Metals Handbook, Sodium-NaK Supnlement," C. B. Jackson Editor-in-Chief, TID 5277, July 1955.

32. J. J. Owens, J. F. Nejedlik, J.W. Voqt, "Mercury Materials Fvaluation and selection," TRW ER-4103, nctober 1960.

33. J. F. Nejedlik, "Mercury Materials Fvaluation and Selection," Peport No. 2, TRW ER-4461, April 1961.

34. J. F. Nejedlik, Mercury Materials Evaluation and Selection," Report No. 3, TRW ER-5024, Auaust 1962.

35. W. D. Benjamin, "Metallurgical Analysis of the Model 3 PCS II-1 Boiler," TRW TM-4082, March 1965.

36. R. J. Ziobro, "Failure Investigation of the 5C-1 SNAP 2 Boiler," TRW ER-5245, February 1963.

37. W. D. Benjamin, "Metallurgical Analysis of the SNAP 5C-2 Boiler," TRW TM-3795-67, September 1963.

38. W. D. Benjamin, "Metallurgical Analysis of the 5C-4 Boiler," TRW TM-4085, April 1965.

39. E. J. Vargo, "5C-5 Boiler Tube Failure," TRW Letter Renort dated March 16, 1965.

40. W. D. Benjamin, "Metallurgical Analysis of the 5C-7 Boiler," TRW TM-4304, August 1967.

41. W. D. Benjamin, Metallurgical Analysis of the 5C-8B Boiler," TRW TM-4343, December 1967.

42. W. D. Benjamin, "Metalluraical Analysis of the 5C-9 Boiler," TRW TM-3971, June 1964.

43. W. D. Benjamin, "Metallurqical Analysis of the 5C-10 Boiler," TRW TM-4358, January 1968.

44. W. D. Benjamin, "rotallurgical Analysis of the 5C-13 Boiler," TRW TM-4350, December 1967.

45. E. H. Evans, E. J. Vargo, J. B. Pearson, "Embrittlement of Haynes Alloy No. $25(\mathrm{~L}-605)$ During High Temperature Exposure," TRW TM-3488-67, August 1962 . 